\title{
WestVirginiaUniversity
}

THE RESEARCH REPOSITORY @ WVU

Graduate Theses, Dissertations, and Problem Reports

2018

\section{Predicting Student Success in Online Physical Education}

Tyler Goad

Follow this and additional works at: https://researchrepository.wvu.edu/etd

\section{Recommended Citation}

Goad, Tyler, "Predicting Student Success in Online Physical Education" (2018). Graduate Theses,

Dissertations, and Problem Reports. 5684.

https://researchrepository.wvu.edu/etd/5684

This Dissertation is protected by copyright and/or related rights. It has been brought to you by the The Research Repository @ WVU with permission from the rights-holder(s). You are free to use this Dissertation in any way that is permitted by the copyright and related rights legislation that applies to your use. For other uses you must obtain permission from the rights-holder(s) directly, unless additional rights are indicated by a Creative Commons license in the record and/ or on the work itself. This Dissertation has been accepted for inclusion in WVU Graduate Theses, Dissertations, and Problem Reports collection by an authorized administrator of The Research Repository @ WVU.

For more information, please contact researchrepository@mail.wvu.edu. 
Predicting Student Success in Online Physical Education

Tyler Goad, Ms.Ed.

Dissertation submitted to the College of Physical Activity and Sport Sciences

At West Virginia University

In partial fulfillment of the requirements for the degree of

Doctorate of Philosophy in Kinesiology

With an emphasis in

Coaching and Teaching Studies

Emily Jones, Ph.D., Co-Chair

Sean Bulger, Ed.D., Co-Chair

Eloise Elliott, Ph.D.

Barbara Ludlow, Ph.D.

David Daum, Ph.D.

College of Physical Activity and Sports Sciences

\section{Morgantown, West Virginia}

April 2018

Keywords: online physical education, health related fitness, student success, distance learning

Copyright 2018 Tyler Goad 


\section{ABSTRACT \\ Predicting Student Success in Online Physical Education \\ Tyler Goad, M.S.}

Background/Purpose: Scholars have posited that the demand for online learning is not going away, and the question is no longer if online physical education (OLPE) is practical but rather, what are the most effective ways of administering OLPE to accommodate students (Daum \& Buschner, 2012). Currently, limited data are available on student retention rates and attrition factors in OLPE courses. Several early OLPE studies (Brewer, 2001; Mosier, 2010; Ransdell et al., 2008) as well as the 2007 NASPE Initial Guidelines for Online Physical Education have suggested that certain prescreening efforts be in place prior to student enrollment in OLPE, however, at present no such empirically sound and theoretically based screening instruments exist. Screening and pre-screening systems can help identify students who are at risk of failing and/or not completing online coursework. The purpose of the study is to identify online student cognitive characteristics and environmental factors associated with success and/or failure within college online health-related fitness (HRF) courses. Methods/Analysis: Students ( $\mathrm{N}=821$ ) enrolled in Auburn University's 16-week online HRF course-Active Auburn- during the Fall 2017 participated in the study. At the beginning of the course, participants responded to two previously validated research instruments, the Educational Success Prediction Instrument Version-2 (ESPRI-V2; Roblyer, et al., 2008) and the Distance Learning Survey (DLS; Osborn, 2001). A Pearson's Chi Square analysis was used for student demographic and environmental categorical data. Next, a one-way between subjects analysis of variance (ANOVA) was employed to compare completers and non-completers mean scores for each ESPRI-V2 and DLS cognitive factor (i.e. study environment). Lastly, a direct binary logistic regression was performed to assess the impact of significant factors from the previous analysis on the likelihood that student would complete or not complete an online HRF course. Results: The model contained 6 independent variables (GPA, class standing, hours worked outside of school, achievement, organization and study environment). The full model containing all predictors was statistically significant $(\chi 2(6, \mathrm{~N}=821)=94.296, \mathrm{p}<.001)$, indicating that the model was able to distinguish between students who completed and did not complete the online HRF course. Four of the independent variables made a unique statistically significant contribution to the model: (1) GPA, (2) Class Standing, (3) Hours Worked Outside of School and (4) Organization. The strongest predictor of a course completion were student who reported entering the course with a GPA of 2.6- 4.0, recording an odds ratio of 3.96. This indicated that students who entered the course with a GPA above a 2.6 were almost 4 times more likely to complete an online HRF course than those who entered with a lower GPA, controlling for all other factors in the model. Conclusion: Upon course entry, students who did not complete the course generally reported a combination of the following factors: GPA below 2.6, worked more than 20 hours outside of school, underclassman class standing, and reported weak organizational beliefs. This analysis provides an initial understanding of the unique student characteristics affecting online HRF course completion. 


\section{Acknowledgements}

I would like to express the deepest appreciation to my committee co-chairs Dr. Emily Jones and Dr. Sean Bulger, you both have been tremendous mentors and wordsmiths for me. I would like to thank you for encouraging my research and for bringing out the anvil to hammer out my ideas when you needed to. Your advice on both research as well as on my career have been invaluable. I would also like to thank my committee members, Dr. Eloise Elliott, Dr. Barbara Lublow, and Dr. David Daum for serving on my committee: thank you all of your guidance over the years. Without all of your supervision and constant help this dissertation would not have been possible.

In addition, a special thank you my friends Brooke Towner, Adam Keith, Cory Breithoff, Karl Zang, Gentry Shrewsbury, Lynda Bowers, Natasha Ademakinwa, and Robert Posehn. I came to West Virginia knowing not knowing anyone and I consider you all close friends today. Thank you for all the support, encouragement, and free psychological counseling over the past four years. You all made the GTA office a great place to work and I'm sure we'll stay in touch as we all start our careers.

A special thanks to my family. Words cannot express how grateful I am to my mother and father for all of the sacrifices you've made on my behalf. You've always encouraged me to continue my education and supported me during my studies. At the end I would like express appreciation to Hannah Kipfer, we've been through all the ups and downs of this process. I'm grateful for your belief in me, your support, and your love. I could not have done it without you. 
TABLE OF CONTENTS

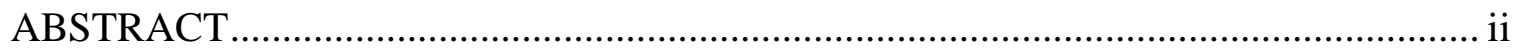

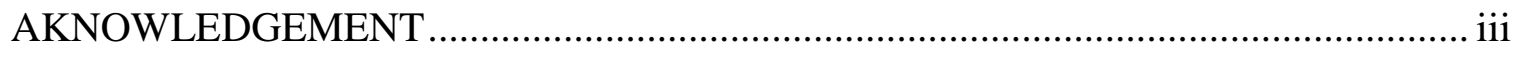

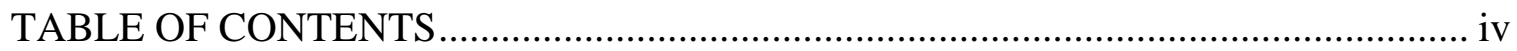

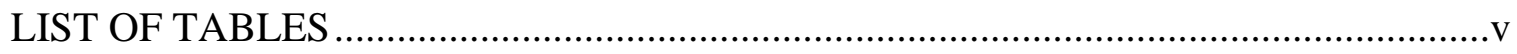

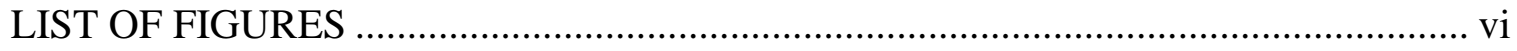

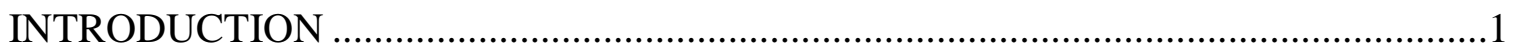

Research in Online Physical Education ...........................................................

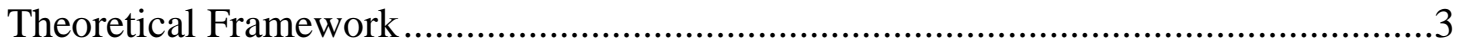

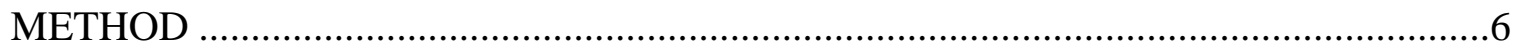

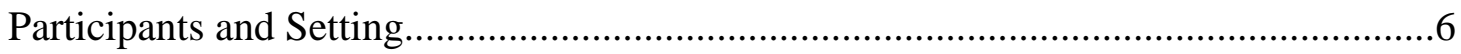

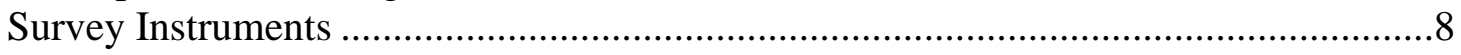

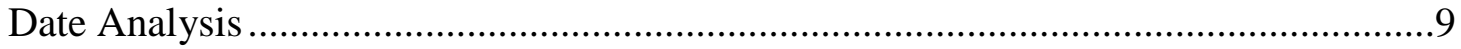

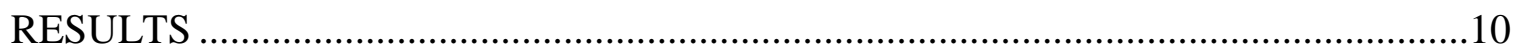

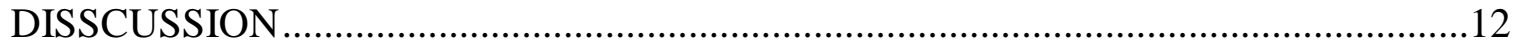

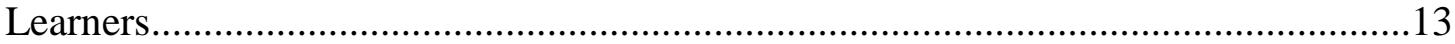

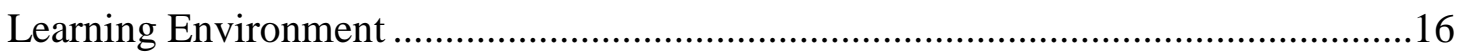

Implications for Learning Goals and Tasks .......................................................... 18

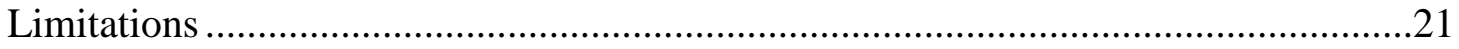

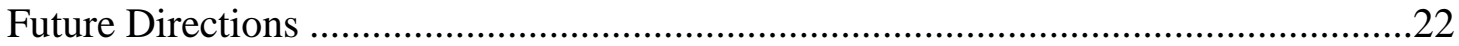

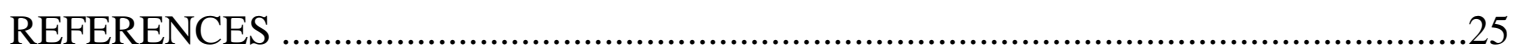

Appendix A Extended Background .....................................................................41

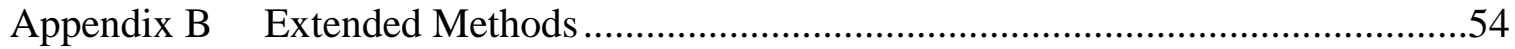

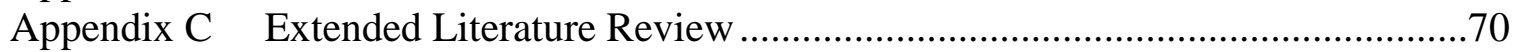

Appendix D ESPRI Survey Constructs and Items................................................147

Appendix E Distance Learning Survey...............................................................148

Appendix F Behavioral Regulation in Exercise Questionnaire Version 2 .................150

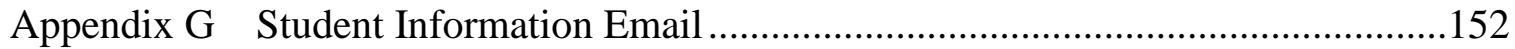

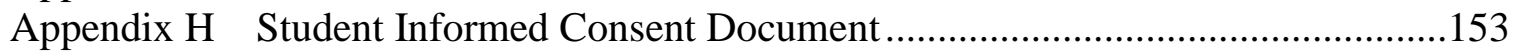

Appendix I AU University Online HRF Course Syllabus ..........................................154 


\section{LIST OF TABLES}

Page

Table 1 Description of Factors and Examples of Survey Instruments

Table 2 Overview of Analysis

Table 3 Comparison of Student Demographics

Table 4 Comparison of Student Environmental Factors

Table 5 ANOVA Results: Student Cognitive Factors

Table 6 Direct Binary Logistic Regression Predicting Student Success

Table $7 \quad$ E-Learning Course Classifications

Table 8 Advantages and Disadvantages of Online Physical Education

Table 9 National Guidelines for Technology Use in Physical Education

163

Table 10 Description of Factors and Items in Survey Instruments

Table 11 Overview of Proposed Analysis 


\section{LIST OF FIGURES}

Page

$\begin{array}{lll}\text { Figure } 1 & \text { Online Behavior Change Model } & 39\end{array}$

Figure 2 Instructional Design Process for Online Behavior Change Model 40 


\section{Introduction}

For students, distance education programs provide the flexibility and access to education that may not be readily available to them otherwise. Distance education programs have become increasingly popular as institutions look to not only cut cost, but to also expand beyond their traditional regions without investing in brick and mortar operations (Saba, 2005). Currently 5.8 million high school students are predicted to be enrolled in online courses (Allen \& Seaman, 2016). This upward trend is likely to continue as states such as Virginia, Alabama, Florida, Michigan, Idaho, New Mexico and Georgia have enacted legislation that would mandate students complete an online course as a high school graduation requirement (Kennedy \& Archambault, 2012; Rice \& Yang, 2013). While online learning has been practiced for over two decades, the amount of research has not kept pace with its rapid expansion (Barbour, 2010; Rice, 2006). It has been suggested a next step for research in this field is greater examination between subject areas and educational contexts (Smith, Clark, \& Blomeyer, 2005). However, not all disciplines have fully embraced online education.

Hesitancy to support online education within the physical education profession has been evident (Daum \& Buschner, 2014) where content primarily focuses on promoting healthy lifestyles through physical activity and the teaching of fundamental motor skills and movement patterns (Buchanan \& Brock, 2016; Rink, 2013). Concerns within online physical education (OLPE) surround the instruction, assessment and confirmation of the physical activity completed by students (Daum \& Buschner, 2012; Mohnsen, 2012; Society of Health and Physical Educators [SHAPE], 2007). Despite these concerns OLPE is becoming more prevalent. According the 2016 SHAPE of the Nation Report, 31 states allow students to satisfy required physical education credits online. The number of states permitting OLPE has increased by 11 since 2010. 
In response to the emerging trend of OLPE in K-12 settings, national governing bodies such as the SHAPE established guidelines for OLPE. The 2007 SHAPE Initial Guidelines for Online Physical Education provide suggestions for OLPE relative to course content, site management, instructional design, technology, and assessment. These guidelines have been used to inform the development of OLPE programs and provide a framework for evaluating courses currently being delivered. However, at the time of their formation, only a single peer reviewed OLPE research study (Goc Karp \& Woods, 2003) was available to inform the guidelines.

\section{Research in Online Physical Education}

Although OLPE practices have expanded across the country since the 2007 SHAPE Initial Guidelines for OLPE, research in the area still remains limited. As of 2017, published research focusing on OLPE includes six peer-reviewed articles (Daum \& Buschner, 2012; Daum \& Woods, 2015; Goad \& Jones, 2017; Goc Karp \& Woods, 2003; Kane, 2004; McNamara, Swalm, Stearne, \& Covassin, 2008; Mosier \& Lynn, 2012). Remaining OLPE research is comprised of six doctoral dissertations (Daum, 2012; Futrell, 2009; Jackson, 2015; Mosier, 2010; Trent, 2016; Williams, 2014). These initial studies provide a foundation for understanding the characteristics of OLPE stakeholders and highlight areas that warrant further investigation. Specifically the OLPE research raises questions about course delivery, design, and instructional methods in relation to student learning and fitness gains. However, researchers have critiqued that these initial studies are disconnected and lack sufficient depth (Daum \& Buschner, 2014). These limitations highlight the need for future research in OLPE and using larger sample sizes, more coordinated approaches, and a consistent set of instruments for cognitive and physical fitness data (Daum \& Buschner, 2014). The landscape of education is changing and with it, 
OLPE research must identify program strengths and weaknesses to better accommodate learner needs.

\section{Theoretical Framework}

While there are no established curricular models in OLPE, the most common one observed in the OLPE literature is Fitness for Life (Corbin, Le Masurier \& McConnell, 2014), also known as Wellness for Life (Daum \& Buschner, 2014). The primary objective of the Wellness for Life curriculum is to improve student health behaviors and fitness levels. Coursework focuses on physical fitness and wellness concepts and principles (Corbin, Le Masurier \& McConnell, 2014), specifically those related to physical fitness, cardiovascular endurance, nutrition, weight management, and stress.

The Wellness for Life curriculum is underpinned by theories of behavior change (e.g., Self Determination Theory, Theory of Reasoned Action, Social Cognitive Theory) and the primary goals are to guide and equip students with knowledge and skills needed to adopt healthy lifestyles. Many internet and web-based health behavior interventions are grounded in behavior change theory, yet none account for the influence of administering the intervention online (Ritterband, Thorndike, Cox, Kovatchev, \& Gondev-Frederick, 2009). The conceptual framework used to inform the current study is the Online Behavior Change Model. The model is designed to help guide development as well as explain health behavior change produced by internet interventions (Figure 1). The Online Behavior Change Model provides a framework to develop and improve online health related fitness (HRF) courses by helping to conceptualize, identify, and measure factors affecting students and instructors.

Hilgart, Ritterband, Thorndike, and Kinzie (2012) proposed a reorganization of the Online Behavior Change Model into three segments: 1) analysis, 2) evaluation, and 3) strategy 
(see Figure 2). Instructional design process models have been developed to guide and support the use of the internet in the delivery of discipline-specific and educational content (Hilgart, et al., 2012). Process models aim to establish the needed balance between emerging technologies, curriculum, learner support, and student characteristics. Online course components such as appearance, content delivery, student use, and support represent variables that can be responsive and influenced by student and environmental characteristics (Ritterband, et al., 2009). The reorganization was based on instructional design theory (IDT) and provided a theoretical-based approach for identifying and targeting factors contributing to student attrition and drop out, specifically within the user and environmental factors.

Ritterband et al. (2009) describe user characteristics (i.e. gender, age, ethnicity, etc.) as fixed, however, they can still be influenced by environmental factors such as family, friends, employer, school, or societal level influences such as social media, policy, and other cultural factors. These environmental factors can then affect website use and student persistence through an online course. Instructional frameworks that account for the impact of the internet on variables such as user characteristics and environmental factors can help guide OLPE programs better accommodate and respond to the needs of the modern student. The current study will focus on the analysis segment of the framework and examine user and environmental characteristics that serve as predictors of success within online HRF courses.

Examining student-centric barriers to success in online HRF courses will aid in the development of early warning systems for OLPE programs. Currently, limited data are available on the student retention and attrition rates in OLPE. Mosier's 2010 investigation of the Florida virtual schools (FLVS) OLPE program offered insight to student demographic data such as age, gender, ethnicity, GPA, reasons for enrolling, and completion rates. The study found that 52 
percent of students were designated as completers ( $n=10,333), 40$ percent non-completers/never activated/no grade ( $\mathrm{n}=8,054)$, and 8 percent non-completers who withdrew or failed the course $(n=1,557)$. Moiser's findings did not provide explanations of factors that contributed to student completion. In fact, very few studies have explored the potential factors associated with retention and attrition in OLPE. While Ransdell and colleagues (2008) suggested program quality was a primary factor linked to student dropout, others have attributed dropout rates in online physical activity courses to lack of support, poorly designed courses and inexperienced and/or incompetent instructors (Brewer, 2001).

Physical education has extended into the virtual world and the quality of delivery and student/instructor experiences have been examined by scholars within the field (Daum \& Woods, 2015; Goc Karp \& Woods, 2003; Futrell, 2009; Kane, 2004; Mosier, 2010; Williams, 2014) however, factors associated with student success in OLPE have not been thoroughly explored. Identifying factors that influence student completion or non-completion in online HRF courses would provide valuable information for students, academic advisors, online instructors, instructional designers, and K-12 and university-level administrators. Equipped with the knowledge of factors that associate with and may predict student completion or non-completion can assist OLPE stakeholders to make more informed decisions related to necessary supports, strategies, tools, course design, pacing, and communication tactics (Roblyer et al., 2008) aimed at facilitating student success and persistence through online HRF courses. Scholars have called for empirical and theoretical research to identify predictive factors of success in online learning (Alem, Plaisent, Bernard, \& Chitu, 2014). Similar work is needed in OLPE. This would allow for a deeper understanding of the support, design, and delivery strategies needed in OLPE to facilitate student success. 
The purpose of the study was to identify online student characteristics and environmental factors associated with success and/or failure within online HRF courses. Four research questions guide the proposed study: (1) To what extent do student cognitive characteristics influence success in a university level online HRF course? (2) To what extent do student demographics influence course completion in a university level online HRF course? (3) To what extent do student environmental characteristics influence course completion in a university level online HRF course? (4) What combination of student cognitive characteristics, environmental characteristics, and demographics produce a model that best predicts course completion in university level online HRF courses?

\section{Methods}

\section{Participants and Setting}

Students ( $\mathrm{n}=862)$ enrolled in Auburn University’s 16-week online HRF course-Active Auburn— during the Fall 2017 Semester were invited to participate in the study. Auburn University was selected as the site of the study due to their implementation and development of model online HRF courses that are grounded in the Appropriate Instructional Practice Guidelines for Higher Education Physical Activity Programs (Melton, Russell, Moore, \& Sweeney, 2009; Russell, Wadsworth, Hastie, \& Rudisill, 2014). The asynchronous online course was designed to expose students to the basic concepts associated with the development and maintenance of physical activity, as well as to the different fitness opportunities offered in their local area.

Instructors of Active Auburn are graduate assistants trained by the program coordinator on the proper procedures of delivering the course. Specifically, the precourse orientation focuses on effective instructional technology use and online pedagogy (Russell, et al., 2014). Additional training is required for first year instructors, who are required to enroll in a seminar course with 
an emphases on high education pedagogical skills and instructional strategies (Russell, et al., 2014). Instructors of Active Auburn are primarily responsible for maintaining gradebooks and communicating with the students (Brock, Wadsworth, Hollett, \& Rudisill, 2016). The course delivery, presentation of content, assessment and grading are standardized across all sections of Active Auburn courses. Quizzes and fitness tracking goals were automatically assessed by the institutional learning management system.

After IRB permission had been obtained, survey instruments were built into the LMS course shell for all Active Auburn section as pre-course components. One week before the start of the Fall 2017 semester, online HRF course students at Auburn University received an informational email detailing the intent of the study and outline of the information that would be collected (Appendix D). The Pre-semester survey was built into the course as part of normal educational practice in Active Auburn. Informed consent for the Educational Success Prediction Instrument Version-2 (ESPRI-V2; Roblyer, et al., 2008) and the Distance Learning Survey (DLS; Osborn, 2001) was obtained through the assessment tool of the institutions LMS as the first page of the survey (Appendix E). Participation in the study was voluntary and those who chose to participate typed their full name into the available text box to confirm their consent to participate. Students had two weeks at the beginning of the term to respond to the Pre-semester survey which took approximately 15 minutes to complete. Data from the surveys were automatically collected in the institution LMS grade recording tool. Student responses were exported from the LMS as a Microsoft Excel file, de-identified and assigned a research code by a person uninvolved in the research to ensure participant anonymity. Incomplete and duplicate survey responses were removed from the final data set before data was inputted in to SPSS version 21. 


\section{Survey Instruments}

To address the research questions, two validated research instruments founded in models of attrition and retention to identify factors influencing the success and failure in online learning environments were used, the ESPRI Version-2 (Roblyer, et al., 2008) and the Distance Learning Survey (DLS; Osborn, 2001). Instruments such as the ESPRI-V2 and DLS have been used to identify the potentially successful and at-risk students who enroll in online courses (Osborn, 2001; Roblyer, et al., 2008). The survey instruments define student success as 'one who completes a course with a passing grade and failure as either non-completion or completion with a failing grade. For the purposes of the current study the pass/fail criteria was defined as: students completing the course with a grade of A, B, or C were designated as completers (i.e. passing); students who withdrawal (W), drop (I), or complete the course with a grade of D or F were identified as non-completers.

The ESPRI-V2 is a 23-item survey that consisting of four cognitive factors: (1) technology use/self-efficacy, (2) achievement beliefs/locus of control, (3) instructional risk taking, and (4) organization strategies. Within each construct, respondents indicate their level of agreement (strongly disagree 1 - strongly agree 7). While the ESPRI-V2 addresses student cognitive characteristics, the survey items associated with those factors pertain to the high school level and do not address concerns students may have in higher education. Osborn’s (2001) survey addresses student environmental and demographic characteristics with items in each construct focused on university level online courses. The two surveys were pilot tested with four sections of the Active Auburn course during the Summer 2017 term. Within the four sections, 93 students completed the pilot survey. After the pilot study, minor edits were made to survey questions and protocol instructions. For the current study, the single-item predictor variables as 
well as the financial support and study environment factors that relate to a collegiate population was used in Active Auburns pre-course survey. The factors and single item predictors from each of the two instruments—-Roblyer's et al. (2002; 2008) ESPRI-V2 and Osborn’s (2001) DLSemployed for the current study are outlined in Table 1.

\section{Data Analysis}

First, to explore the relationship between each of the independent variables — cognitive, environmental, and demographic factors - to the dependent variable of online course completion or non-completion, different bivariate statistical methods were employed (Table 2). For scaled data, a one-way analysis of variance (ANOVA) comparing the mean scores for each of the five ESPRI-V2 and DSL cognitive factors to the dependent variable were used. For the categorical data (i.e., student demographic and environmental factors), a Pearson’s Chi Square test was performed.

Significant factors derived from the above analysis were used as predictors in a binary logistic regression with course completion status as the dependent variable (completers $=1$, noncompleters $=0$ ). From the bivariate analyses computed for the demographic and environmental categorical variables, the following were used in the logistic regression; GPA $(0=2.6-4.0,1=0$ 2.5), class standing ( 0 = sophomore/junior/senior, 1 = freshmen), hours worked outside of school $(0=1-20,1=21-40+)$ and with 3 cognitive factors (achievement beliefs, organization, and study environment) as independent variables. For the interpretability of the model based on an overall test of parameters, categorical data from the inventory were grouped for the purposes of visibility between the dichotomous outcome of completers and non-completers (Tabachnick \& Fidell, 2014). Although the sample sizes are not equally distributed, they do reflect the true difference in the various types of students at Auburn University. Various combinations of student 
demographic, environmental, and cognitive factors were inputted into a logistic regression to determine the optimal model to predict student course completion or non-completion.

\section{Results}

Of the 862 students enrolled in Active Auburn, 821 completed the ESPRI-V2 and DLS for a response rate of $95 \%$. Of the total sample of students $(\mathrm{N}=821)$ responding to the surveys, 634 were identified as completers (male $=238$, female $=396$ ) and 187 as non-completers (male $=77$, female $=110)$. The large majority of students were White/ Caucasian $(85.7 \%)$ between the ages of 18-23 (96\%). A Pearson’s Chi Square analysis revealed no significant differences between completers and non-completers in relation to the demographic factors of age, gender, and ethnicity (Table 3). However, significant effects for class standing $\left(\chi^{2}(1, N=821)=4.90\right.$, p $=.027$ ) were found, indicating that completers were more likely to be upperclassmen. It was also found that completers $\left(\chi^{2}(1, N=821)=52.19, \mathrm{p}=.000\right)$ were generally above a 2.6 GPA. Again, a Pearson Chi Square analysis was employed for a comparison of student environmental factors between completers and non-completers. The analysis found no significant differences between the two groups in relation to course load, financial situation, or whether the student lived on or off campus (Table 4). A significant difference between the two groups amount of hours worked outside of school (HWOS) was found $\left(\chi^{2}(1, N=821)=15.99, \mathrm{p}=.000\right)$. Student were more likely to complete the online HRF course if they worked no more than twenty hours outside of school. It was also found that there were differences between the completers and noncompleters previous online course experience $\left(\chi^{2}(3, N=821)=10.08, \mathrm{p}=.018\right)$. The most pronounced difference was found between completers and non-completers with no prior online course experience. 
A one-way between subjects analysis of variance (ANOVA) was employed to compare completers and non-completers mean scores for each ESPRI-V2 and DLS cognitive factors (i.e. study environment). No statistically significant difference was found between completers and non-completers mean scores for instructional risk taking and technology skills/self-efficacy (Table 5). Both completers and non-completers rated themselves highly in technology skills/selfefficacy and low in instructional risk taking. However, a significant difference was observed between the two groups mean scores for achievement beliefs $(F(1,819)=17.35, p=.000)$, organization $(F(1,819)=27.53, p=.000)$, and study environment $(F(1,819)=20.60, p=.000)$. Those who completed the online HRF course rated themselves higher in study environment, organization, and achievement beliefs than those who did not complete the course.

A direct binary logistic regression was performed to assess the impact of significant factors from the previous analysis on the likelihood that student would complete or not complete an online HRF course. The model contained 6 independent variables (GPA, class standing, hours worked outside of school, achievement, organization and study environment). The full model containing all predictors was statistically significant $\left(\chi^{2}(6, \mathrm{~N}=821)=94.296, \mathrm{p}<.001\right)$, indicating that the model was able to distinguish between students who completed and did not complete the online HRF course. For the present logistic regression model, the C-statistic 0.727 represents the goodness of fit as measured by the area under the Receiver Operating Characteristic (ROC) curve. The ROC curve ranges from .5-1 demonstrating the predictive accuracy of a logistic regression model (Peng, Lee, \& Ingersoll, 2002). A value of .5 and below indicates a very poor model, meaning that the model is no better than predicting an outcome than random chance (Peng, Lee, \& Ingersoll, 2002). A value of 1 means that the model assigns higher probabilities to all the observed data in the model correctly. For the current studies model, this means for $72.7 \%$ 
of all possible pairs of students — one completer and one non-completer - the model assigned a higher probability to those who completed the online HRF course. As shown in Table 6, only four of the independent variables made a unique statistically significant contribution to the model: (1) GPA, (2) Class Standing, (3) Hours Worked Outside of School and (4) Organization. The strongest predictor of online HRF course completion was 2.6-4.0 GPA, recording an odds ratio of 3.96. This indicated that students who entered the course with a GPA above a 2.6 were almost 4 times more likely to complete an online HRF course than those who entered with a lower GPA, controlling for all other factors in the model.

\section{Discussion}

Despite the growing body of knowledge in online student success and retention, attrition rates still pose a significant problem to distance education programs (Alem, et al., 2014; Hart, 2012; Simpson, 2013). Intervention strategies relating to online course delivery, faculty interventions and advisement have been shown to be increasingly effective. However, factors associated with the learner and learning environment must also be identified and better understood to effectively support at-risk students these through intervention strategies (Hilgart et al., 2012; Ritterband, et al., 2009). By analyzing profiles of completer and non-completers of a university-level online HRF course a better understanding of the factors associated with online student persistence/attrition can be achieved. The purpose of screening tools like the ESPRI-V2 and DLS is not to exclude students from enrolling in online HRF courses, but to gain insight through valuable data that helps inform the creation and implementation of evidence-based interventions. The discussion of study findings has been organized around the three analysis phase variables of the Instructional Design Process for the Online Behavior Change Model: 
learners, learning context, and the implications to support students at-risk of not completing learning task/goal.

\section{Learners}

Similar to previous findings, the current study did not find learner characteristics of age, gender, and ethnicity to be significantly different between completers and non-completers (Lee \& Choi, 2011; Park, Boman, Care, Edwards \& Perry, 2008; Willging \& Johnson, 2009). While these learner traits have been found to be moderators in some cases (Fryer \& Bovee, 2016, 2002; Osborn, 2001; Xu \& Jaggars; 2014), Roblyer and colleagues (2008) assert that it is unlikely these non-malleable factors (e.g. age, gender and ethnicity) alone would predict completion or noncompletion of an online course. To date, no consensus has been met among researchers on the importance of a student's age, gender, and ethnicity upon entry to the online course in predicting student success (Alem, et al., 2014).

Consistent with previous research, results of this study found a significant difference between completers’ GPA and class standing (Hart, 2012; Osborn, 2001; Rankin, 2013; Roblyer et. al, 2008). In the current study, students with a cumulative GPA above 2.6 were four times more likely to complete the online HRF course. Hart (2012) postulated that students with a higher GPA have adopted successful behaviors that allow them to better maneuver online course work. Differences between completers and non-completers responses to cognitive characteristics survey factors support Hart's (2012) contention. In the current study, a significant difference was found between completers and non-completers on achievement beliefs and organization.

Students who rated themselves higher in each of these categories were associated with the completing group. The highly autonomous and asynchronous format of Active Auburn could of benefited students who perceive themselves to have high achievement beliefs and organization 
skills, while creating an obstacle for those students who do not. Especially if those students adhered to the common misconception that online courses are not as rigorous as face-to-face courses and take less time to complete (Williams, 2015).

Class standing was also found to be significantly different between completers and noncompleters. Online HRF course students were over two times more likely to complete the course if they entered the course as a sophomore, junior or senior. Mosier's (2010) study examining high school students enrolled in online HRF courses within the Florida Virtual Schools found similar statistically significant results regarding class standing and course completion. Specifically, Moiser found that $59 \%$ of seniors $(n=5,512)$ completed the online HRF course in comparison to $44 \%$ of freshman ( $\mathrm{n}=704)$ students (2010). Moiser speculated that a student's proximity to graduation might contribute to the differences observed in course completion rates; that is, upper level students could have been more motivated to enroll in the online course to fulfill graduation requirements while underclassmen could have chosen the course based on personal preferences (Mosier, 2010).

Additionally, in the current study the influence of class standing in course completion could have been attributed to student's lack of prior exposure and use of the institutions' learning management system (LMS), Wellness Dashboard, and fitness tracker used by Active Auburn. Because the data were gathered in the Fall 2017 term means that enrolled freshmen could have been interacting with the specific software and hardware required for Active Auburn for the first time. It stands to reason that targeting students previous experience with the specific software and hardware required to complete the course is worth exploring in the future due to freshman completion rates being significantly different from upperclassmen despite the fact that only 16 students reported no prior online course experience. The low result is likely due the 2009 
initiative enacted by the Alabama state legislation requiring high school students complete an online course as a part of their high school graduation requirements (Kennedy \& Archambault, 2012; Rice \& Yang, 2013). It is possible that freshman in this study did not have previous experience navigating the specific software and hardware employed by the Active Auburn which could have attributed to the discrepancies between class standing and course completion rather than general experience with online courses alone.

Finings in regards to student's cognitive characteristics appear to support this notion as well. Contrary to previous research (Hayatt, 2015; Osborn, 2001; Roblyer et al., 2008; Roblyer, Blomeyer \& Rankin-Reed, 2006; Rankin, 2013), this study found no significant difference between completers' and non-completers’ instructional risk taking and technology skills/selfefficacy. Specifically in the field of OLPE, students' difficulty navigating technology has often been cited as a negative contributing factor (Brewer, 2001; Futrell, 2009; Kane, 2004; Goc Karp \& Woods, 2003). Daum and Buschner (2014) point out, "It is easy to wonder how many of the issues the teacher and students faced in [Goc] Karp and Woods (2003) and Kane’s (2004) studies were due to the technology of the time...” (p. 209). Yet, studies that are more recent have pointed to similar issues in instances where students did not persist to completion in OLPE (Daum \& Buschner, 2012; Williams, 2014).

In the current study, both completers and non-completers rated themselves highly in technology skill/ability. Instructors in online HRF course are now teaching a generation of students, often times referred to as “digital natives” who have never known a life without computers, cell-phones, and the internet (SHAPE, 2009). Most recently, Trent's (2016) descriptive overview of an OLPE course in Georgia found that over 90 percent of students surveyed indicated they knew how to use the internet, audio, video, presentation and word 
processing software. However, personal technology use does not equate to a student's ability to use technology for learning. Similar thoughts have been expressed by PETE instructors in regard to their students, who they perceive as having a limited functional skillset and generally a superficial understanding of technology’s role in instruction (Daum, 2012; Goad \& Jones, 2017). Again, it may be more appropriate in future studies to adjust technology self-efficacy/skills screening questions to reflect the specific hardware and software used throughout the course rather than focusing on a student's self-beliefs of their general proficiencies.

\section{Learning Environment}

The design of learning environments within online courses has been found to influence student success (Rice, 2006). Hilgart et al. (2012) defines the learning environment as the context in which the instruction will take place, specifically focusing on three domainsphysical, social, and institutional. The physical domain refers to the environment where the learner will completes tasks; the social reflects interactions with others, such as peers and influential networks (e.g. family, friends, employer, etc.); and institutional considerations relate to the goals and views held by the organization offering the course. Researchers posit that by examining these three environmental domains, one can construct a snapshot of how a student's willingness and ability to persist through an online course is influenced (Hilgart et al., 2012). The physical components of an online course such as appearance, content delivery, student use, and support have the potential to be responsive to student and environmental characteristics (Ritterband et al., 2009). Ritterband et al. (2009) describe user characteristics (i.e. gender, age, ethnicity, etc.) as fixed, however, influenced by environmental and societal-level factors including but not limited to friends and family, finances, employer, school, social media, policy, cultural norms, etc. These environmental factors have been seen to affect student website use and 
persistence through online courses (Hart, 2012; Ivankova \& Stick, 2005; Osborn, 2001; Xu \& Jaggers, 2014). To better understand the impact of these variables on enrolled students, needs assessments/analysis can inform online course designers and instructors in selecting relevant motivation, learning, and instructional theories to leverage environmental factors to meet course objectives.

Contrary to previous online student success research, the current study found no significant difference between completers and non-completers in regards to course load, type of student and financial dependents/aid/stability (Hart, 2012; Ivankova \& Stick, 2005; Osborn, 2001; Xu \& Jaggers, 2014). However, a significant difference between completers and noncompleters was reported for hours worked outside of school. Students who worked 20 hours or less outside of school were nearly two times more likely to complete to course. Hart (2012) referred to factors such as hours worked outside of school (HWOS) as "non-academic issues" that present unique barriers to student success. For example, Shin and Kim (1999) examined the relationship among learner background characteristics and course success through a path analysis that revealed an interrelationship among GPA and job load (i.e. HWOS). Demonstrating how “non-academic issues” can affect a student’s academic performance. Additionally, research has found statistically significant differences in the amount of time spent engaged in course activities (e.g. time spent viewing content, reading/responding to posts, etc.) between completers and noncompleters of online courses (Foon Hew, 2016; Hart, 2012; Shelton, Hung \& Lowenthal, 2017). In the current study, it is possible that the amount of hours worked outside of school affected some student’s ability to access and become actively engaged in course content.

\section{Implications for Learning Goals and Tasks}


When applying the IDT Behavior Change Framework, Hilgart et al. (2012) describes the analysis phase as finding the gaps between "what is" and "what should be.” The use of the ESPRI-V2 (Roblyer et al., 2008) and DLS (Osborn, 2001) in the current study, served as the instrument to analyze the possible gaps between students who completed an Active Auburn and those who did not. By identifying the gaps between ideal performance and reality, the causes of those gaps can be studied and quantified. The results of the study revealed that upon course entry, students who did not complete the course generally reported a combination of the following factors: GPA below 2.6, worked more than 20 hours outside of school, freshmen in class standing, and reported weak organizational beliefs.

Given the results of previous research possible remediation strategies for students who fit the above profile could benefit from early identification and pre-course orientation modules. Roblyer, Blomeyer and Rankin-Reed (2006) suggest pre-course orientation sessions for students that focus on goal-orientation and self-management strategies. Ideally, pre-course orientations that utilize stories or scenarios that illustrate subject matter content and are designed with scaffolded learning opportunities encouraging goal setting, planning, and reflection (Roblyer, Blomeyer \& Rankin-Reed, 2006). The objectives of these pre-course intervention strategies align with findings from research examining self-regulated learning strategies on online student success (Broadbent, 2017; Hart, 2012; Hyatt, 2015). Broadbent (2017) found that time management and effort regulation strategies emphasizing scheduling, planning, selfmanagement, and effort during study time were found to positively influence online student grades. This aligns with Hyatt’s (2015) findings that suggests successful students reported the use of self-awareness, self-efficacy, and goal setting strategies to stay motivated throughout online courses. For example, teaching students to use an agenda for weekly planning, prioritizing 
tasks, and creating short, medium, and long term plans could foster self-management skills in atrisk students.

Non-academic issues should also be considered in designing support strategies for online students. Research has shown a significant difference between completers and non-completers of online course in the amount of time spent engaged in course activities (Foon Hew, 2016; Hart, 2012; Shelton, Hung \& Lowenthal, 2017). To encourage online students to engage more frequently with course materials and peers, it has been suggested that, when possible, course content be made personally relevant and easily accessible to students (Foon Hew, 2016; Shelton, Hung \& Lowenthal, 2017). For students who work more than 20 hours outside of school, mobile learning strategies could make the course more accessible, meet the demands of their schedule, and provide individualized content.

In OLPE programs, mobile fitness applications have the capability of linking content to authentic assessments through the use of the device mobility, multimedia, and wireless connectivity in a flexible environment for students with demanding work schedules. Kwak’s (2014) study examining mobile fitness applications features and functions found personalization and social media features strongly influence student acceptance and use of mobile fitness applications. The social component within OLPE programs is often cited as a deficiency by teachers and students (Daum and Buschner, 2014; Mosier, 2010; Williams, 2014). Shelton, Hung, and Lowenthal (2017) assert that a lack of social interaction in online courses leaves students feeling isolated, which can lead to a lack of engagement and increase their risk of withdrawing. Furthermore a lack of social engagement has been cited possible factor for a lack of physical fitness gains within online HRF courses (Hager et al., 2012; McNamara et al. 2008). 
Hager et al., (2012) speculated that students would be more accountable with peers around while participating in physical activity rather than alone.

Promoting an online learning community can be done by making content relevant to students and employing a constructivist approach to online course design and delivery (Rice, 2006). The student-centric Wellness for Life curriculum, used in the majority of online HRF courses, aligns well with these constructivist learning approaches. It would seem that with proper integration, online HRF courses could further individualize the content and learner experience through the use of various mobile fitness applications. Online HRF courses integrating mobile fitness applications equipped with personalization and social media features would allow students to create, share, and discuss health/fitness content relevant to their own personal goals. Further, use of mobile applications may also allow students to tailor the course content to their own fitness/health goals. This would enable online HRF instructors to provide individualized feedback relevant to personalized learning goals and increase online student engagement (Hart, 2012). Use of constructivist learning approaches and proper integration of contemporary technologies could serve to bridge the communication divide and make health/fitness content personally relevant to students.

While previous success and retention studies have focused on the influences of nonmalleable traits such as demographics and cognitive style, Roblyer et al. (2008) and Osborn’s (2001) studies hypothesized that online success was a function of various factors, at least some of which could be modified with pre-course orientation and course design/delivery methods. Findings from previous studies indicate that a combination of student factors and learning conditions can predict online student success, though predicting success will probably be much easier than predicting failure. Results from the current study provide insight to potential 
differences between ideal student performance and attrition in an OLPE setting. This information can be used to better inform the design, delivery, and development of programs to support student success in online HRF courses.

\section{Limitations}

Limitations of this study included student self-reporting procedures and the generalizability of results. Discipline-specific factors related to online student motivation to exercise was incomplete due to the distribution of surveys at the midterm. Many non-completers who filled out the pre-course ESPRI-V2 and DSL surveys did not complete the midterm survey, diluting the sample size. Group size relations between completers and non-completers affected the variability between some environmental and demographic categorical data, which may have contributed to not finding a significant relationship between variables when statistical methods were applied. This affected the study’s ability to find meaningful significant relationships between completers and non-completers. For example, of the 821 students who completed the survey only 16 reported no prior online course experience. Additionally, the pass rate was 77.47 percent with 185 students not completing the online HRF course. It is possible that this level of group variability increased the probability of a Type II error for factors that indicated no level of significance due to a low number of non-completers results.

Lastly, results from the study are not generalizable to other online HRF courses due to the unique context of the individual university programs. It seems likely that a set of factors specific to an institution's population must be generated in order to calculate meaningful probability of passing scores for online students. For example, it is unlikely that the results from the student population here- 85.7 percent White, 96 percent between ages of 18-23, with a relatively high completion rate — are transferable to a distance education program with a more diverse 
population of students and/or higher non-completion rate. However, the current study use of the screening instruments can be replicated at another site to find the student demographic and environmental factors relevant to their individual university.

\section{Future directions}

There is considerable diversity in online student success literature about the factors influencing student completion and non-completion (Alem, et al., 2014; Hart, 2012). Studies have shown that factors included in the ESPRI-V2 and DSL play a role in identifying successful and unsuccessful students. However, no one set of characteristics or factors have emerged as dominant due to a lack of replication studies, measurement of different student populations, and disciplines. The focus of future research should examine the application and impact intervention strategies have in relation to supporting student success.

Moreover, this research could be more impactful if conducted at the site in which the initial research was piloted due to the unique profiles of students enrolled at different distance education programs. Factors that influencing online student attrition have been found to be more or less influential in different high education settings (e.g. community, private, and for profit colleges) and student populations. For example, Xu and Jaggars (2014) large scale study of 34 community colleges during Fall 2004- Spring 2009 found that courses delivered in an online format had a significant negative relationship with course completion and final grade. In addition it was found that these gaps in course completion and performance remained even after student and course characteristics were accounted for, indicating that the typical community college student had more difficulty succeeding in online courses in comparison to face-to-face (Xu \& Jaggars, 2014). This type of longitudinal research conducted at the current study's site would allow for a stronger prediction model and intervention strategies that are refined based on the 
unique student populations and environments. Through a continuing line of research that builds on the previous results could lead to a clearer understanding and delineation between factors associated with student success in online HRF courses.

While it is beyond the scope of the current study to determine what period of time the non-completing students withdrew from the course, future research should take into account when student dropout occurs. Research has shown that students who withdraw tend to disengage from online courses within the first few weeks, usually before the first exam is scheduled or major assignment due (Murphy \& Stewart, 2017; Simpson, 2013). Additionally, research has found significant differences in the amount of time spent engaged in online course activities (e.g. time spent viewing content, reading/responding to posts, etc.) between completers and noncompleters (Foon Hew, 2016; Hart, 2012; Shelton, Hung \& Lowenthal, 2017). It would appear from these recent studies that online course dropout occurs in the first few weeks and is associated with the frequency that student engage in the course. This would suggest that online instructors should closely monitor the rate at which students are engaged in the course at the beginning of the term and make contact with those who are not.

Furthermore, students who disengage early from course work have also been found to be those who are repeating the course (Murphy \& Stewart, 2017). This also appears to be the case in OLPE, Moiser (2010) found that only 34 percent of students who were non-completers in previous semesters completed the OLPE course. Students who are repeating online HRF courses should be identified by advisement and retention specialist at enrollment. At a minimum this information should be communicated to the instructor so that student repeating the online HRF course can be closely monitored at the beginning of the term. Support strategies and early monitoring of online student engagement may help facilitate course completion. Future research 
would benefit from examining this predominately at-risk population of students to better understand the characteristics and factors affecting student who do not complete an online courses.

Early identification of discipline specific factors related to student persistence and attrition in online HRF courses would allow for the application of evidence-based interventions. However, in the current study due to early disengagement of students not completing the course it was difficult to measure discipline specific measures such as exercise frequency, adherence, and motivation related to course completion. Future studies may want to consider collecting discipline specific measurements as a pre-enrollment screening requirement to ensure that data is collected. 


\section{References}

Alem, F., Plaisent, M., Bernard, P., \& Chitu, O. (2014). Student online readiness assessment tools: A systematic review approach. The Electronic Journal of e-Learning, 12(4), 375382.

Allen, E., \& Seaman, J. (2016). Online report card tracking online education in the United States. MA: Sloan Center for Online Education.

Barbour, M. (2010). Researching K-12 online learning: what do we know and what should we examine? Distance Learning, 7(2), 7-12.

Barbour, M. K., \& Kennedy, K. (2014). K-12 online learning: A worldwide perspective. Education Faculty Publication, Paper 188.

Beldarrain, Y. (2008). Engaging the 21st century learner: An exploratory study of the relationship between interaction and achievement in the virtual high school. (3311390 Ph.D.), Capella University.

Brewer, J. D. (2001). The impact of a web-based versus face-to-face instructional format of a lifetime fitness course on students' wellness knowledge, attitudes and behaviors and levels of health-related physical fitness. (3019351 Ph.D.), Kansas State University.

Broadbent, J. (2017). Comparing online and blended learner's self-regulated learning strategies and academic performance. The Internet and Higher Education, 33, $24-32$.

Brock, S., Wadsworth, D., Hollett, N., \& Rudisill, M. (2016). Using movband technology to support online learning: An effective approach to maximizing resources in kinesiology. Kinesiology Review, 5(4), 289-294.

Buchanan, A. M., \& Brock, S. (2016). What If they see me miss? Nuances of teaching in a movement-based environment. Strategies, 29(3), 16-20. 
Cardinal, B. J., \& Spaziani, M. D. (2007). Effects of classroom and virtual "lifetime fitness for health" instruction on college students' exercise behavior. Physical Educator, 64(4), 205213.

Cavanaugh, C., Barbour, M. K., \& Clark, T. (2009). Research and practice in K-12 online learning: A review of literature. International Review of Research in Open and Distance Learning, 10(1).

Corbin, C. B., Le Masurier, G., \& McConnell, K. (2014). Fitness for Life (6 Ed.). Champaign, IL: Human Kinetics.

Daum, D. N. (2012). Physical education teacher educator's attitudes toward and understanding of online physical education. (3570649 Ph.D.), University of Illinois at Urbana-Champaign.

Daum, D. N., \& Buschner, C. (2012). The status of high school online physical education in the United States. Journal of Teaching in Physical Education, 31(1), 86-100.

Daum, D. N., \& Buschner, C. (2014). Research on teaching blended and online physical education. In R. Ferdig \& K. Kennedy (Eds.), Handbook of Research on K-12 Online and Blended Learning (pp. 201-221): ETC Press.

Daum, D. N., \& Woods, A. M. (2015). Physical education teacher educator's perceptions toward and understanding of K-12 online physical education. Journal of Teaching in Physical Education, 34(4), 716-724.

Foon Hew, K. (2016). Promoting engagement in online courses: What strategies can we learn from three highly rated MOOCS. British Journal of Educational Technology, 47(2), 320341.

Fryer, L. K., \& Bovee, H. N. (2016). Supporting students' motivation for e-learning: Teachers matter on and offline. The Internet and Higher Education, 30, 21-29. 
Futrell, J. (2009). A comparative study of virtual high school instruction versus traditional instruction of high school student outcomes and attitudes in physical education. (3360073 Ph.D.), Capella University.

Goad, T., \& Jones, E. (2017). Training online physical educators: A phenomenological case study. Education Research International, 2017, 12.

Goc Karp, G., \& Woods, M. L. (2003). Wellness NutriFit online learning in physical education for high school students. The Journal of Interactive Online Learning, 2(2).

Hager, R., George, J. D., LeCheminant, J. D., Bailey, B. W., \& Vincent, W. J. (2012). Evaluation of a university general education health and wellness course delivered by lecture or online. American Journal of Health Promotion, 26(5), 263-269.

Hart, C. (2012). Factors associated with student persistence in an online program of study: A review of the literature. Journal of Interactive Online Learning, 11(1), 19-42.

Hayatt, S. (2015). Motivating and retaining online students: Research based strategies that work. Journal of College Student Retention Research Theory and Practice, 19(1).

Hilgart, M. M., Ritterband, L. M., Thorndike, F. P., \& Kinzie, M. B. (2012). Using instructional design process to improve design and development of Internet interventions. Journal of Medical Internet Research, 14(3).

Ivankova, N., \& Stick, S. (2005). Collegiality and community - Building as a means for sustaining student persistence in the computer - Mediated asynchronous learning environment. Online Journal of Distance Learning Administration, 8(3).

Jackson, J. M. (2015). An examination of the perceptions of online physical education: How fit is online PE? (3710217 Ed.D.), Bowling Green State University. 
Kane, J. (2004). The dog ate my disk: Teacher and student perspectives of an online personal fitness course. Florida Alliance for Health, Physical Education, Recreation, Dance \& Sport, 42(2), 8-12.

Kennedy, K., \& Archambault, L. (2012). Offering preservice teachers field experiences in K-12 online learning- A national survey of teacher education programs. Journal of Teacher Education, 63(3).

Kocher Brown, P. L. (2003). A comparison of online instruction versus traditional classroom instruction in a Fitness for Life course. (3093873 Ed.D.), The University of North Carolina at Greensboro.

Kwak, J. Y. (2014). Determinants of users' intention to adopt mobile fitness applications: an extended technology acceptance model approach. (Doctor of Philosophy), University of New Mexico, Albuquerque, New Mexico.

Lee, Y., \& Choi, J. (2011). A review of online course dropout research: implications for practice and future research. Educational Technology Research \& Development, 59(5), 593-618. doi: 10.1007/s11423-010-9177-y

McNamara, J. M., Swalm, R. L., Stearne, D. J., \& Covassin, T. M. (2008). Online weight training. Journal of Strength \& Conditioning Research (Lippincott Williams \& Wilkins), 22(4), 1164-1168.

Melton, B., Russell, J., Moore, C., \& Sweeney, M. (2009). Appropriate instructional practice guidelines for higher education physical activity programs (2nd ed.). Reston, VA: National Association for Sport and Physical Education.

Mohnsen, B. (2012). Implementing online physical education. Journal of Physical Education, Recreation \& Dance, 83(2), 42-47. 
Mosier, B., \& Lynn, S. (2012). An initial exploration of a virtual personal fitness course. Online Journal of Distance Learning Administration, 15(3).

Mosier, B. A. (2010). A descriptive study of Florida virtual school's physical education students: An initial exploration. (3462335 Ph.D.), The Florida State University, Tallahassee, FL.

Murphy, C. A., \& Stewart, J. C. (2017). On-campus students taking online courses: Factors associated with unsuccessful course completion. The Internet and Higher Education, 34, $1-9$.

Osborn, V. (2001). Identifying at-risk students in videoconferencing and web-based distance education. American Journal of Distance Education, 15(1), 41-54.

Park, C. L., Boman, J., Care, W. D., Edwards, M., \& Perry, B. (2008). Persistence and attrition: What is being measured? Journal of College Student Retention: Research, Theory \& Practice, 10(2), 223-233.

Peng, C.-Y. J., Lee, K. L., \& Ingersoll, G. M. (2002). An introduction to logistic regression analysis and reporting. The Journal of Educational Research, 96(1), 3-14.

Rankin, D. (2013). Predictors of success for high school students enrolled in online courses in a single district program. (Doctor of Philosophy), Virginia Commonwealth University, Richmond, Virginia.

Ransdell, L. B., Rice, K., Snelson, C., \& Decola, J. (2008). Online health-related fitness courses. The Journal of Physical Education, Recreation \& Dance, 79(1), 45-52.

Rice, K., \& Yang, D. (2013). Idaho’s K-12 online teaching endorsement: Lessons learned in online teacher preparation. Paper presented at the International Association for K-12 Online Learning, Blended and Online Learning Symposium, Orlando, FL. 
Rice, K. L. (2006). A comprehensive look at distance education in the K-12 context. Journal of Research on Technology in Education, 38(4), 425-448.

Rink, J. (2013). Teaching physical education for learning. Boston, MA: McGraw-Hill.

Ritterband, L. M., Thorndike, F. P., Cox, D. J., Kovatchev, B. P., \& Gonder-Frederick, L. A. (2009). A behavior change model for internet interventions. Annals of behavioral medicine: a publication of the Society of Behavioral Medicine, 38(1), 18-27.

Roblyer, M. D., Blomeyer, R., \& Rankins-Reed, R. (2006). Systematically Designed Online Support for virtual school students: A theory into practice product. Paper presented at the Society for Information Technology \& Teacher Education International Conference 2006, Orlando, Florida, USA.

Roblyer, M. D., Davis, L., Mills, S. C., Marshall, J., \& Pape, L. (2008). Toward practical procedures for predicting and promoting success in virtual school students. American Journal of Distance Education, 22(2), 90-109.

Roblyer, M. D., \& Marshall, J. C. (2002). Predicting success of virtual high school students: Preliminary results from an educational success prediction instrument. Journal of Research on Technology in Education, 35(2), 241.

Russell, J., Wadsworth, D., Hastie, P., \& Rudisill, M. (2014). Incorporating E-learning to enhance instruction and student experiences in collegiate physical activity courses. Kinesiology Review, 3(4), 247-252.

Saba, F. (2005). Critical issues in distance education: A report from the United States. Distance Education, 26(2), 255-272.

SHAPE. (2007). Initial guidelines for online physical education. Position Statement. Reston, VA: Author. 
SHAPE-America. (2016). Shape of the nation: Status of physical education in the USA. Reston, VA.

Shelton, B., Hung, J.-L., \& Lowenthal, P. (2017). Predicting student success by modeling student interaction in asynchronous online courses. Distance Education, 38(1), 59-69.

Shin, N., \& Kim, J. (1999). An exploration of learner progress and drop-out in Korea National Open University. Distance Education, 20(1), 81-95.

Simpson, O. (2013). Student retention in distance education: Are we failing our students? Open Learning, 28(2), 105-119.

Smith, R., Clark, T., \& Blomeyer, R. L. (2005). A synthesis of new research on K-12 online learning.

Tabachnick, B. G., \& Fidell, L. S. (2014). Using Multivariate Statistics (6th ed.). Boston: Pearson/Allyn and Bacon.

Trent, M. (2016). Investigating virtual personal fitness course alignment with the national guideline for online physical education. (Doctor of Philosophy Dissertation), Georgia State University, Atlanta, GA.

Wicks, M. (2010). A national primer on K-12 online learning version 2 (pp. 50). Vienna, VA: International Association for K-12 Learning.

Willging, P., \& Johnson, S. (2009). Factors that influence students' decision to dropout of online courses. Journal of Asynchronous Learning Networks, 13(3), 115-127.

Williams, L. (2014). A case study of virtual physical education teachers' experiences in and perspectives of online teaching. (Ph.D.), University of South Florida, Tampa, FL. Williams, T. (2015). 7 myths about online education, U.S. News \& World Report. 
Xu, D., \& Jaggars, S. S. (2014). Performance gaps between online and face-to-face courses: Differences across types of students and academic subject areas. Journal of Higher Education, 85(5), 633-659. 


\section{TABLES}

Table 1

Description of Factors and Examples of the Survey Instruments

\begin{tabular}{lcl}
\hline Factor & $\begin{array}{l}\text { Number of } \\
\text { Items }\end{array}$ & Factor Description \\
\hline $\begin{array}{l}{ }^{1} \text { Technology Skills/ } \\
\text { Self-efficacy }\end{array}$ & 6 & Computer skill and access technology. \\
$\begin{array}{l}{ }^{1} \text { Achievement beliefs } \\
\begin{array}{l}{ }^{1} \text { Instructional risk- } \\
\text { taking }\end{array}\end{array}$ & 6 & $\begin{array}{l}\text { Belief in oneself and in one's ability to achieve. } \\
\text { Taking responsibility for one's actions and taking individual } \\
\text { initiative. }\end{array}$ \\
${ }^{2}$ Organization & 5 & $\begin{array}{l}\text { Ability to approach tasks in an organized and goal-oriented } \\
\text { way. } \\
\text { Perception of the environment, including physical space and } \\
\text { time. }\end{array}$ \\
${ }^{2}$ Demograhpics & 5 & Age, Gender, Ethnicity, Class standing, and self-reported GPA \\
\hline${ }^{1}$ Factors and & 5 &
\end{tabular}

Note: ${ }^{1}$ Factors and items from ESPRI-V2 (Roblyer, et al. (2008)

${ }^{2}$ Factors and items from DLS (Osborn, 2001) 
Table 2

Overview of Analysis

\begin{tabular}{|c|c|c|c|}
\hline $\begin{array}{l}\text { Research } \\
\text { Question }\end{array}$ & $\begin{array}{l}\text { Independent Variable(s) } \\
\text { (Instrument) }\end{array}$ & $\begin{array}{l}\text { Dependent } \\
\text { Variable }\end{array}$ & Analysis \\
\hline RQ 1 & Cognitive Factors: (ESPRI-V2) & $\begin{array}{l}{ }^{*} \text { Course } \\
\text { completion status }\end{array}$ & ANOVA \\
\hline RQ 2 & $\begin{array}{l}\text { Demographics: Age, Gender, } \\
\text { Ethnicity, Class standing, and self- } \\
\text { reported GPA (DLS) }\end{array}$ & $\begin{array}{l}{ }^{*} \text { Course } \\
\text { completion status }\end{array}$ & $\begin{array}{l}\text { Descriptive statistics, } \\
\text { frequency distribution, } \\
\text { and Pearson's Chi } \\
\text { Square test }\end{array}$ \\
\hline RQ 3 & $\begin{array}{l}\text { Environment: Course load, } \\
\text { Previous online course experience, } \\
\text { Type of student, Hours of work } \\
\text { outside of school, and Financial } \\
\text { stability (DLS) }\end{array}$ & $\begin{array}{l}{ }^{*} \text { Course } \\
\text { completion status }\end{array}$ & $\begin{array}{l}\text { Descriptive statistics, } \\
\text { frequency distribution, } \\
\text { and Pearson's Chi } \\
\text { Square test }\end{array}$ \\
\hline RQ 4 & $\begin{array}{l}\text { Cognitive Characteristics (ESPRI- } \\
\text { V2) } \\
\text { Demographics (DLS) } \\
\text { Environment (DLS) }\end{array}$ & $\begin{array}{l}{ }^{*} \text { Course } \\
\text { completion status }\end{array}$ & $\begin{array}{l}\text { Binary logistic } \\
\text { regression }\end{array}$ \\
\hline
\end{tabular}

*Course completion status: Students completing the course with a grade of $\mathrm{A}, \mathrm{B}$, or $\mathrm{C}$ will be designated as successful (i.e. passing); students who withdrawal (W), drop (I), or complete the course with a grade of $\mathrm{D}$ or $\mathrm{F}$ will be identified as unsuccessful (i.e. failing). 
Table 3

Comparison of Student Demographics Between Completers and Non- Completers

\begin{tabular}{|c|c|c|c|c|c|c|}
\hline \multirow[t]{2}{*}{ Factor } & \multicolumn{2}{|c|}{ Completer } & \multicolumn{2}{|c|}{ Non-Completer } & \multicolumn{2}{|c|}{ Total } \\
\hline & $\mathrm{n}$ & $\%$ & $\mathrm{n}$ & $\%$ & $\mathrm{n}$ & $\%$ \\
\hline \multicolumn{7}{|l|}{ Age } \\
\hline $18-23$ & 610 & 77.4 & 178 & 22.6 & 788 & 96 \\
\hline $23-40+$ & 24 & 72.7 & 9 & 27.3 & 33 & 4 \\
\hline \multicolumn{7}{|l|}{ Gender } \\
\hline Male & 396 & 78.3 & 110 & 21.7 & 506 & 61.6 \\
\hline Female & 238 & 75.6 & 77 & 24.4 & 315 & 38.4 \\
\hline \multicolumn{7}{|l|}{ Ethnicity } \\
\hline Non-Minority & 547 & 77.7 & 157 & 22.3 & 704 & 85.7 \\
\hline Minority & 87 & 74.4 & 30 & 25.6 & 117 & 14.3 \\
\hline \multicolumn{7}{|l|}{ *Class Standing } \\
\hline Upper-Classmen & 509 & 78.9 & 136 & 21.1 & 645 & 78.6 \\
\hline Freshmen & 125 & 71 & 51 & 29 & 176 & 21.4 \\
\hline \multicolumn{7}{|l|}{ *GPA } \\
\hline $2.6-4.0$ & 572 & 81.6 & 129 & 18.4 & 701 & 85.4 \\
\hline $0-2.59$ & 62 & 51.7 & 58 & 48.3 & 121 & 14.6 \\
\hline
\end{tabular}

*Pearson Chi Square Results $p<.05$ 
Table 4

Comparison of Student Environmental Factors Between Completers and Non- Completers

\begin{tabular}{|c|c|c|c|c|c|c|}
\hline \multirow[t]{2}{*}{ Factor } & \multicolumn{2}{|c|}{ Completer } & \multicolumn{2}{|c|}{ Non-Completer } & \multicolumn{2}{|c|}{ Total } \\
\hline & $\mathrm{n}$ & $\%$ & $\mathrm{n}$ & $\%$ & $\bar{n}$ & $\%$ \\
\hline \multicolumn{7}{|l|}{ Course Load } \\
\hline 1-4 Courses & 119 & 73.5 & 43 & 26.5 & 162 & 19.7 \\
\hline 5+ Courses & 515 & 78.1 & 144 & 21.9 & 659 & 80.3 \\
\hline \multicolumn{7}{|l|}{ *Online Experience } \\
\hline 0 Courses & 8 & 50 & 8 & 50 & 16 & 1.9 \\
\hline 1-2 Courses & 478 & 78.7 & 129 & 21.3 & 607 & 73.9 \\
\hline 3-4 Courses & 117 & 77 & 35 & 23 & 152 & 18.5 \\
\hline 5+ Courses & 32 & 67.4 & 15 & 32.6 & 46 & 5.6 \\
\hline \multicolumn{7}{|l|}{ Type of Student } \\
\hline Distance Learner & 292 & 75.6 & 94 & 24.4 & 386 & 47 \\
\hline On Campus & 342 & 78.6 & 93 & 21.4 & 435 & 53 \\
\hline \multicolumn{7}{|l|}{ *HWOS } \\
\hline 1-20 Hours & 549 & 79.8 & 139 & 20.2 & 688 & 83.8 \\
\hline 21-40+ Hours & 85 & 63.9 & 48 & 36.1 & 133 & 16.2 \\
\hline \multicolumn{7}{|l|}{ Financial Dependents } \\
\hline Yes & 27 & 69.2 & 12 & 30.8 & 39 & 4.8 \\
\hline No & 607 & 77.2 & 175 & 21.3 & 782 & 95.2 \\
\hline \multicolumn{7}{|l|}{ Financial Aid } \\
\hline Parents & 333 & 76.6 & 102 & 23.4 & 435 & 53 \\
\hline Scholarship/Grant & 173 & 82 & 38 & 18 & 211 & 25.7 \\
\hline Self-pay/Loan & 89 & 71.8 & 35 & 28.2 & 124 & 15.1 \\
\hline Other & 39 & 76.5 & 12 & 23.5 & 51 & 6.2 \\
\hline \multicolumn{7}{|l|}{ Financial Stability } \\
\hline Confident & 548 & 77.8 & 156 & 22.2 & 704 & 85.7 \\
\hline Uncertain & 86 & 73.5 & 31 & 26.5 & 117 & 14.3 \\
\hline
\end{tabular}

*Pearson Chi Square Results $p<.05$ 
Table 5

ANOVA Results: Student Cognitive Factors

\begin{tabular}{|c|c|c|c|c|c|}
\hline Cognitive Factors & SS & df & $\mathbf{F}$ & Sig & $\eta^{2}$ \\
\hline \multicolumn{6}{|l|}{ Achievement Beliefs } \\
\hline Between Groups & 396.38 & 1 & 17.35 & .000 & .045 \\
\hline Within Groups & 18710.15 & 819 & & & \\
\hline Total & 19106.53 & 820 & & & \\
\hline \multicolumn{6}{|l|}{ Organization } \\
\hline Between Groups & 507.30 & 1 & 27.53 & .000 & .063 \\
\hline Within Groups & 15091.83 & 819 & & & \\
\hline Total & 15599.14 & 820 & & & \\
\hline \multicolumn{6}{|l|}{ Instructional Risk Tacking } \\
\hline Between Groups & 32.78 & 1 & 1.01 & .314 & .041 \\
\hline Within Groups & 26506.27 & 819 & & & \\
\hline Total & 26539.00 & 820 & & & \\
\hline \multicolumn{6}{|c|}{ Technology Skills/ Self-Efficacy } \\
\hline Between Groups & 1.69 & 1 & .128 & .720 & .027 \\
\hline Within Groups & 10794.17 & 819 & & & \\
\hline Total & 10795.86 & 820 & & & \\
\hline \multicolumn{6}{|l|}{ Study Environment } \\
\hline Between Groups & 221.94 & 1 & 30.59 & .000 & .058 \\
\hline Within Groups & 5940.40 & 819 & & & \\
\hline Total & 6162.35 & 820 & & & \\
\hline
\end{tabular}

*ETA Squared $\left(\eta^{2}\right)$ reported for factor effect size. 
Table 6

Direct Binary Logistic Regression Predicting Student Success

\begin{tabular}{|c|c|c|c|c|c|c|c|}
\hline \multirow[t]{2}{*}{ Predictor } & \multirow[t]{2}{*}{ B } & \multirow[t]{2}{*}{$\mathrm{SE}$} & \multirow[t]{2}{*}{ Wald } & \multirow[t]{2}{*}{$\mathrm{P}$} & \multirow[t]{2}{*}{$\begin{array}{l}\text { Odds } \\
\text { Ratio }\end{array}$} & \multicolumn{2}{|c|}{$\begin{array}{l}\text { 95\% CI for Odds } \\
\text { Ratio }\end{array}$} \\
\hline & & & & & & Lower & Upper \\
\hline GPA & 1.385 & .224 & 38.186 & $.000^{*}$ & 3.994 & 2.574 & 6.196 \\
\hline Class Standing & .789 & .219 & 13.313 & $.000^{*}$ & 2.221 & 1.447 & 3.409 \\
\hline HWOS & .588 & .230 & 6.533 & $.011^{*}$ & 1.800 & 1.147 & 2.825 \\
\hline Online Experience & & & 7.707 & .052 & & & \\
\hline 0 Courses & -.286 & .652 & .192 & .611 & .752 & .209 & 2.699 \\
\hline 1-2 Courses & .753 & .753 & 4.415 & .036 & 2.123 & 1.052 & 4.285 \\
\hline 3-4 Courses & .534 & .394 & 1.844 & .174 & 1.706 & .789 & 3.691 \\
\hline Achievement & .023 & .021 & 1.133 & .287 & 1.023 & .981 & 1.067 \\
\hline Organization & .066 & .025 & 6.965 & $.008 *$ & 1.068 & 1.017 & 1.122 \\
\hline Study Environment & .071 & .040 & 3.194 & .074 & 1.074 & .993 & 1.162 \\
\hline (Constant) & -5.256 & .874 & 36.158 & .000 & .005 & & \\
\hline \multicolumn{8}{|l|}{ Model Summary } \\
\hline \multirow[t]{2}{*}{ Final Step } & \multicolumn{2}{|c|}{-2 Log likelihood } & & \multirow{2}{*}{\multicolumn{2}{|c|}{$\begin{array}{l}\text { C-Statistic } \\
.727\end{array}$}} & \multicolumn{2}{|c|}{ Asymptotic 95\% CI } \\
\hline & 779.34 & & & & & .685 & .770 \\
\hline
\end{tabular}

*Direct Logistic Regression Results $p<.05$ 


\section{FIGURES}

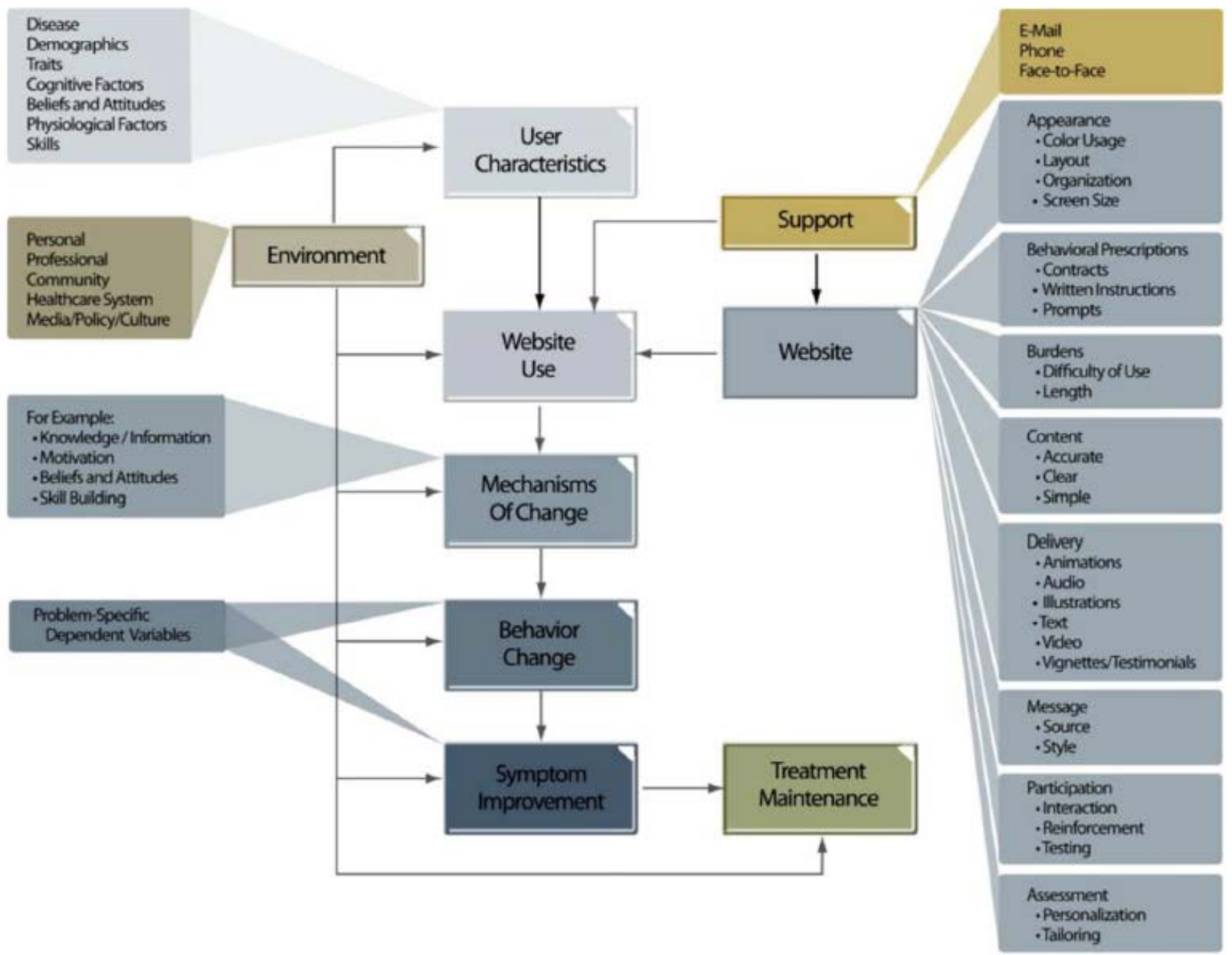

Figure 1. Online Behavior Change Model (Ritterband, et al., 2009, p. 14). 


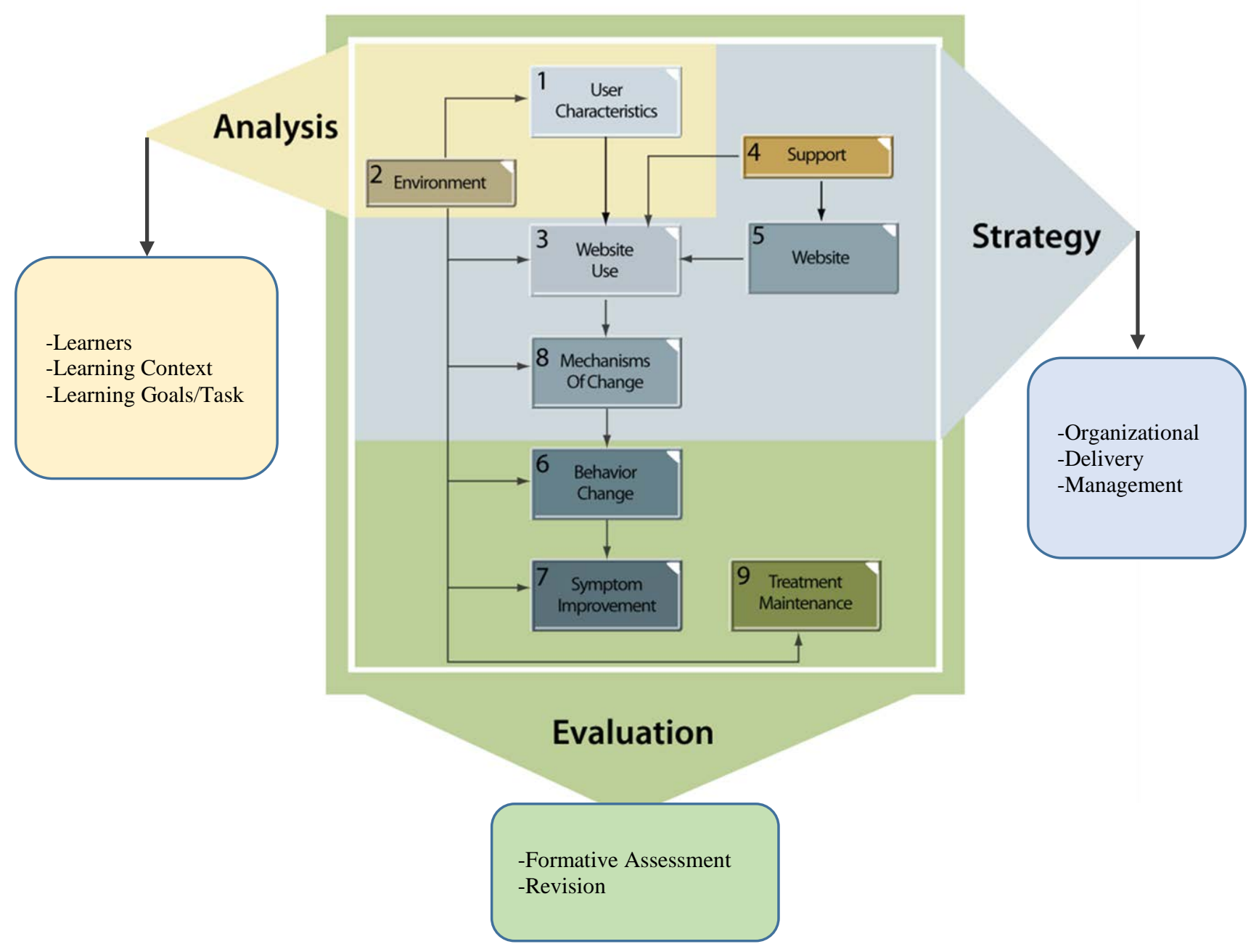

Figure 2. Instructional Design Process Model for Online Behavior Change Model (Hilgart et al., 2012, p. 17). 


\section{APPENDIX A}

\section{Extended Background}

Learning from a distance has been a part of the American education system since the eighteenth century (Saba, 2003). Early iterations of distance education came in the form of correspondence courses offered by educational institutions. These courses delivered, planned, and prepared educational materials to students who were not physically in the same location as their peers or instructor (Kaplan \& Haenlein, 2016). Over time distance educators have adapted their mode of delivery to the technology of their time. From local radio waves, to satellite television programming, and now over the internet, distance education courses are more accessible than ever (Pittman, 2003; Saba, 2003; Watkins \& Wright, 1991). By 1998, more than 800 higher education institutions, representing all 50 states, offered courses and degrees through distance education programs utilizing the internet (Saba, 2003). As of 2014 over 2.8 million students were enrolled exclusively in distance education courses at universities and over 2.9 million students were enrolled in at least one online course (Allen \& Seamen, 2016). While the form in which education is delivered from a distance has evolved over the decades, the underlying need for it has remained much the same.

For students, distance education programs provide the flexibility and access to education that may not be readily available to them otherwise. Within higher education, distance education programs have become increasingly popular as institutions look to not only cut cost, but to also expand beyond their traditional regions without investing in brick and mortar operations (Saba, 2005). As face-to-face course begin to transition to a digital space, concerns arise surrounding the quality of the instruction after making the crossover. While online learning has been 
practiced for over two decades, the amount of research has not kept pace with its rapid expansion (Barbour, 2010; Rice, 2006).

Generally, research in distance education has focused on two primary categories: (1) effects of delivery models on student performance, and (2) descriptive qualities and characteristics of teaching behaviors and learning experiences (Barbour, 2010). It has been suggested a next step for research in this field is greater examination between subject areas and educational contexts (Smith, Clack, \& Blomeyer, 2005). However, not all disciplines have fully embraced online education. Hesitancy to support online education within the physical education profession has been evident (Daum \& Buschner 2014) where content primarily focuses on promoting healthy lifestyles through physical activity and the teaching of fundament motor skills and movement patterns (Buchanan \& Brock, 2016; Price, 2015; Rink, 2013). In physical education, movement is not simply an included part of the curriculum, but rather, movement is the curriculum (Rink, 2013). Concerns within online physical education (OLPE) surround the instruction, assessment, and confirmation of the physical activity completed by students (Daum \& Buschner, 2012; Mohnsen, 2012; SHAPE, 2007). The first K-12 school system to deliver physical education content online was the Florida Virtual School (FLVS). Founded in 1997 with 77 students, the FLVS population grew to nearly 206,000 full and part time students in 2012. Mosier (2010) suggested that “due to the demands of high stakes testing for core subjects such as reading, writing, and mathematics” (p.9) OLPE programs like FLVS may become more of the norm. This upward trend is likely to continue as states such as Virginia, Alabama, Florida, Michigan, Idaho, New Mexico and Georgia have taken the initiative and enacted legislation mandating completion of an online course as a part of high school graduation requirements (Kennedy \& Archambault, 2012; Rice \& Yang, 2013). 
Online education has seen tremendous growth over the past decade and currently 5.8 million high school students are predicted to be enrolled in online courses (Allen \& Seaman, 2016). Parallel with this expansion, OLPE has become increasingly prevalent within the United States in the past decade, with thirty-one states now allowing required physical education credits to be taken online (SHAPE America, 2016). In response to the emerging trend of OLPE in K-12 settings, national governing bodies such as the Society of Health and Physical Educators (SHAPE) established guidelines for OLPE. The 2007 SHAPE Initial Guidelines for Online Physical Education, provide suggestions for OLPE relative to course content, assessment, technology, instruction design, and course site management. These guidelines have been used to inform the development of OLPE courses and provide a framework for evaluating courses currently being delivered. However, at the time of their conception, only a single peer reviewed OLPE research study (Goc Karp \& Woods, 2003) was available to inform the guidelines.

Although OLPE practices have extended across the country since the 2007 SHAPE Initial Guidelines for Online Physical Education, research in the area of OLPE still remains limited. As of 2016, published research focusing on OLPE included one peer-reviewed articles that compare face-to-face, hybrid, and online weight training courses at the university level (McNamara, Swalm, Stearne, \& Covassin, 2008) and four peer-reviewed research articles investigating secondary (K-12) OLPE (Goc Karp \& Woods, 2003; Kane, 2004; Daum \& Buschner, 2012; Daum \& Woods, 2015; Mosier \& Lynn, 2012). Remaining OLPE research is comprised of five doctoral dissertations examining students, instructors, and physical education teacher educators’ perceptions of OLPE (Daum, 2012; Futrell, 2009; Jackson, 2015; Trent, 2016; Williams, 2014). These initial studies do provide a foundation for understanding the characteristics of OLPE 
stakeholders and highlight areas that warrant further investigation. However, researchers have noted that the initial studies are disconnected and lack sufficient depth (Daum \& Buschner, 2014). These limitations highlight the need for future research in OLPE and would benefit from larger sample sizes, coordinated research, and a set of constant instrument gathering cognitive and physical fitness data (Daum \& Buschner, 2014).

Results of available OLPE research raise questions about the course delivery, course design, and instructional methods in relation to student learning and fitness gains. Previous research in OLPE could have potentially been influenced by the inherent contextual factors surrounding online courses or as Daum and Buschner (2014) in there literature review of K-12 OLPE research suggested, the OLPE courses could have simply been influenced by the technology available at the time. While student learning in OLPE has been found to be similar to traditional face-to-face physical education, fitness gains in comparable sections have produced contrasting results (Brewer, 2001; Hager et al., 2012; McNamara et al., 2008). Speculated reasons for a lack of fitness improvements in OLPE have been attributed to low student motivation, lack of face-to-face interaction, curriculum design, and students technological fluency. Given the availability and access to emerging educational technologies and instructional tools, previously identified OLPE limitations and barriers such as academic rigor, social interaction, effective instruction, and high student attrition rates (Mosier, 2010; Mosier \& Lynn, 2012; Ransdell, Rice, Snelson, \& Decola, 2008) are becoming less prevalent. Technologies such as physical activity and fitness trackers, online exergames, handheld devices and mobile applications specifically have the potential to quell concerns in OLPE. However, technology use does not equate to optimal and effective integration methods. McNamara et al. (2008) noted that there, "Seems to be a point of saturation where too much technology results in 
poor performance. It seems that the practitioner must balance instruction and training with just the right amount of personal attention and modern technology” (p. 1167). Scholars have posited that the demand for online learning is not going away and the question is no longer if OLPE is practical but rather, how to effectively administer OLPE to accommodate the online student (Daum \& Buschner, 2012) and promote success for all online learners.

Future instructors of OLPE will be encountering a new generation of learners who have never known life without technologies such as personal computers, mobile devices, streaming media, and the World Wide Web. Learners born into this current generation have been termed 'digital natives’ and are said to have been “immersed in technology all their lives, imbuing them with sophisticated technical skills and learning preferences” (Bennett, Maton, \& Kervin, 2008, p.775). They are considered proficient multi-taskers, active learners, and dependent on technologies for information access and communication (Oblinger \& Oblinger, 2005). As a result, the landscape of education is changing and with it, OLPE stakeholders must identify program strengths and weaknesses to better accommodate the online student.

Instructional design process models have been developed to guide and support the use of the internet in the delivery of discipline-specific and educational content (Hilgart, Ritterband, Thorndike, and Kinzie, 2012). Process models aim to establish the needed balance between emerging technologies, curriculum, learner support, and student characteristics. Online course components such as appearance, content delivery, student use, and support represent variables that can be responsive and influenced by student and environmental characteristics (Ritterband, Thorndike, Cox, Kovatchev, \& Gondev-Frederick, 2009). Ritterband et al. (2009) describe user characteristics (i.e. gender, age, ethnicity, etc.) as fixed, however, they can still be influenced by environmental factors such as family, friends, employer, school, or societal level influences such 
as social media, policy, and other cultural factors. These environmental factors can then affect website use and student persistence through an online course. Instructional frameworks that account for the impact of the internet on variables such as user characteristics and environmental factors can help guide OLPE programs better accommodate and respond to the needs of the modern student.

Studies that have focused on OLPE student perceptions and characteristics shed light on possible factors affecting their persistence in online courses. However, limited data exist on student retention rates and attrition factors in OLPE. Mosier's 2010 investigation of the FLVS OLPE program offered insight to student demographic information such as age, gender, ethnicity, GPA, reasons for enrolling, enrollment type (traditional, accelerated, or extended) and completion rates. The study found that of all students enrolled, 52 percent were designated completers ( $n=10,333), 40$ percent non-completers/never activated/no grade $(n=8,054)$, and 8 percent non-completers who withdrew or failed the course $(n=1,557)$. Correlations between student characteristics and completion data reveal a need for further study into the factors surrounding OLPE student persistence and attrition.

The study conducted by Mosier in 2010 represents the most comprehensive examination of student characteristics within OLPE. The findings aligned with previous descriptive research (Futrell, 2009; Kane, 2004; Goc Karp \& Woods, 2003) that described student characteristics and experiences within OLPE; including student perceptions about the flexibility and personalization of OLPE. Furthermore, descriptive studies have shed light on possible student, environmental, and programmatic factors affecting persistence in OLPE courses. Student characteristics such as responsibility, autonomy, internal locus of control, time management and proficient communication skills have been suggested to make-up the type of student who is successful in 
OLPE courses (Daum \& Buschner, 2012). However, these characteristics are similar to those students who persist in most educational environments - virtual or face-to-face (Roblyer \& Marshall, 2002; Roblyer, et. al, 2008). Ransdell et al. (2008) indicated that the dropout rate in OLPE courses were linked to programmatic and environmental factors. Similarly Brewer (2001) attributed a higher dropout rate in online sections of a physical activity course to a lack of support, poorly designed courses, and inexperienced and/or incompetent instructors.

What remains to be explored in OLPE are student characteristics such as physical activity competencies, background information, cognitive beliefs, and environmental factors that may influence student persistence and attrition in OLPE. Several early OLPE studies as well as the 2007 SHAPE Initial Guidelines for Online Physical Education have suggested that certain prescreening efforts be in place prior to student enrollment in OLPE, however, at present an empirically sound and theoretically based OLPE screening instrument does not exist (Mosier, 2010; Ransdell et al., 2009). Scholars have called for empirical and theoretical research to identify predictive factors of success in online learning (Alem, et al., 2014) and similar work is needed in OLPE. Screening and pre-screening systems can help identify students who are at risk of failing and/or not completing online coursework. Such tools have the potential to provide schools with data-based advising resources that can be used to improve performance and persistence in online coursework (Hart, 2012). This would allow for a deeper understanding of the support, design, and delivery strategies needed in OLPE to facilitate student success. Examining pre-existing barriers and facilitators to OLPE student success, will not only inform course design and delivery, but could also aid in the development of early warning systems in OLPE courses. 


\section{Statement of the Problem}

The purpose of the study is to identify online student characteristics and environmental factors associated with success and/or failure within online health-related fitness (HRF) courses.

\section{Research Questions}

Four research questions guide the proposed study:

RQ1: To what extent do student cognitive characteristics influence course completion in a university level online HRF course?

RQ2: To what extent do student demographics influence course completion in a university level online HRF course?

RQ3: To what extent do student environmental characteristics influence course completion in a university level online HRF course?

RQ4: What combination of student cognitive characteristics, environmental characteristics, and demographics produce a model that best predicts course completion in university level online HRF courses?

\section{Conceptual Framework}

Many health behavior web-based interventions are grounded in behavior change theory, yet none account for the influence of their intervention being administered online (Ritterband, et al., 2009). Thus, the Online Behavior Change Model (Figure 1) was created to, "help guide future internet intervention development and predict and explain behavior changes and symptom improvement produced by internet interventions” (Ritterband, et al., 2009, p. 18). The Online Behavior Change Model is informed by various disciplines and theories of motivation, social marketing/adverting, web-based design/development techniques, and models of knowledge transfer such as the Information-Motivation-Behavioral-Skills Model (Fisher, 2002) and Health Belief Model (Becker, Drachman, \& Kirscht, 1974). Combining different aspects of these past 
models and theories, Ritterband et al. (2009) designed the Online Behavior Change Model to account for the effects of the internet when delivering behavior change interventions. The Online Behavior Change Model provides a framework to develop and improve OLPE courses by helping to conceptualize, identify, and measure factors affecting students and instructors.

To better inform the design and development of internet interventions, Hilgart, et al., (2012) proposed updates to the Online Behavior Change Model on the premise that the existing model contains many design related elements (i.e. user characteristics, environment, content, support, etc.). The infusion of Instructional Design Theory (IDT) provides an additional supporting framework for assessing learner needs, determining gaps in student attitudes, and exploring behaviors and knowledge relative to desired outcomes. Hilgart et al., (2012) asserts that the infusion of the instructional design process enhances the models ability to achieve the desired outcome of a behavior change by providing a systematic method to refine and enhance the planning, implementation, and evaluation of an online program. Updates to the model included the overlaying of three IDT phases onto the existing model that include, analysis, strategy, and evaluation (Figure 2).

Hilgart's et al. (2012) IDT infusion update to Ritterband's et al. (2009) Online Behavior Change Model will provide the theoretical bases for the current study. The current study will focus on the IDT analysis phase of Online Behavior Change Model, this section of the theoretical framework focus on two key components; student characteristics and environmental characteristics (e.g. demographics, course learning objectives, assessment of students, financial stability, etc.). Although there are many studies published in regards to best online teaching practices, little is known about how to identify students at risk of dropping out of an online course (Alem, Plaisent, Bernard \& Chitu, 2014; and Hart, 2012). Analysis of these online 
student and environmental characteristic would allow for a deeper understanding of the unique commodities of learners present in OLPE. Provided with information from the analysis phase of the IDT process better informs OLPE stakeholders in the development of support, design, and delivery strategies to facilitate student success.

\section{Scope of the Study}

For the purpose of this study, the combination of these two models provide a theoreticalbased approach for identifying and targeting factors that contribute to student attrition and drop out, specifically related to user and environmental factors. The current study will focus on the analysis section of the framework and examine the student characteristics and environmental factors that serve as predictors of success within university level online HRF courses.

\section{Assumptions}

- Online HRF courses have a high rate of failing students or students who do not persist to the conclusion of the course.

- The online HRF courses are fully developed and have sufficient support.

- University online HRF courses will be student centered with majority of course work focused on acquiring knowledge of basic physical fitness and wellness concepts in addition to a physical activity component.

- All students will answer questions truthfully.

\section{Limitations}

- Results from completed surveys may not be applicable to other online HRF courses due to the unique context of individual universities.

- Access to student's final grades at the end of the course may be a prohibiting factor for conducting the study at select universities. 
- Group size relations between passing and failing an online HRF course may affect the ability to find a significant relationship between student, environmental, and demographics characteristics.

- Course instructor differences in communication and student assessment.

\section{Definition of Terms}

Attrition- As the opposite of persistence, attrition is withdrawal from an online course (Hart, 2012).

Blended/ hybrid course- Course that blends online and face-to-face delivery. Substantial proportion of the content is delivered online, typically uses online discussions, and typically has a reduced number of face-to-face meetings (Allen \& Seaman, 2012).

Completer failing- A student who finishes an online health related fitness courses with a grade of $\mathrm{D}$ or $\mathrm{F}$.

Completer passing- A student who finishes an online health related fitness courses with a grade of $\mathrm{A}, \mathrm{B}$, or $\mathrm{C}$.

Health related fitness- Classified as combining health concepts with physical activity. The purpose of these courses are to facilitate students in applying the knowledge of health and fitness concepts in order to design, implement, and evaluate personalized health related fitness programs. These courses are commonly referred to as wellness or fitness for life courses (Hensley, 2000).

Learning management system (LMS) - Web-based learning platforms that students access course content (e.g., instructional materials, audio/video, presentations, digital text books, etc.), discussion boards, quizzes, and submit assignments. Components of the LMS may include a variety of web-based video and audio communications that are accessible and utilized by the instructor synchronously or asynchronously to deliver content (Rice, 
2006). The LMS allows the instructor to manage the class, upload assignments, develop projects, create discussion forums, and score/grade (Mohnsen, 2012; Wicks, 2010).

Non-completer/ withdrawn- A student who does not finishes an online health related fitness courses or withdrawals from the course before its conclusion.

Online course- A course will be considered an online courses if 80 percent or more of the content is delivered online and students have no face-to-face meetings (Allen \& Seaman, 2012).

Online physical education- Student learning and participation in physical education through the internet with no requirement to attend class in person (SHAPE, 2007).

Persistence- The ability to complete an online course despites obstacles or adverse circumstances (Hart, 2012).

Traditional/ Face-to-face course- Course where no online technology used content is delivered in writing or orally (Allen \& Seaman, 2012).

Web facilitated- Course that uses web-based technology to facilitate what is essentially a faceto-face course. May use a learning management system or web pages to post the syllabus and assignments (Allen \& Seaman, 2012).

\section{Significance of the Study}

Research in the area of distance education has suggested that online course experiences can promote student independence and accelerated learning (Allen \& Seaman, 2012; Mohnsen, 2012). According the 2016 SHAPE of the Nation Report, 31 states allow students to satisfy required physical education credits online. The number of states permitting online physical education (OLPE) has increased by 11 since 2010. This upward trend is likely to continue as states such as Virginia, Alabama, Florida, Michigan, Idaho, New Mexico and Georgia have 
enacted legislation that would mandate students complete an online course as a high school graduation requirement (Kennedy \& Archambault, 2012; Rice \& Yang, 2013). Physical education has extended into the virtual world and the quality of delivery and student/instructor experiences have been examined by scholars within the field (Daum, 2012; Goc Karp \& Woods, 2003; Futrell, 2009; Kane, 2004; Mosier, 2010; Williams, 2014). Factors associated with student success in OLPE, however, have not been thoroughly explored. Identifying factors that influence student success or failure in online HRF courses would provide valuable information for students, academic advisors, online instructors, instructional designers, and K-12 and universitylevel administrators. Equipped with the knowledge of factors that associate with and may predict student success or failure within online HRF courses can assist OLPE and online physical activity stakeholders to make more informed decisions related to necessary supports, strategies, tools, course design, pacing, and communication tactics aimed at facilitating student success and persistence through online HRF courses (Roblyer, Davis, Mills, Marshall \& Pape, 2008). 


\section{APPENDIX B \\ Extended Method}

This section outlines the research design and methodology, participants, measures, and proposed data analysis employed in the current study. The purpose of the study is to identify online student characteristics and environmental factors associated with success and/or failure within online HRF courses. Four research questions guide the proposed study:

RQ1: To what extent do student cognitive characteristics influence course completion in a university level online HRF course?

RQ2: To what extent do student demographics influence course completion in a university level online HRF course?

RQ3: To what extent do student environmental characteristics influence course completion in a university level online HRF course?

RQ4: What combination of student cognitive characteristics, environmental characteristics, and demographics produce a model that best predicts course completion in university level online HRF courses?

Insights gained from the proposed study will allow for a greater understanding of OLPE student demographics, cognitive characteristics, achievement beliefs, physical activity behaviors, and how they relate to student success. Equipped with the knowledge enables OLPE stakeholders to make more informed decisions related to necessary supports, strategies, tools, course design, pacing, and communication tactics to facilitate student success and persistence through online HRF courses (Roblyer, Davis, Mills, Marshall \& Pape, 2008).

\section{Research Design}


A factorial research design will be implemented for the current exploratory study. This research design is appropriate when an investigator is seeking to describe and measure the effect each variable, as well as the effects of interactions between sets of variables on a dependent variable (Creswell, 2012). Participants enrolled in university-level online HRF courses will be recruited to participate in the study. To address the research questions, three validated research instruments founded in models of attrition and retention to identify factors influencing the success and failure in online learning environments will be used, the ESPRI Version-2 (Roblyer, et al., 2008), the Distance Learning Survey (DLS; Osborn, 2001), and the Behavioural Regulation in Exercise Questionnaire Version 2 (BREQ-V2; Markland \& Tobin, 2004).The constructs and single item predictors from each of the three instruments—Roblyer's et al. (2002; 2008) ESPRI-V2, Markland and Tobin (2004) BREQ-V2 and Osborn’s (2001) DLS— employed for the current study are outlined in Table 10. The survey instruments define student success as 'one who completes a course with a passing grade and failure as either non-completion or completion with a failing grade'. For the purposes of the current study the pass/fail criteria will be defined as: students completing the course with a grade of $\mathrm{A}, \mathrm{B}$, or $\mathrm{C}$ will be designated as successful (i.e. passing); students who withdrawal (W), drop (I), or complete the course with a grade of $\mathrm{D}$ or $\mathrm{F}$ will be identified as unsuccessful (i.e. failing).

\section{Instrumentation}

A combination of instruments measuring factors associated with student persistence and attrition in an online course will be used to address the current studies research questions. Specifically, to address the four research questions related to these two components, the ESPRIV2, DLS, and BREQ-V2 will be utilized. Instruments such as the ESPRI-V2 and DLS have been used to identify the potentially successful and at risk students who enroll in online courses 
(Osborn, 2001; Roblyer \& Marshall, 2002). The BREQ-V2, which measures participant’s motivations for engaging in physical activity, will be employed to account for the discipline specific context (Markland \& Tobin, 2004). Data gathered from the ESPRI-V2 and BREQ-V2 will be analyzed to address RQ1, the DLS will address RQ2 and RQ3, and a combination of items from the ESPRI-V2, BREQ-V2 and DLS will address RQ4 (Table 5).

The Educational Success Prediction Instrument Version 2. The ESPRI-V2 is a robust 23-item survey that measures stakeholder understanding and development of the structure, strategies, and support system of an online course necessary for learning and retention (Appendix A). Originally designed for use in high school virtual schools and later adapted for use at the university level (Black, 2006), the ESPRI-V2 has been demonstrated to be a valid and reliable tool for predicting student success in online courses (Black, Ferdig, \& DiPietro, 2008; Roblyer \& Marshall, 2002; Roblyer, et al., 2008; Rankin, 2013). The instrument is comprised of four constructs: (1) technology use/self-efficacy, (2) achievement beliefs/locus of control, (3) instructional risk taking, and (4) organization strategies. Within each construct, respondents indicate their level of agreement (strongly agree 1 - strongly disagree 7) on statements such as "When I have to do something on a computer, I usually try to figure it out myself,” or "I tend to wait until the last minute to get things done.”

Version 1 of the ESPRI was a 70-item instrument the utilized a 7-point Likert scale measuring five cognitive belief constructs (Roblyer \& Marshall, 2002). For the initial validation study of the ESPRI, the survey was distributed to students ( $n=135)$ across 13 New England region virtual high schools. The researchers found that the instrument was able to predict passing students with 100 percent confidence and failing with 95 percent. It was found that successful online students rated themselves higher in organizational skills, self-efficacy, initiative, 
technology skill/access, and spent less time working outside of school. Although, Roblyer and Marshall (2002) found the ESPRI to be successful, it was recommended that the instrument be tested with additional groups and a larger population to confirm the validity of the ESPRI.

The instrument was later refined by Roblyer, Davis, Mills, Marshall, and Pape (2008) based upon past factor analysis and logistical regression findings within each of the constructs, omitting items that made little contribution to the prediction indexes. Version 2 of the ESPRI was administered to the same New England region virtual high school $(\mathrm{N}=2,880)$ as the original Roblyer and Marshall (2002) study. The ESPRI-V2 was reduced from the original 70 items contained within the 2002 version:

Because online instructors and administrators had observed that online students would be more likely to complete an abbreviated instrument, a factor analysis was done to determine if items could be reduced in number for future administrations while maintaining acceptable reliability and maximizing explained variance among items (Roblyer, et al., 2008, p. 98).

A principle components extraction method with varimax rotation was used with the purpose of reducing items while maintaining as much information possible from the original constructs (Roblyer, et al, 2008). The results, allowed for elimination of the construct of responsibility and reduced the ESPRI-V2 to 23 items comprising four constructs: technology use/self-efficacy (six items); achievement beliefs/locus of control (six items); instructional risk taking (six items), and organization strategies (five items). The total scale reliability for the 23-item version of the ESPRI-V2 was found to be alpha $=0.92$. This Cronbach's alpha score indicates a high level of internal consistency among the ESPRI-V2 constructs. A Cronbach alpha score that is greater than or equal to 0.7 is considered adequate to determine reliability in an instrument (Tabachnick \& Fidell, 2014). 
To analyze the data, Roblyer et al. (2008) employed a logistical regression using the five cognitive belief constructs and various combinations of student demographic factors as independent variables with course completion (i.e. pass/fail) as the dependent variable. Roblyer, et al. (2008) found that the best combination of predictors from the outcome of a direct logistical regression included: ESPRI sum; student background variables of age and self-reported GPA; the environmental variables, home computer availability and available school time for online course work. This model was able to predict student success in an online course at 93 percent and student failure at 30.4 percent (Roblyer, et. al., 2008). The authors concluded that the measurements made within the ESPRI-V2 in combination student demographic (e.g. GPA, success in previous online course, etc.) and environmental characteristics develop a useful predictive model for online student success.

While the ESPRI-V2 addresses student environmental and demographic characteristics, the survey items associated with those factors pertain to the high school level and do not address concerns students may have in higher education. Osborn’s (2001) distance learning survey represents the only other study identified by Alem et al. (2014) systematic review of 5,107 published and unpublished papers on student online readiness assessment tools that met all of the quality criteria for student online persistence and success instruments. Moreover, Osborn’s (2001) survey addresses student environmental and demographic characteristics with items in each construct focused on university level online courses.

Distance Learning Survey. The ESPRI-V2 and DLS are both founded in models of attrition and retention to identify factors influencing the success and failure in online learning environments. Osborn's (2001) prediction model is based on a combination of both student characteristics and course environment characteristics within a graduate student population. Four 
models contribute to Osborn’s (2001) framework; Billings Model of Correspondence Course Completion, Tinto’s Model of Student Persistence, Kennedy and Powell’s Descriptive Model, and Kember’s Open Learning Model. From these models Osborn asserts there are three central constructs to understanding 'behavioral intention to persist' in online courses, these include: (1) entry characteristics; (2) social integration; and (3) academic integration. These three general areas informed the initial development of the Distance Learning Survey (DLS) which consisted of the nine following constructs predicting completion, (1) computer confidence; (2) enrollment encouragement; (3) financial; (4) locus of control; (5) motivation; (6) study environment; (7) support; (8) preparation; and (9) tenacity. Additionally, the DLS included seven-single item predictor variables, (1) age; (2) GPA; (3) educational level; (4) hours worked per week; (5) credit hours taken in the current semester; (6) number of previous distance learning courses taken; and (7) years out of college (Osborn, 2001).

For the initial validation study the DLS was distributed to students enrolled in online and videoconferencing courses at the University of North Texas $(\mathrm{N}=396)$. The survey consisted of 28 Likert scale items (1 strongly disagree to 5 strongly agree) within nine constructs and seven ordinal or ratio predictive variables (Osborn, 2001). The survey was administered at the beginning of the semester to university students (84 percent graduate-level students) and results of course completion were provided by the instructors of each course (Osborn, 2001). Similar to the ESPRI-V2, the DLS instruments defines student success as one who completes a course with a passing grade and failure as either non-completion or completion with a failing grade. To determine the predictive validity of the DLS survey, a discriminant analysis procedure based course completion was conducted and tested against a sample randomly selected from the population (Osborn, 2001). The results of which found that six constructs, including: (1) 
computer confidence, (2) enrollment encouragement, (3) locus of control, (4) motivation, (5) study environment, (6) tenacity — accounted for 56.81 percent of the variance between student success and failure (Osborn, 2001). Contributing to the prediction model were four single-item predictor variables, number credit hours taken in the semester; previous experience with distance learning; educational level; and GPA. The remaining three constructs and four single-item predictor variables were able to correctly classify 82 percent of the students as completers or non-completers (Osborn, 2001).

Osborn found that 87 percent of online graduate students in the study were successful in the online courses studied. The author attributed this high pass rate to student age and proximity to degree completion. Other entry characteristics, such as GPA and educational level, made an important contribution to the final prediction equation, but were not sufficient predictors individually. Additionally, Osborn found that at-risk students were generally taking more credit hours, unstable study environments, lower motivation, less computer confidence, previously dropped out of college and had no experience in an online courses. At-risk students tended to be undergraduates with lower GPAs who received less encouragement to take an online course from family, friends, or employers (Osborn, 2001). Osborn’s results and interpretations correspond with previous findings of online student success (Hart, 2012; Ivankova \& Stick, 2005; Roblyer et al., 2008; and Xu \& Jaggers, 2014). For the current study, the single-item predictor variables as well as the financial support and study environment factors that relate to a collegiate population will be integrated into the OLPE student success survey (Appendix B).

Osborn suggested using the DLS instrument in other disciplines and/or with undergraduate populations could contribute to more precise discriminant functions and merits further research. Content area experience and demonstrated ability, measured by discipline 
specific screening, have been shown to be significant predictors of online student success (Slykhuis \& Park, 2006; Rankin, 2013; Yuan \& Kanthawala, 2015). Specifically in OLPE, It has been found that students with higher perceived health related fitness levels, positively impact their motivation to engage in physical activity (Decarlo, 2016). It has been suggested that physical education teachers should be aware of student's motivations to exercise and address health related fitness concepts according to these levels. By measuring students motivations to engage or to not engage in physical activity will inform stakeholder in how to better support students in OLPE course work.

Behavioral Regulation in Exercise Questionnaire-Version 2. In addition to the four constructs of the ESPRI-V2 and single item predictors of the DLS, a physical activity readiness construct will be added for the current studies OLPE student success survey. The physical activity construct will be particularly important as the subject matter inherently requires a large amount of hands-on learning and practice, intensive instructor-student interaction, and immediate personalized feedback. Items included in the physical activity readiness construct will come from Markland and Tobin’s (2004) BREQ-V2 (Appendix C). The BREQ-V2 is a modification to Mullan, Markland, and Ingledew (1997) original BREQ survey and was an effort to reinstate amotivation items into the instrument. Originally the BREQ survey included amotivation items, but they were dropped after Mullan et al., (1997) found that these items caused a high level of skewness and a restricted range of scores when attempting to validate the initial instrument, thus these items were excluded. Mullan et al (1997) speculated that this was likely a result of the participants used in the initial validation study who were already exercising regularly since they were recruited from a local fitness center. Markland and Tobin (2004) content that the significance of the additional amotivational items to the BREQ allows for the researchers to 
investigate the past history and consequences of amotivation in relation to exercise behaviour (Markland and Tobin, 2004).

Mullan and Tobin (2004) used modified amotivation items that they hypothesized would exhibit a wider range of responses with the participants who had taken part in an exercise referral scheme at a local community leisure center. At the leisure center, participants were incentivized to undergo a medical examination and fitness assessment in order to receive a free exercise prescription and set of twelve exercise session with a personal trainer. If the participant was found to be either overweight, obese, have moderate hypertension or depression then they would receive a referral. Over the 3 years, 580 participants had received referrals and BREQ-V2 questionnaires were mailed to all of those participants. The researchers received a response rate of 35 percent ( $n=194)$. Overall, the sample of participants were at the upper end of the overweight category of the body mass index and were on average 55 years of age.

The BREQ-V2 completed by participants consisted of 19 Likert scale questions ranging from "not true for me" to "very true for me.” The 19 questions of the BREQ-V2 make up five categories on the continuum of motivation as described by self-determination theory; (1) amotivation, (2) external, (3) introjected, (4) identified, and (5) intrinsic (Markland \& Tobin, 2004). Participants are categorized on the spectrum from amotivated to intrinsically motivated based upon their responses to the BREQ-V2. Those who indicate a higher levels of autonomous regulation of motivation (i.e. identified and intrinsic) are more likely to engage in regular physical activity. The researchers suggest that it is the quality and not the intensity of motivation that is the most influential factor associated with frequent exercise participation and positive perceptions of physical activity (Markland \& Tobin, 2004). 
Markland and Tobin (2004) found that the addition of amotivation items to the initial BREQ possessed good factorial validity $(\mathrm{M}=0.76$, range $=0.74-.88$, and $\mathrm{p}<0.001)$ and internal consistency $(\alpha=.90)$. Although, it was found that the additional amotivation scale possessed a level of skewedness due to participants indicating low level of amotivation with a small range of scores, it was not on the same level as Mullen et al., (1997). Markland and Tobin (2004) attributed this to recruiting participants from an exercise referral scheme in which subjects voluntarily participated and would likely have some motivation to exercise. For OLPE, the BREQ-V2 provides a validated instrument to measure student physical activity motivation levels in relation to successful course completion.

In Mullan et al. (1997) initial development of the BREQ, the item-aggregation approach to categorizing the data was suggested. Markland and Tobin (2004) utilized a Relative Autonomy Index (RAI) for scoring the BREQ-V2. In this approach, the scores from each of the motivation subscales are weighted then aggregated into an index which represents the extent to which a person is motivate to engage in physical activity (Ryan \& Connell, 1989). However, Chemolli and Gagne (2014) contend that use of the RAI is statistically problematic when investigating motivational dynamics across multiple domains. The authors suggest a multidimensional conceptualization of motivation that scores individuals for each type of category (Chemolli \& Gagne, 2014). Furthermore, the authors advocate that using this alternative scoring method is especially prudent in research involving person-based profiles (e.g. completers and non-completers). Thus, for the current study scores will be computed by averaging response options across each the five BREQ-V2 motivation categories

\section{Pilot Study}


The three surveys were pilot tested with two sections of online HRF courses at West Virginia University as well as four sections at Auburn University during the Summer 2017 term. Surveys were embedded into the assessment tool (i.e. quizzes) of each University’s respective LMS during two phases. The ESPRI and DLS were embedded in the Pre-semester and the BREQ-V2 for the Mid-semester. Data for both phases were collected via the LMS assessment tools and results exported as Microsoft Excel files. Before data were sent from Auburn University data were de-identified and participants assigned a research code to ensure student anonymity. This also enables individual student performance (i.e. completers/non-completers) end of term data to be linked to pre and mid-semester survey responses. Data from both phases were then cleaned and made ready to merge with individual student course completion status at the end of the term.

Within the four online HRF courses at Auburn University, 93 students (77.5 percent response rate) completed the pilot survey. Of the 93 students who completed the survey, 77 students (82.8 percent) were categorized at completers and 16 students (17.2 percent) as noncompleters. Due to inadequate statistical power due to the sample size in relation to the number of constructs, inferences made from the results of the data would be prone to a Type II error. However, feedback on survey items and instruction were used to inform edits to the survey instruments as necessary.

\section{Participants}

For the purpose of the current study, the criterion for participant inclusion will be students enrolled in university-level online HRF courses. HRF courses are classified as combining health concepts with physical activity and commonly referred to as wellness or fitness for life courses (Hensley, 2000). As defined by Allen and Seaman (2012), a HRF course will be 
considered an online courses if 80 percent or more of the content is delivered online and students have no face-to-face meetings.

Students will be recruited from a four-year institution in the southeastern region offering online HRF courses. Students must be enrolled in the 16-week online HRF course during the Fall 2017 Semester. With the permission of the online program coordinator, instruments will be built within the LMS course shell as pre, mid-, and post course components. One week before the start of the online HRF course students will receive an informational email explaining the purpose of the study and detail the information that will be collected (Appendix D). Informed consent for the surveys will be obtained through the assessment tool of the institutions LMS were students can choose to opt-in or opt-out of the study (Appendix E).

\section{Setting}

Auburn University is a public land-grant institution with an undergraduate population of nearly 23,000 students. The ethnic makeup of the undergraduate population consist of mainly white/non-Hispanic students (77 percent). Only 19 percent of undergraduates live on campus with the majority of students living close by in the surrounding area.

Auburn University was selected as the site of the study due to their implementation and development of model online HRF courses. Development of the online HRF course-Active Auburn—has been in progress since 2014 (Russell, Wadsworth, Hastie, \& Rudisill, 2014). Auburn Universities wellness program and Active Auburn created with the current trends and research within college wellness and grounded in the Appropriate Instructional Practice Guidelines for Higher Education Physical Activity Programs (Melton, Russell, Moore, \& Sweeney, 2009; Russell, et al., 2014). The asynchronous online course was designed to allow students to participate in physical activity of their choice at any time or anywhere that best fits 
their schedule. Within Active Auburn students are exposed to the basic concepts associated with the development and maintenance of physical activity, as well as to the different fitness opportunities offered in their local area. Throughout the 16-week course students engage in health-promoting and wellness activities through five course modules: (1) exercise vocabulary; (2) health benefits of engaging in regular physical activity; (3) FITT principles; (4) behavioral change strategies; and (5) preparing and recovering from exercise. In order to validate the completion of physical activity, Active Auburn requires students to purchase a fitness tracker for the course. Physical activity is tracked, electronically recorded, and synced to course LMS using a fitness tracking device (e.g. Fitbit, MovBand 3, Jawbone, Apple Watch, etc.). Students who do not already own a fitness tracking device are encouraged to purchase a MovBand 3, but all students in the course are allowed to use any fitness tracking device for the course. Students are required to register their fitness trackers to their course section and sync their fitness tracking data weekly. Each week the syllabus (Appendix F) outlines the "move goals” that students are required to achieve and then sync to the course LMS in order to receive participation points.

As of the 2015-2016 academic year, Active Auburn had an enrollment of 1,534 students. The majority of students enrolled were female $(1,192)$ in contrast to the number of males enrolled (342). Instructors of Active Auburn are graduate research and teaching assistance who are trained by the program coordinator on the proper procedures of delivering the course. Training includes tutorials on how to operate the LMS and troubleshooting common technical issues that arise with the fitness trackers in order to facilitate student learning in the course. The course delivery and presentation of content and assessment are standardized across all sections of Active Auburn courses. The program coordinator of Active Auburn uploads the standardized course shell into the LMS and is the only person able to make any changes to the course. 
Grading is standardized across all sections of Active Auburn with quizzes and fitness tracking goals automatically assessed by the institutional LMS. If students have any grade disputes they are only handled by the program coordinator.

\section{Procedures}

After IRB approval was received, data will be collected in three phases: (1) Pre-semester, (2) Mid-semester, and (3) End of semester. One week before the start of the Fall 2017 semester, online HRF course students at Auburn University will receive an informational email explaining the purpose of the study and outline the information that will be collected (Appendix D). Presemester data will draw from the ESPRI-V2 and DLS factors and single item predictors. Students will be prompted by the online HRF course program coordinator to complete both surveys upon entry to their online HRF course. Also, a course announcement will be posted in each of the online HRF course sections to let students know the Pre-semester survey is available. Informed consent for the surveys will be obtained through the assessment tool of the institutions LMS were students can choose to opt-in or opt-out of the study (Appendix E). Directions for completing the survey follow the informed consent page and can be viewed by the student if they choose to opt into the survey. Students will have two weeks at the beginning of the term to respond to the Pre-semester survey which will take them approximately 15 minutes to complete. A reminder email will be sent to students and an announcement posted to each online HRF course after one week in an effort to increase student participation. Mid-semester data from the BREQ-V2 will be collected in the same fashion as the Pre-Semester data during week 8 of the online HRF course. Lastly, end of semester data will consist of student's final grade or withdrawal status in the HRF course that will be provided by the online HRF program coordinator. 
Data from the surveys will be automatically be collected in the institution LMS grade recording tool. The LMS grade recording tool will automatically link the student's name and identification data to their individual survey responses. Student responses will be exported from the LMS as a Microsoft Excel file and will be de-identified by a person uninvolved in the research to ensure participant anonymity. Furthermore, participants will be assigned a research record code so that Mid-semester data (BREQ-V2) and End-semester individual student performance (i.e. completers/non-completers) can be linked at the end of the term. A code list will be kept in an encrypted password-protected file and stored on a secure computer at Auburn University with access to only the online HRF program coordinator. The codes list will also be backed up on a flash drive which will be kept in a locked cabinet in the office of the Auburn University online HRF program coordinator. After which, de-identified survey data will be sent to the researcher only through encrypted password-protected files to ensure security.

Collected data from the each of the three phases will be merged into one data set by using the de-identified code list numbers to match student survey responses in each phase to course completion status. Incomplete survey data will be removed and only the first responses for duplicate survey data will be kept.

\section{Analysis}

To determine what specific factors and/or combination of student cognitive, environmental, and demographic characteristic best predict success in online HRF courses several quantitative methods will be used, including; descriptive statistics, frequency distributions, whole-instrument and component scale reliabilities, analysis of variance and a binary logistic regression. First, to explore the relationship between each of the independent variables — cognitive, environmental, and demographic characteristics — to the dependent 
variable of success or failure in an online HRF course, different bivariate statistical methods will be employed (Table 11). For scaled data a one-way analysis of variance (ANOVA) will be employed to compare the mean scores for each of the ESPRI-V2 and BREQ-V2 factors to the dependent variable. To address research questions two and three, a Pearson’s Chi Square test will be used with the categorical data of the DLS (i.e. student demographic and environmental characteristics). Significant factors derived from the above analysis will then be used as predictors in a binary logistic regression with course completion status as the dependent variable. A binary logistic regression is a category prediction approach that is used to predict the odds of an outcome based on independent predictor variables. This data analysis approach is applicable when the dependent variable consists of two categories only, in this case pass or fail (Tabachnick \& Fidell, 2014). Various combinations of student demographic, cognitive, and environmental characteristics will be inputted into a logistic regression to determine the most optimal combination of factors that best predict student success or failure in online HRF courses. 


\section{APPENDIX C}

\section{Extended Literature Review}

Distance education has been a facet of the American education system since the late 1800’s (Saba, 2003). Distance education is defined as, “Any form of providing education to students who are separated by distance (i.e., who are not physically present in the same space) and in which the pedagogical material is planned and prepared by an educational institution" (Kaplan \& Haenlein, 2016, p. 443). Through the years the median in which distance education operates has evolved. The earliest version of distance education came in the form of correspondence courses, which distributed content to students by postal mail. Mail was the dominant delivery mode until 1910 when instructional radio emerged as a promising new technology for correspondent courses (Pittman, 2003). From the time period of 1918-1945 the U.S. government issued over 200 radio broadcasting licenses to educational institutions, but ultimately the technology failed to attract a large enough audience to sustain itself (Pittman, 2003). The true accomplishment of radio technology correspondence courses were that they paved the way for the next generation of multimedia teaching and learning technology; television, programmed instruction, telephone, and videotape. Although instructional television in the 1960’s never reached its potential, it did have limited success and established teaching courses at a distance as a viable option (Watkins \& Wright, 1991). A vast majority of the blame for instructional television, never realizing its potential, was placed on the poor quality of programming, much of which was comprised of teacher's delivering lectures. Further advancements in communication technology, such as cable and satellite television, became a viable delivery method for distance education courses in the late 1970's and was utilized up until the early 1990’s (Watkins and Wright, 1991). A popular use of this median, established in 1987, 
was the Mind Extension University (MEU). MEU was a cable television channel with a partnership of more than 30 colleges and universities that used the educational network to deliver video course material to students. Prominent subscribers to the "student credit by cable network" included Penn State, Washington State, University of Oklahoma, and University of California (Gorski, 1994). MEU eventually shut its doors in 2000 as the emergence of new informational technology_World Wide Web_-became rapidly adopted in education (Saba, 2003).

Although delivering distance education courses through computer based technologies utilizing the internet were in existence since the mid 1980’s, programs only began to gain traction in the mid 1990’s. In 1987, the first scholarly journal on the subject appearedAmerican Journal of Distance Education - despite the fact that fewer than 10 states were actively engaged and promoting distance education at the time (Saba, 2003; Watkins and Wright, 1991). With the rapid increase in internet usage by 1998, more than 800 institutions, representing all states, offered courses and degrees through distance education programs utilizing the internet (Saba, 2003). Enrollments continued to increase on pace with advancement and improvements made in communication technologies. As of 2014 over 2.8 million students were enrolled exclusively in distance education courses at universities and over 2.9 million students were enrolled in at least one online course (Allen \& Seamen, 2016). Altogether, students enrolled in distance education courses account for 28 percent of the total enrollment within higher education (Allen \& Seamen, 2016). The integration of the internet within distance education has now made it an integral part of college and universities.

\section{Today's Distance Education}

As distance education has evolved and grown with advents in telecommunication technology, so has the terminology within the field. Now, as Rice (2006) stated, "Distance 
education, distance learning, e-learning, Web-based instruction, virtual schools, and online learning are all terms used interchangeably to describe this broad, somewhat confusing, and constantly changing field of nontraditional instruction” (p. 426). Within higher education, distance education programs has become an increasingly popular as institutions look to cut cost while maintaining quality programs. This avenue of education also provides institutions with the opportunities to expand beyond their traditional regions without investing in traditional brick and mortar operations (Saba, 2005) .

Online learning, within distance education programs defined by four different formats, that are dependent upon the ratio of course time spent in a face-to-face classroom versus online; web-facilitated, blended/hybrid, and online courses (Table 7). Student enrolled online courses are often times assumed to only be separated by distance, but some online course methods can separate them by time as well (Kaplan \& Haenlein, 2016). Two methods—synchronous and asynchronous - dictate the pace of online courses. In a synchronous online course format students are presented with the content simultaneously in real time or by a set meeting schedule (Rice, 2006; Saba, 2003). Conversely, asynchronous online courses students meet at different times, typically communicating with instructors and peers through either email or discussion boards. A third method used in distance education are self-paced coursed, these allow students to learn at their own pace through an adaptive release of course content, typically dependent upon the completion of course work in a specific order set by the instructor (Rice, 2006). Distance education programs may exclusively adhere to one of the above methods or employ a combination of different aspects of each in order to fit an online course into the traditional academic calendar (Rice, 2006). 
As distance education programs grow, so do the avenues for students to communicate with peers from diverse social, economic, and cultural backgrounds (Barbour \& Kennedy, 2014). Learner interaction within distance education are characterized by three different types; learnerto-content, learner-to-instructor, and learner-to-learner (Rice, 2006). Learner-to-content interactions are related to the appropriateness of course content and delivery method in consideration with online course objectives and characteristics of learners. For example, in an online wellness course, it would be prudent for the instructor to consider providing videos to the students demonstrating the correct movement patterns of an exercise that was assigned. The design of learning environments within online courses has been found to influence student success (Rice, 2006). Learner-to-instructor interactions consider the type of communication, feedback, access, and support instructors use to contact students (e.g. telephone call, webconferencing, email, etc.). Similarly, learner-to-learner interactions consider the same parameters of learner-to-instructor interactions, but also the procedures for dialogue. It is important to consider the procedures for dialogue amongst peers as it has been shown that interaction amongst students online has been shown to increase the likelihood that online students will persist through a course (Beldarrain, 2008; Cavanaugh, Barbour, \& Clark, 2009; Rice, 2006). An instructor dictates when and how students are to interact with one another, while also fostering a sense of community. Promoting an online learning community can be done by making content relevant to students by employing a constructivist approach to online instruction.

Distance education research has often advocated for a shift in pedagogical practice in online learning from a teacher centered to a more student centered constructivist approach (Rice, 2006). Constructivist learning theory advocates that the acquisition of new knowledge is gained through personally relevant experiences and social interaction (Beldarrain, 2008). Specifically, 
these experiences contribute to a student's sense of self-efficacy, autonomy, internal locus of control, as well as attitude. Instructors within an online courses who adhere to a constructivist learning approaches, act as a facilitator of knowledge and not the dispenser, supporting learners in tasks that promote greater autonomy with inquiry-based assignments, encouragement of reflective thinking, and support of collaborative interactions with feedback from peers and instructors on emerging issues relevant to course content (Barbour \& Kennedy, 2014;

Cavanaugh, Barbour, \& Clark, 2009; Rice, 2006).

To efficiently distribute course content across the variety of formats, methods, and facilitate learner interactions within online instruction, institutions have invested in web-based learning platforms called learning management systems (LMS). Computer based portions are delivered through a variety of LMS such as Blackboard, Canvas, and Moodle (Mohnsen, 2012; Wicks, 2010). Through the LMS, students access course content (e.g., instructional materials, audio/video, presentations, digital text books, etc.), discussion boards, quizzes, and submit assignments. Components of the LMS may include a variety of web-based video and audio communications that are accessible and utilized by the instructor synchronously or asynchronously to deliver content (Rice, 2006). The LMS allows the instructor to manage the class, upload assignments, develop projects, create discussion forums, and score/grade (Mohnsen, 2012; Wicks, 2010). Instructions for assignment and project portions of online course are also provided by the teacher via the LMS, and students can complete the activities at a location that is most convenient for them (e.g., home, school, park, etc.).

As traditional face-to-face course begin to transition to a digital space, concerns arise surrounding the quality of the instruction after making the crossover. While online learning has been practiced for over two decades, the amount of research has not kept pace with its rapid 
expansion (Barbour, 2010; Rice, 2006). Generally, research in distance education focused on two primary categories: (1) comparisons of student performance based upon delivery model, and (2) examination of qualities and characteristics of teaching/learning experiences (Barbour, 2010). These early and often time descriptive studies, provide a foundational of knowledge to help determine the effectiveness of online learning and perceptions of those who experience it. It has been suggested the next step within distance education research is to discrimination between subject areas and the variety of educational contexts of each (Smith, Clack, \& Blomeyer, 2005)

\section{Online Physical Education}

Online physical education (OLPE) is unique in distance education because particular features of the subject matter are specific to teaching movement and within the psychomotor domain (Buchanan \& Brock, 2016; Rink, 2013). Inherently, this presents a different set of challenges for OLPE teachers who are held accountable for learning standards and outcomes established by professional organizations, such as the National Association for Sport and Physical Education (SHAPE; Daum \& Buschner, 2014). Unique attributes within physical education such as: (1) the requirement of movement, (2) potential for physical injury, (3) communal nature of physical education, (4) the physical environment needed to complete course work, (5) the emotional context, (6) large class sizes, and (7) group work/teamwork/role taking (Buchanan \& Brock, 2016). The features of a traditional face-to-face physical education become even more apparent when transitioning PE content and instructional approaches online.

OLPE has been viewed by some within the field as an oxymoron due to the inability to conceptualize effectively instructing and evaluating the physical activity component online (Mohnsen, 2012). Concerns about the validity of implementing OLPE has come into question. 
Apprehensions surrounding OLPE range from student accountability, course rigor, safety, retention rate, and ability to meet the same set of standards set in traditional face-to-face physical education courses (Allen \& Seaman, 2012; Daum \& Buschner, 2012; Mohnsen, 2012; SHAPE, 2007; Wicks, 2010). Table 8 outlines a list of advantages and disadvantages of OLPE as outlined by Mohnsen (2012). The reality is the landscape of education is changing and with it instructors of OLPE must identify program strengths and weakness to better accommodate the online student (Mohnsen, 2012).

Currently, there are no official standards for instructing OLPE separate from traditional face-to-face physical education, but in 2007 SHAPE issued a set of guidelines for current and future programs offering OLPE course. Initial guidelines for teaching OLPE were established by SHAPE as a result of emerging use of OLPE in K-12. The Initial OLPE Guidelines provide suggestions for OLPE relative to course content, assessment, technology, instruction design, and course site management. However, at the time of their conception, only a single peer reviewed OLPE research study (Goc Karp \& Woods, 2003) was available to inform guidelines. As of 2016, published research within OLPE includes two peer-reviewed article that compares a faceto-face, hybrid, and online weight training course at the university level (Goc Karp \& Woods, 2003; McNamara, Swalm, Stearne, \& Covassin, 2008), three peer-reviewed research articles investigating secondary OLPE (Kane, 2004; Daum \& Buschner, 2012; Mosier \& Lynn, 2012). The remaining research specific to OLPE is comprised of three doctoral dissertations examining OLPE student, instructors, and physical education teacher educators’ perceptions of OLPE (Daum, 2012; Futrell, 2009; Williams, 2014). These initial studies have provided the foundation for understanding the characteristics of the stakeholders involved and highlight areas within OLPE that warrant further investigation. However, Daum and Buschner (2014) have noted that 
these initial eight studies are disconnected and lack sufficient depth. This section will describe the current status of OLPE, characteristics of students and instructors, and relevant research findings related to OLPE.

Status of OLPE. According to Mohsen (2012), during the 2009-2010 school year, 1.5 million K-12 students were enrolled in online or hybrid programs. This number includes all core curriculum courses and specialty classes, such as; music, art, physical education, etc. (Mohnsen, 2012). It was once predicted that by 2019 half of all high school courses would be online (Christensen, 2008), clearly this is not the case, however, online education has seen tremendous growth over the past decade and currently 5.8 million high school students are predicted to be enrolled in online courses (Allen \& Seaman, 2016). Step in line with this expansion, OLPE has become increasingly prevalent within the United States. According the 2016 SHAPE of the Nation report, thirty-one states now allow for required physical education credits to be taken online, up from 22 states in the 2010 report. Additionally, only seventeen of those states require OLPE to be taught by a certified physical education teacher. (Daum \& Buschner, 2012). This upward trend is likely to continue as states such as Virginia, Alabama, Florida, Michigan, Idaho, New Mexico and Georgia have taken the initiative and enacted legislation mandating completion of an online course as a part of high school graduation requirements (Kennedy \& Archambault, 2012; Rice \& Yang, 2013).

The most prevalent and accepted mode of delivery in OLPE is the hybrid method, also referred to as blended learning (Brewer, 2001; Mohnsen, 2012; Mosier, 2012; SHAPE, 2007). The blended method, also known as a hybrid online course, consists of the students completing the majority of course work outside of class and periodically meeting in person for assessment, instruction, and/or safety guidelines (Allen, Seaman, \& Garrett, 2007; Mohnsen, 2012; SHAPE, 
2007). Allen and Seaman (2012) defined blended/hybrid courses as consisting of 30-79 percent of content delivered online. The hybrid model for learning is student-centered and allows for students to designate lesson pace, schedule, and setting (Allen \& Seaman, 2012; Mosier, 2012).

While there are no established curricular models in OLPE, the most common one observed in the OLPE literature is the Fitness for Life (Corbin \& Le Masurier, 2014), also known as Wellness for Life. Daum and Buschner (2012) reported that 67 percent of secondary OLPE instructors in their study followed a Wellness for Life Curriculum. In Mosier’s (2010) investigation of the Florida Virtual Schools, the largest state supported OLPE program, their OLPE course were under the title of Fitness and Lifestyle Design. Although these Wellness for Life type courses in OLPE may be under a different title, they all share similar core curricular and assessment components.

Wellness for life in OLPE. The primary objective of wellness for life courses is to improve student health behaviors and fitness levels. This method of instruction is student centered with majority of course work focused on students acquiring knowledge of basic physical fitness and wellness concepts (Brewer, 2001; Hager et al., 2012). Specifically, content related to physical fitness, cardiovascular endurance, nutrition, weight management, and stress. It is important to note that wellness courses at institutions may have different titles such as; wellness for life, lifetime activities, fitness for life, active living, or health related fitness, but many foundational concepts mirror the popular Lifetime Fitness for Health (LFH) curriculum (Corbin \& LeMasurier, 2014). The goal of LFH courses are to expose students to a variety of life time activities in hopes of encouraging them to adopt more active and healthy life style. Although a healthy behavior change does not guarantee reduction in disease, evidence indicates the adoption of a healthy lifestyle has a positive effect of reducing the risk (Hager et al., 2012). 
Core concepts reported in these LFH courses included; physical activity, components of fitness, overweight/obesity, nutrition and stress management (Strand, et al., 2010). A number of colleges and universities still require students' to take physical education courses within their general education credit hours to graduate (Strand, Egeberg, \& Mozumdar, 2010).

Limited research is available in regards to the status of college and university wellness programs, but the courses have increase in popularity over the last 10 years (Strand, Egeberg, \& Mozumdar, 2010). Strand, et al., investigated the prevalence and characteristics of wellness programs at two year $(n=51)$ and four year $(m=76)$ higher education institutions located in the nine states that comprise the Central District Association- American Alliance for Health, Physical Education, Recreation and Dance (CDA-AAHPERD). Strand et al., defined wellness programs for the purposes of this study as, "Programs that are committed to helping students meet their physical, social, and mental health needs” (p. 47). Questions for the survey instrument were developed around previous research and recommendations made by a team of experts in the field (Strand, Egeberg, \& Mozumdar, 2010). Surveys were emailed to the wellness directors or representative at the 241 institutions in CDA-AAHPERD and had an overall response rate of 53 percent. ). From those who responded it was revealed that 65 percent of two-year and 79 percent of four-year institutions provided a wellness program. Furthermore, it was found that health related fitness courses were even more prevalent. Eighty-nine percent of two-year and 82 percent of four-year institutions indicated that they offered LFH courses.

The wellness programs/health related fitness courses on those campuses were most commonly affiliated with the health, physical education, and recreation department, although other affiliations included student affairs, health centers, and medical schools. Wellness programs and physical education were specifically addressed in two questions that related to 
collaboration and program redundancy on the survey. Sixty-three percent of two-year and 54 percent of four-year institutions indicated that collaboration existed between wellness programs and physical education departments. When surveyed about the ability of wellness programs to replace physical education at their institution, 77.5 percent of all respondents disagreed or strongly disagreed, compared to 6.6 percent who agreed or strongly agreed. The authors assert that while institutions of higher education are looking at ways to increase enrollment and then retain those students' affective wellness programs could provide the avenue to accomplish that task by enhancing the health of their current students, which in turn can improve academic success (Lindsey \& Sessoms, 2006; Strand, et al., 2010). Lastly, results from this study indicated that a majority of the two-year and four-year institutions provided wellness courses with an online component. Four-year institutions reported their HRF courses were offered in a webenhanced (55.5 percent), hybrid (14.3 percent) and fully online (28.6 percent) formats. The webenhanced courses were described as meeting in a traditional face-to-face classroom setting at a regularly scheduled time, but the majority of course content was available online for students to access before, during, or after class. HRF hybrid courses in the study was limited required faceto-face classroom time with the majority of student work being completed individually and online HRF courses were fully delivered over the internet.

Several studies have been conducted on the effectiveness of wellness for life courses held in a traditional setting versus online, in relation to gains in knowledge and fitness. Hager, George, LeCheminant, Bailey, \& Vincent (2012) conducted a study spanning three semesters comparing students’ fitness and knowledge gains made in a general education health and wellness courses. Participants in the study ( $n=1,638$ female, $m=1,333$ male) were students enrolled in Brigham Young University’s general wellness course and comprised 82 percent of 
the university's freshman and sophomores at the time of the study. Measurements recorded and analyzed in the course were: physical activity readiness questionnaire (self-assessed); personal fitness assessment (pre/post); physical activity assessment (pedometer 14-day period); and 10week exercise assignment (self-assessed). The questionnaire was comprised of self-reported items on: body weight, height, age, GPA, diet, and exercise habits (Hager et al., 2012).

Data analysis included general linear model, a repeated measures ANOVA procedure utilizing a regression approach to describe the relationship between wellness for life courses influence on physical activity and diet to courses delivered through lecture versus online across three semesters (Hager et al., 2012). The study found similar improvements made in health wellness knowledge, but a significant difference in fitness level gains made in the traditional course that did not occur in online courses. Noteworthy interactions between the lecture and online included: perceived change in physical activity 12 percent $F(2,2,970)=118.67$; $p<.001)$; participation in moderate physical activity four percent $F(2,2,970)=36.48$; p <.001); number of days participating in vigorous physical activity 2 percent $F(2,2,970)=29.84$; $\mathrm{p}<.001)$; and for outcomes showing positive changes ranging from two to 15 percent for the lecture group, versus less than one to 10 percent for the online group. Hager et al., (2012) concluded that, "More research and curriculum development may be needed if online approaches in wellness courses are going to have comparable impact as class lecture formats” (p.268).

In a similar fashion, McNamara, Swalm, Stearne, and Covassin (2008) investigated wellness knowledge and strength gains made in three university weight training course each delivered in a different format: traditionally $(n=27)$; online $(m=27)$; and hybrid formats $(l=25)$. The study employed a repeated measures multivariate ANOVA comparing pretest and posttest scores for knowledge (exam), upper body strength, and lower body strength estimated to be at 
maximum one repetition. The results indicated that all three groups showed significant improvements in knowledge. The main effect for group $(p=0.93)$ and between group $(\mathrm{p}=.95)$ where not significant. A one-way ANOVA was performed on the three sections pretest knowledge and strength scores that indicated the online section was at a significantly different level for upper body strength. For that reason an analysis of covariance was performed to adjust the means for upper body strength. The traditional $(t(3)=-7.56, p<.05)$ and hybrid groups $(t(3)$ $=-6.06, \mathrm{p}<.05)$ showed significant improvement, while the online section $(t(3)==1.71, \mathrm{p}>.05)$. The results for lower body strength yielded the same outcome, the traditional $(\mathrm{t}(3)=-7.35$, $\mathrm{p}<$ $.05)$ and hybrid $(t(3)=-6.32, \mathrm{p}<.05)$ significantly improved, while the online section $(t(3)=-39$, $\mathrm{p}>$.05) showed no improvement.

The results demonstrated that significant gains could be achieved in strength and wellness knowledge in the courses being delivered traditionally and in a hybrid format, but in the online format only wellness knowledge improved (McNamara et al., 2008). McNamara et al. speculated that the reasons for a lack of strength improvements in the online section could be attributed to low student motivation and/or lack of face-to-face interaction with the student by the instructor. Furthermore, McNamara et al. noted that there does, "Seem to be a point of saturation where too much technology results in poor performance. It seems that the practitioner must balance instruction and training with just the right amount of personal attention and modern technology” (p. 1167).

Similar to Hager et al. (2012), Brewer (2001) examined the difference between health related knowledge and fitness posttest results of a traditional $(n=30)$ wellness for life course versus an online $(m=18)$ course. Student health knowledge was measured by the Wellness Knowledge, Attitude and Behavior Instrument (WKABI) which is primarily focused on 
nutrition, physical activity, and stress management. The physical fitness assessments for this study where attained through: 12 minute run/walk test; three-minute step test; estimated one repetition max bench/squat; 60 second push up/curl up; set and reach (flexibility); and skinfold measurements for body fat percentage. The study examined two sections of a wellness for life course during the course of a semester; one section taught online and one face-to-face. Both courses presented identical course material and were designed to expose students to specific areas of fitness (focus on walk/jog activities), nutrition, and stress management (Brewer, 2001).

An ANCOVA was used to determine the significant differences between posttest scores for health related knowledge, attitude, behaviors, and fitness of the traditional course versus the online section. In this study, the between subjects factor was the students who were enrolled in either the online course or face-to-face course. The within subjects factor was comprised of the pre/post test scores for the WKABI and the physical fitness assessments. The students pretest scores for each of the dependent variables were the covariates, allowing for clearer results of the effects of traditional versus online instruction. Data for this study was examined at the $\mathrm{p}<.01$ significance level due to the large number of variables (Brewer, 2001). Mean scores for both groups improved pre to post test and no significant differences for scores between the courses were revealed for any of the variables tested with the exception of stress, bench press $(F(1,44)=11.65, \mathrm{p}<.01)$ and sit and reach $(F(1,44)=7.52, \mathrm{p}<.01$; Brewer, 2001). The preposttest scores for these variables showed improvement for the online course while the mean posttest scores declined in the traditional course. The author speculates that these results could be attributed to subjects in the online course participating in resistance training activities and weight training in addition to the physical activity assignments. Another factor the author 
attributes these results to be sound course design and a flexible work schedule for online students.

Cardinal's (2007) research also examines the effectiveness of an OLPE course at the collegiate level. Similar to the previous studies this one focuses on exercise behavior and health related behavioral change. A major difference is that this study does not compare the physical fitness component aspects of a wellness for life course in a traditional classroom to an online setting. Students $(n=109)$ in this study participated in a 10-week course that consisted on nine 80 minute lessons that focused on fitness for life concepts and behavioral change strategies. The fitness for life model is the most common curricular model in OLPE (Daum, 2012). Both the online and traditional course curriculum where identical. Participants in the study were volunteer students from three groups: classroom $(n=49)$; online $(m=15)$; and subjects enrolled in non-fitness for life courses $(l=45)$ acted as the control group. Self-reports where collected using the Weekly Leisure Time Exercise Questionnaire before and after the 10 week intervention assessing exercise behavior, decisions, and self-efficacy (Cardinal, 2007). A repeated measures analysis of covariance was performed on the three groups: classroom, online, and control in relation to their pretest and posttest exercise scores. The exercise behavior scores improved significantly from pretest $(M=38.8, \mathrm{SD}=23.9)$ to posttest $(M=47.2, S D=28.6)$ over time $(F(1,103)=7.82, \mathrm{p}<.01)$ regardless of group. The authors indicated that this supports previous studies findings in wellness for life curricula positively affecting behavior change. All three groups increased their exercise behavior, the classroom group experienced a 133 percent increase in exercise compared to the control group which translates into 35 additional minutes per week (Cardinal, 2007). A 52 percent increase-23 minutes more per week —in exercise behavior was 
also seen between the classroom group and the online group. Lastly, the online group exercised behavior increased 15 minutes per week over the control group.

A second repeated measures ANOVA analysis of covariance was conducted comparing the same three groups on their process of behavioral change, cognitive, decisional balance, and self-efficacy scores. Significant differences between groups were found in behavioral $(F(2,103)$ $=4.28, \mathrm{p}<.05)$ and cognitive $(F(2,103)=3.66, \mathrm{p}<.05)$ posttest scores. No significant difference was found between groups in decision balance $(F(2,103)=.04, \mathrm{p}=.96)$ or self-efficacy $(F(2,103)=1.05$, p. $=.35)$. The author concludes that these results support previous studies in the effectiveness of fitness for life courses and behavioral change. Although both the classroom and online sections were effective in comparison to the control group. The author suggest that a hybrid program, one that meets face-to-face periodically throughout the semester while the majority of the course takes place online, may be more effective than a fitness for life course online.

Wellness for Life courses, such as the ones described in the studies above, are beginning to move online due to the cost, access, and general education College/University credit requirements. The benefits of technological innovation have the potential to quell concerns in the practice of OLPE. However, simple adoption of technology does not ensure the quality and effective OLPE delivery. This was demonstrated by McNamara et al. (2008) who studied fully online weight training intervention that was effective in translating the cognitive aspects of the course, but not the physical. Hager et al. (2012) research supported these results, but on a much larger scale $(n=2971)$ in a Wellness for Life course. The results of these similar studies support the findings in Daum's (2012) investigations into the perceptions of OLPE instructors and their inability to suffice SHAPE standard 1 while feeling comfortable achieving the benchmarks set 
for SHAPE standard 2. Furthermore, Hager et al. (2012) and McNamara et al. (2008) both suggested that the online sections of their courses did not make physical fitness gains due to a lack of motivation, social, and emotional support available in traditional settings. The authors felt that the students would be more accountable with peers around while completing physical activity rather than alone. The social component within OLPE is often cited as lacking, investigating the effect of integrating components within the curriculum and their effect on physical activity have been suggested as areas for future research.

In contrast to Hager et al. (2012) and McNamara et al. (2008), Brewer (2001) found both fitness and wellness knowledge gains significantly increased in traditional and online sections of wellness for life courses. Brewer attributed the positive physical fitness results in the online section to a sound course design and flexibility of the curriculum. It should be noted that the sample size was small for this study $(n=48)$ and especially for the online section $(m=18)$. Cardinal (2007) found similar results, participants $(n=109)$ enrolled in online or face-to-face Fitness for Life courses saw fitness level increases from having participated in the course. While the results of the study are questionable from a design standpoint, the author did find that the online section of the course increased their physical activity level, but not as much as the classroom section, a 52 percent difference (Cardinal, 2007). It should also be noted that selfreported data were used to gather the data for this study. Also in all of the studies different instruments where used in gathering knowledge and physical fitness data. These limitations highlight the need for future research in OLPE would benefit from larger sample sizes, coordinated research, and a set of constant instrument gathering cognitive and physical fitness data (Daum \& Buschner, 2014). 
Differences in the results of available research raise questions about the course delivery, course design, and instructional methods in relation to students learning and fitness gains. The studies above could have potentially been influenced by the inherent contextual factors surrounding online courses. Speculated reasons for a lack of fitness improvements in the online sections examined where attributed to low student motivation, lack of face-to-face interaction, curriculum design, and students technological fluency. McNamara et al. (2008) noted that there, "Seems to be a point of saturation where too much technology results in poor performance. It seems that the practitioner must balance instruction and training with just the right amount of personal attention and modern technology” (p. 1167). Future OLPE teachers will not only need to be fluent in physical education content knowledge and online pedagogy, but also the technology tools that allows them to effectively developed, deliver, and assess students in an online environment (Price, 2015; Williams, 2014).

Instructional and educational technology in OLPE. Innovative technology in education often promises to make work in the classroom efficient, stress-free, and interactive. To effectively use a technology tool in an educational setting, an instructor first needs to identify how that tool will enhance student achievement. Within OLPE, technology is inherently a key component that makes online delivery of the discipline possible. The limitations of what technology can do in the gym are diminishing as each new device that is released that boasts improvements in mobile processing, screen resolution, storage capacity, battery life, and connectivity. However, the simple adoption of technology does not ensure optimal effective integration methods. In doing so, technology can improve the effectiveness, quality, and delivery method of OLPE. Appropriate practices integrating technology in physical education should be aligned with learning objectives that fit students’ development level and content aligned with 
standards (SHAPE, 2009). The SHAPE organization issued a position statement outlining guidelines (Table. 3) for appropriate use of technology in 2009. Developing programs in OLPE that adhere to these guidelines and selecting the appropriate technology to facilitate student learning is an area in need of research (Price, 2015; Mohnsen, 2012; Mosier, 2014; SHAPE, 2007). Research has been conducted examining current PETE undergraduate student training with technology and use in physical education.

Woods, Goc Karp, Hui, Perlman (2008) conducted a study investigating physical education teachers' perceived technology abilities and actual use in the gym. The participants ( $\mathrm{N}=114)$ were K-12 physical education teachers who were members of the Northwest District Association of the American Association of Health, Physical Education, Recreation, and Dance. The Physical Education Technology Usage Survey for Physical Education Teachers (PETU-PE) was used to assess participants in six computer usage categories: productivity, peripherals, physical education technology applications/basic programs, computer basics/ operating systems, trouble shooting, and design and delivery. For each category, participants were to rate their perceived competency indicated by either proficient, intermediate, or beginner. Results through the survey indicated the instructors used technology in a variety of ways, but most prevalent was the use of video recording, pedometers, timing devices, and aerobic exercise equipment (Woods et al., 2008). Woods et al. noted that teachers perceived themselves as novices in using databases, heart rate monitors, and body composition analyzers. Barriers to these technologies indicated by the participants were lack of financial support, training, time, and preparation in their physical education teacher education courses (Woods et al., 2008).

Channels in which to expose potential OLPE instructors to appropriate technology practices is within preservice preparation programs and professional development opportunities 
for current physical educators. The results from the Woods et al., (2008) study support findings from Daum and Buschner’s (2012) study that current online physical educators were not prepared in their undergraduate programs to teach online. The knowledge gained from studies such as these lays the foundation for PETE faculty in constructing comprehensive preservice preparation programs that include the instructional skill necessary to teach OLPE. The benefits of each emerging technological innovation have the potential to quell concerns in the practice of OLPE on lacking academic rigor, social interaction, effective instruction, and high student attrition (Ransdell, Rice, Snelson, \& Decola, 2008).

Activity and fitness tracking. Fitness trackers have the ability to alleviate OLPE instructors’ concerns about physical activity being completed. Fitness tracking peripherals such as Fitbit, Jawbone Up, Map-my-fitness, MOVband, Nike+ Fuelband, Polar Loop, Omron Activity Monitor, and Moves app can be paired with mobile devices to track students’ level of activity (Mosier, 2014). These activity tracking peripherals record and measure several different dimensions of fitness such as: sleep patterns, energy expenditure, nutrition habits, mood, and movement (i.e., steps, distance, and speed; Mosier, 2014). Paired with a mobile device, the activity trackers can display fitness data to the students instantly via tables, charts, and graphs that can be shared with other users. Currently, many of the fitness trackers have a mobile application component integrated in them. Furthermore, many of the devices have built-in activity sensors (e.g., accelerometer, gyroscope, GPS) and have been shown to be accurate when it comes to step count (Wu, Dasgupta, Ramirez, Peterson, \& Norman, 2012). Wu, et al., (2012) studied the reliability of using only an iPod Touch to measure movement in the physical activities; walking, jogging, sitting and walking up/down stairs with the existing accelerometer and gyroscope sensors onboard the iPod. It should be noted that the hardware built into the 
iPod's that was examined in the study was the same as the iPhone 4's at the time and the latter device was selected due to a significantly lower cost. Subjects $(n=16)$ in the study participated in 13 activities at different paces found the iPod accurately measured jogging (91.7 percent) and walking (90.1-94.1 percent) of the time when combining the time and frequency features of both the accelerometer and gyroscope sensors built into the iPod. The study found that the iPod did not as accurately predict walking up and down stairs (52.3-79.4 percent; Wu et al., 2012). Accurate fitness monitoring devices such as the one described in this study presents an objective tool to assess the amount of activity occurring in an OLPE course, alleviating some concerns of validating student completion of required physical activity within OLPE.

One such school that has already implemented the requirement of physical activity trackers within their OLPE courses is the FLVS (Daum, Mosier, Buschner, Smith, Cain \& Witherspoon, 2015). The students enrolled are required to purchase a MovBand physical activity tracker which they are to sync to their personal computers at least once a week to log the amount of “Moves" they have completed (Daum, et al., 2015). The fitness tracker data synced by the students is recorded to the "Wellness Dashboard," which is computer software accessed via the internet that displays the students record and progress towards there fitness goals. The unit of "Moves" recorded by the fitness tracker required in the FLVS is different than the traditional steps recorded by a pedometer, about 12,000 "Moves" are equal to 9,980 steps. Students are required to record at least 84,000 “Moves” per week with a goal of achieving 420 minutes of moderate to vigorous physical activity (Daum, et al., 2015). The recommendations on required amounts of "Moves" a week is based upon the Movable Company’s research with the aim of ensuring that children and adults reach the CDC recommended daily physical activity levels. 
Mobile fitness applications. The FLVS also provides a mobile application version of the “Wellness Dashboard,” software that provides students a tool to synchronize and monitor their weekly fitness goals anytime anywhere (Daum, et al., 2015). Wicks (2010) suggested the emergence of Smartphone apps changed the way student's access internet content and significantly changed how instructors present content and course material. In OLPE applications like the Wellness Dashboard have the capability of linking content to authentic assessments with the use of the devices mobility, multimedia, and wireless connectivity. The fitness mobile application in combination with the fitness trackers ability to accurately measure movement gives instructors in OLPE the capability of objectively assessing the physical activity required in the course. Additionally, accurate devices enable OLPE teachers to give students personalized feedback. Online physical activity courses equipped with this technology allow students to tailor OLPE content to their own fitness/health goals, supporting Williams (2014) suggestion that technology and content in OLPE follow a constructivist's framework and be student centric in design.

In a recent study, Kwak (2014) examined student’s behavioral intention to adopt mobile fitness applications within a wellness for life course. The participants were students $(n=385)$ enrolled in a wellness for life course at a large south-western university. A modified model of the Technology Acceptance Model (TAM) was employed to measure students’ behavioral intention to adopt mobile fitness applications within the context of an online wellness for life course. Participants completed the modified TAM survey after completing the online wellness course. The survey examined student's responses to the following constructs: perceived usefulness, ease of use, personalization, personal innovativeness in information technology 
(PITT), perceived enjoyment, involvement in sports and exercise participation, social influences, and self-efficacy's predictive value in determining behavioral intention.

A stepwise multiple regression was performed to develop a model to describe sports and exercise participants use of mobile fitness applications (Kwak, 2014). The constructs of PITT ( $\beta$ $=.511, p<.001)$ and personalization $(\beta=.268, p<.001)$ accounted for 43.4 percent of the variance in perceived ease of use. The same constructs, PITT $(\beta=.118, p<.01)$ and personalization $(\beta=$ $.647, \mathrm{p}<.001$ ) accounted for 48.9 percent of the variance in perceived usefulness. All of the constructs except for three (external influence, perceived enjoyment, and self-efficacy) were able to collectively explain 75 percent of the variance in the studies model. Overall perceived usefulness had the strongest effect on a participant's behavioral intention to use a mobile fitness application. This indicates that student's external motivation in using a mobile fitness application is a key factor. Another noteworthy finding was that personalization options within mobile fitness applications were a significant predictor of behavioral intention, indicating fitness applications need to be user driven. The positive social constructs in this study indicate a need for fitness applications to link with social media features. Lastly, this study extends the TAM into the field of physical activity and adds constructs that are unique to technology in an online physical education setting. Mobile technologies are increasingly being integrated in classrooms in an effort to facilitate and enhance students' learning and academic institutions are investing in mobile devices intended to provide educational value to students.

Different mobile applications can provide visual demonstrations of physical skills that students can model. This allows the student to break down the higher level skills into small segments at their own pace (Wei \& Liqiang, 2011). A concern that has been voiced by current OLPE instructors and PETE professors has been the effectiveness of teaching motor skills online 
(Daum, 2012; Williams, 2014). The multimedia capabilities current mobile devices possess provide students visual demonstration that are a viable substitute of the visual cues that are normally teacher centered in a traditional course. These mobile learning tools combined with mobile video analysis apps (e.g., CoachMyVideo, Coach’s Eye, Ubersense) provide the student with immediate visual feedback and self-assurance that assignments are being completed correctly.

Another area of concern within OLPE is the lack of social interaction not only between students, but also between instructors to students (Williams, 2014). Learning management systems now allow the students the ability to create, share, and discuss allows for students to collaborate in any learning environment. Built-in features such as discussion boards, journals, wikis, or text message enabling students and instructors in OLPE the ability to communicate instantly. The social component within online courses is often cited by teachers and students as lacking in OLPE (Daum and Buschner, 2014; Mosier, 2010; Williams, 2014). Proper use of social media technology in OLPE has the potential to bridge the communication divide that creates a more socially interactive atmosphere in an OLPE course.

Online exergames. In a more recent study Kooiman and Sheehan (2014a) examined the efficacy of exergames in both a traditional physical education setting and an OLPE setting, in relation to improving cognitive functioning and motivation to participate in activity. This study aimed to validate exergames as a potential part of an OLPE curriculum. Exergaming is a type of interactive video game (i.e. Xbox Kinect) that requires kinesthetic movement by the player to progress through the game (Kooiman \& Sheehan, 2014a). The online exergaming study involved secondary students $(n=124)$ in Southern California public and private schools and 
compared students playing an exergame proximally and online in relation to their motivation to participate and cognitive functioning.

The study used the Xbox Kinect as the platform for exergaming due to the systems internet connectivity, high review scores, and selection of sports related exergames. To measure the changes in cognitive functioning the Bender Visual-Motor Gestalt Test, Second Edition (BVMGT-2) was taken by the participants before and after the exergames sessions. The BVMGT-2 is a visual motor test that integrates with the exergames to identify the participant's level of visual input with motor output (Kooiman \& Sheehan, 2014a). Four covariates; gender, age, school type, and exergaming experience were also taken into consideration in the study (Kooiman \& Sheehan, 2014a). Three sessions where held: session one introduced participants to the equipment and a BVMGT-2 pretest; session two subjects participated in exergaming versus an opponent in the same room and a BVMGT-2 test after ; and session three subjects participated in exergaming versus an online opponent.

An ANCOVA analysis was conducted to compare the effect of exergaming on BVMGT2 performance in both settings, traditional and online. The predicted main effect for exergaming in a traditional setting $(\mathrm{F}(1,117)=53.634, \mathrm{p}=>.001)$ and online $(\mathrm{F}(1,117)=33.323, \mathrm{p}=>.001)$ were both significant. The main effect for gender and exergaming experience were found not to be significant in either the traditional setting, gender $(F(1,117)=.131, \mathrm{p}=.718)$ exergaming experience $(\mathrm{F}(1,117)=2.289, \mathrm{p}=.113)$ or the online, gender $(\mathrm{F}(1,117)=.663, \mathrm{p}=.417)$ exergaming experience $(F(1,117)=324, p=.570)$. The results could indicate that these aspects of cognition may have no effect on students who have different levels of experience with exergames. 
A paired sample t-test were used in a post hoc comparison indicate a significant difference between in the scores for the BVMGT-2 test following traditional play $(\mathrm{M}=70.754$, $\mathrm{SD}=11.866)$ and the BVMGT-2 test following online play $(\mathrm{M}=75.291, \mathrm{SD}=15.323)$; $\mathrm{t}(123)=$ 4.992, $\mathrm{p}<.001, \mathrm{~d}=.338$. The results of the test show that online participants in this study increased their scores on the BVMGT-2 test .34 standard deviations over the traditional group. Kooiman \& Sheehan (2014a) attributed the results to students in the online setting being more engaged in the game due to not having an opponent in the same room. Kooiman and Sheehan state that, “This data can position exergames as the first piece of OLPE curriculum that has been researched as to its effect in a remote setting” (p. 7).

Two of the studies highlight the effectiveness of imaginative course design in OLPE that is being developed in tandem with the improvements in technology that could address concerns highlighted by the previous descriptive studies within OLPE. Kooiman and Sheehan (2014a) OLPE exergaming study showcases a method in how new technology could possibly address concerns in OLPE that pertain to: student accountability, motivation, and social support. The results of which showed improvement in student's visual motor acuity, motivation, heart rate, and relatedness while playing exergames online. Currently in OLPE most teachers rely on activity logs, discussion boards, video submission, and the honor system to assess if students are participating in physical activity assignments (Daum, 2012). Results of exergaming study show that in an OLPE curriculum it could be useful for students by offering them a relevant means to engage in physical activity with the social component of competition and the objective measurement of physical activity logged by the Xbox Kinect. Exergaming also fits well with the current OLPE curriculum which focuses on fitness for lifetime in that it is student centric, allowing students to explore a wide variety of activities. 
Kwak (2014) research also highlights technology that could enhance and add validity to OLPE. With the introduction of Smartphones, the concept of mobile applications was introduced. The emergence of Smartphone apps have changed the way student's access internet content and significantly changed how instructors present content and course material (Wicks, 2010). Mobile fitness applications introduce another avenue for OLPE instructors to present content and track physical activity. The inherent characteristics of mobile learnings capabilities to provide "anytime anywhere" learning presents a mode of delivery that could potentially translate to delivering content in OLPE. Kwak’s (2014) study highlights the acceptance of mobile fitness applications within the context of a wellness for life course. Furthermore, the student centric Wellness for Life curriculum used in the majority of OLPE courses could benefit from mobile fitness applications that are both intuitive, social, and have options for personalization. The results of the study provide information for selecting fitness applications for an OLPE course. Mobile fitness applications that encourage students to explore physical activity through personalized content and connect with peers give OLPE programs the ability to better accommodate the modern student.

\section{Teaching and Learning in Online Physical Education}

The first state effort into offering physical education online was through the Florida Virtual School (FLVS). Founded in 1997 with an enrollment of 77, the FLVS student population boomed to 206,000 full/part time students as of 2012-2013 school year (Florida Virtual School, 2014). FLVS physical education courses were designed to develop overall health and well-being by providing quality physical education programs that meet state standards. A comparison of advance placement exam data from FLVS against the national average showed the FLVS 
program exceeded national averages for results by 10 percent, 70 versus 60 percent (Florida Virtual School, 2014; Wicks, 2010).

Mosier (2012) suggested that programs like FLVS may become the norm, “with the increased instruction time due to the demands of high-stakes testing for core subjects such as reading, writing, and mathematics” (p.9). Speculation is that students in the near future may not have the decision to choose which format of physical education to enroll in. Determining effective methods to deliver OLPE is needed to ensure the quality and effectiveness of programs. Instructors in physical education are now teaching a generation of students, often times referred to as “digital natives” who have never known a life without computers, cell-phones, and the internet (SHAPE, 2009). The digital divide amongst students is quickly shrinking with increasing accessibility to computers with internet access (Wicks, 2010). Furthermore, empirical evidence presented by the U.S. Department of Education (USDE, 2008) suggests that students can benefit from online learning, specifically noting that the hybrid model produces better results in student performance than traditional methods. The tradeoff for flexibility within online courses is often the requirement of more time and effort than face-to-face courses for an online instructor (Brewer, 2001; Daum \& Buschner, 2012). In turn, for students this creates an online setting where coursework is self-paced, regular meetings do not occur, and the instructor is not available for immediate feedback (Daum \& Buschner, 2012; SHAPE, 2007). Examining the experiences and perceptions of the students and instructors participating in OLPE courses, provides the descriptive foundation for accommodating future students and instructors.

\section{Students Enrolled in OLPE}

Currently very little is known about the characteristics of students who enroll in OLPE (Daum \& Buschner, 2014). Ransdell, Rice, Snelson and Decola (2008) suggested that the type of 
student enrolling in OLPE spans a wide range and for different reasons. Students enrolling in OLPE may do so because of academic or extracurricular circumstances that may prevent participation in a traditional setting. For example, high achieving students seeking credit hours to supplement college preparatory hours and students who are elite athletes or musicians whose activities require travel that prevents them from participating could choose to take physical education courses online (Ransdell, et al., 2008; Rhea, 2011). Other students may choose to take a specialty online activity course such as swimming, yoga, kickboxing, etc. because it is not offered or within their schooling context (e.g. home school; Rhea, 2011). There is also a population of students who may feel they are less successful in traditional physical education for a number of reasons, including insecurities performing exercise in front of others, bullying, or simply enjoy the autonomy of the internet (Randell et al., 2008; Rhea, 2011). It has been suggested that the type of student successful in OLPE displays characteristics such as responsibility, autonomy, internal locus of control, time management and communication skills (Daum \& Buschner, 2012; Futrell, 2009; Ransdell, et al., 2008). For those students, they may find OLPE an attractive and effective option if it is geared toward individual physical activity and interests (Price, 2015). Although factors influencing student enrollment in OLPE may be wide ranging, there are a few early studies that offer some insight into students' decision to enroll, attitudes, and perceptions of OLPE.

Futrell’s (2009) research was a comparative examination of traditional physical education versus OLPE at the secondary level in relation to fitness gains and attitudes about physical education. To determine course satisfaction and fitness outcomes, an end of course satisfaction survey (Likert scale 1-5) was implemented to measure attitudes and pretest/posttest Fitnessgram included; the mile run, sit \& reach, trunk lift, curl-up, and push up tests were collected on all 
participants ( $n=60)$. Results of the end of course satisfaction were inconclusive. This may be due in part to participant confusion in answering the survey questions such as, "My experience the experience in class challenging” (Futrell, 2009, p. 117). Similarly, students may have been unable to properly indicate their level of agreeance on questions such as, "Personal fitness should be taught online or face to face” (Futrell, 2009, p. 117). Results from the Fitnessgram test did show that online students ( $n=24)$ achieved significantly significant fitness gains in all categories (Futrell, 2009). A major limitation in drawing conclusions from the online section fitness results was that data were self-reported by those students. Similar to Brewer (2001) students in the section fitness increases were the most significant in exercises relating to the upper body and found limited cardiovascular improvement.

Goc Karp and Woods (2003) research is an early study in OLPE that examined student perceptions of a hybrid OLPE course who were enrolled at the Idaho Virtual Campus high school. Specifically, the course investigated online health concepts modules for nutrition and wellness, and physical activity component was completed face-to-face. Data were collected with a relatively small sample ( $n=19)$ utilizing a variety of methods; a student technology survey, several student assignments, and interviews with the students and their instructor (Goc Karp \& woods, 2003). A Wellness for Life curriculum was used within the course that covered assignments relating to wellness knowledge, goal setting, fitness, and nutrition analysis. Similar to other OLPE studies a dependent t test on pre/post scores indicated a significant gain in student knowledge (Brewer, 2001; Futrell, 2009; Kane, 2004; Goc Karp \& Woods, 2003). Results pertaining to student perceptions of the OLPE course were mixed; on a positive side the students found online learning suitable for some learning styles; focused their learning, allowed for flexibility in learning (own pace and at home). Negative aspects related to their experience 
included; trouble navigating technology; unclear about content being assessed and missed contact with teacher/peers. But it is noteworthy that although students indicated they had trouble navigating the technology in class, the majority of students $(n=12)$ indicated that they were able to perform the basic operations and valued the importance of technology within their learning (Goc Karp \& Woods, 2003). Similar contradictions in student's perceptions were that while they enjoyed the flexibility of the online course they desired more structure-prompts/reminders from instructor, assignment checklist, rubrics, and facilitated interactions with peers—-similar to that they would find in a face-to-face course (Goc Karp \& Woods, 2003).

In a similar fashion, Kane’s (2004) qualitative case study set out to determine teacher and student $(n=38)$ perceptions within an 18 week online personal fitness course. Sources of data collected in the case study included; phone conversations, assignment responses, informal online interviews, site visits, focus groups, student surveys, course evaluation, and faculty meetings (Kane, 2004). Overall the completion rate for the OLPE course studied was slightly over 50 percent. Themes that emerged from the student perspective included; lack of social interaction, a positive view of the flexibility of online learning, and trouble navigating online course work (Kane, 2004). Students indicated that they missed the face-to-face interaction with other students or peers, but enjoyed the flexibility of the course, which raises question about how to integrate meaningful social interaction within OLPE course. Students also had a hard time keeping track of where they were in the course, Kane indicated that this could have been a result of the design and delivery of the course. Furthermore, it was found that the workout logs worked well for older students $-11^{\text {th }}-12^{\text {th }}$ grade- - but younger students often times did not did not turn in their workout logs on time. Kane attributed this to a student's ability self-motivate, other studies examining student persistence in online course work have similarly linked this phenomenon to the 
proximity of a student is in relation to graduation term, finding the closer a student is to graduation the more likely they are to persist through an online course (Osborn, 2001; Rankin, 2013; Roblyer 2005; Roblyer et al., 2008). Hager, George, LeCheminant, Bailey, and Vincent (2012) postulated that students may feel more committed and accountable when they are among other students meeting at an assigned time and place, opposed to the students in the online section who are more self-directed attributing to a high attrition rate in online courses. The implications of these descriptive OLPE studies must be taken into consideration for accommodating not only the students enrolled in OLPE course, but current and future physical educators who are instructing online (Christensen, Horn, \& Johnson, 2008; Wicks, 2010).

Instructors of OLPE. Physical education instructors teaching online are becoming more prevalent as a result of the increase in states offering OLPE courses. OLPE presents a different set of challenges when confirming that state and national standards are being met. Most concerns surround the instruction, assessment, and confirmation of the physical activity completed by students in OLPE. In physical education, movement is not simply an included part of the curriculum, but rather, movement is the curriculum (Rink, 2013). In OLPE, teacher observation is no longer a feasible means to assess participation, instructors in OLPE must adopt alternative pedagogical practices. The challenge for OLPE teachers is modifying their instructional approach to incorporate online teaching methods in order to meet the same benchmarks, curriculum, and assessment standards of traditional courses (Mohnsen, 2012; SHAPE, 2007). Similar to research focusing on students enrolled in OLPE, descriptive studies investigating the experiences and perceptions of OLPE instructors provide insight into how current teachers are conducting OLPE. 
Two seminal studies investigating the experiences and perceptions of OLPE instructors are Daum and Buschner's (2012) mixed methods study and Williams (2014) case study. The researchers in these studies set out to describe OLPE from the view point of those teachers currently instructing the courses. The results of examining the current status of OLPE from the instructor's perspective could help identify effective teaching practices and provides guidance for future research and OLPE teachers.

Daum and Buschner (2012) conducted a descriptive study of secondary (9-12 ${ }^{\text {th }}$ grade) OLPE instructors $(N=32)$ using a survey that employed both qualitative and quantitative measures. The purpose of the study was to investigate high school OPLE course content, instructional design, and teaching methods. Specifically this study intended to addresses the following research items: type of courses are being taught; ability to meet SHAPE standards; courses administration; and students and teachers perception of OLPE. To address these items, current OLPE teachers were surveyed about their training, experiences, and perceptions of OLPE. Descriptive statistics were reported from the survey as well as responses to open-ended questions from OLPE instructors. A thematic analysis was conducted for the open-ended questions into to sort the responses into common themes for comparison as well as a negative case analysis to account for outlier data and themes that emerged through constant comparison. Daum and Buschner's (2012) study sought out information that would describe the current status of OLPE in the United States. The study revealed that the biggest concern of OLPE instructors was validating student completion of physical activity. The most common method used by the instructors at the time of the study were activity/fitness logs. Within these activity logs students are to record their activity and have it verified via a supervisor or often times a parent signature (Daum \& Buschner, 2012). Student accountability in completing fitness activities is a 
contributing factor in the professions perception that OLPE is an oxymoron. As more technological innovations roll out this will be an issue that research can address is finding the most effective instruments in recording physical activity. Schools such as the FLVS where OLPE is very prevalent-accounting for 10 percent of the total course enrollment-physical activity trackers now a required component of all OLPE courses (Mosier, 2010). While these devices have the ability to objectively record activity at this point and time, they do not solve all of the concerns surrounding OLPE.

Participants perceived OLPE could eliminate jobs in the field, especially if not required to be taught by certified physical educators. This could be the reality if OLPE courses are not held accountable for providing effective teaching and quality programming. In the limited research investigating OLPE have shown increases in students health related fitness knowledge, but differ in their results on fitness improvements. The respondents were asked to rate the percentage of their courses based on the four learning domains: (1) cognitive, (2) affective, (3) psychomotor and (4) health-related fitness. More than 50 percent OLPE instructors programs focused on the cognitive $(n=11)$ and health-related fitness $(m=13)$ domains whereas the affective $(l=4)$ and psychomotor $(g=4)$ domains were largely neglected. These results reflect a key finding of the study, that the OLPE instructors perceived that their program's lacked student physical activity participation and the ability to properly develop student's motor skills. Seventytwo percent of the instructors surveyed indicated that their OLPE course did not meet the recommended 225 minutes of moderate to vigorous physical activity a week. The authors concluded that this could have been a result of inexperience in teaching OLPE. Sixty-three percent of the instructors in the study indicated that they had only been teaching OLPE for two years or less, additionally 75 percent of indicated they had "some training” $(n=24)$ and 25 
percent said they had none $(n=8)$ before they started. The authors suggested training and professional development for OLPE teachers in order to improve upon these findings, but especially those new to online education. This study raised the question, "What's going on in OLPE?” Daum and Buschner (2012) concluded that, “The train has left the station and the discussion surrounding OLPE is no longer about its validity, but how to effectively administer it” (p. 95). Assumptions that can be made from the study are; OLPE is more prevalent than ever before, OLPE programming/courses focus heavily on the cognitive domain, teachers of OLPE are in large part new to the field, and many of the programs report not meeting discipline specific learning standards.

Williams (2014) case study followed K-12 OLPE instructors $(n=4)$ and examined their day-to-day online teaching practices. The basis for Williams study was to discover how physical education teachers instruct online. A purposive criterion sampling method was employed in selecting the OLPE teachers from the following set: (1) current/valid state teaching certificate; (2) certified to teach physical education; (3) minimum of two years' experience in traditional PE setting; (4) minimum of two years' experience in OLPE setting; (5) two or more years successful teacher evaluation while teaching online. Teachers participating in the study were then selected based on the level of expressed interest in sharing their thoughts and experiences as an OLPE teacher. Williams utilized a qualitative case study methods in examining the 4 OLPE instructors. Williams states that, “A constructivist, phenomenological paradigm will shape the case study research” (p. 81). The framework chosen supports online teaching and learning practices previously researched. To address this question, the author focused on real world experiences of OLPE instructors. Over the course of 12 weeks a phenomenological case study was conducted. The reported collection methods of data for this study included: (1) interviews with OLPE 
instructors (semi-structured, open ended interview questions); (2) virtual classroom observations/field notes; (3) interview with one administrator; (4) one live "webinar" presentation from an administrator about OLPE curriculum/organization; (5) email communications between the researcher and participants; (6) a researchers, reflection journal.

The findings of the phenomenological case study are presented with a preface that describes the unique OLPE setting of the instructor interviewed and provides a "snapshot" of their virtual classroom. In each of the described case studies Williams covers the following topics: pathways to online teaching, daily instructional practices, managerial tasks, grading, communication, educational theories, enhancement of student learning, and perceptions of student learning outcomes. Four themes emerged from the study: (1) similar pathways to OLPE teaching; (2) individualized instruction provided to students; (3) Teacher-guided student choice; (4) Teacher- facilitated student success (Williams, 2014). Williams noted that a lesser theme mentioned, but admittedly with insufficient data to describe the theme in depth was a need for professional development for in-service PE teachers related to online instruction. The author suggested that teacher of OLPE should possess strong word processing skills, an interest in grading written work, and be able to effectively communicate in different formats (phone, text, skype, etc.). From the data collected, Williams concluded that OLPE is a viable option for some teachers and suggest future lines of research examine OLPE at the secondary level, teacher preparation for online teaching, effective practices/disposition in OLPE, and fitness/cognitive assessments conducted in both settings to objectively find if standards and benchmarks are being met (Williams, 2014). Although not explicitly mentioned by any of the OLPE instructors in the study, the author found that they all adhered to constructivist educational theories and practices. Constructivist theory's supports the instructor as a facilitator of knowledge and not the dispenser. 
In an OLPE the constructivist framework works well in that students are given a choice in what activity they participate in and find meaning in the content as it relates to them (Williams, 2014). This appears to be in line with the theoretical bases that underpins the wellness for life curriculum, which is the most commonly provided in OLPE (Daum \& Buschner, 2014). Specifically relating to a student's sense of self-efficacy (social cognitive), autonomy (selfdetermination), internal locus of control (planned behavior), as well as attitude and environment (reasoned action). More research is needed in OLPE to define best practices, theory, technology training, and practical content (Williams, 2014).

Currently no research exists on PETE programs that are preparing their students for online teaching (Williams, 2014). Furthermore, a good classroom instructor does not necessarily make one an effective online instructor (Williams, 2014). The author has suggested that instructors in an online setting possess, "Enhanced capabilities in communication (written, video and phone), technology, planning, and organization” (Williams, 2014, p.30). While many PETE programs address technology integration in their programs it has been suggested that physical education teacher education preparation programs have not adequately prepared preservice teachers in translating the content from the gymnasium into a digital space (Williams, 2014).

\section{Professional Preparation}

A lack of training in online instruction has become evident in previous OLPE studies (Brewer, 2001; Goc Karp \& Woods, 2003). This is not an isolated issue in physical education and has been cited in other fields as well (Barbour, Siko, Gross, \& Waddell, 2013). Rice and Dawley (2009) found in their national wide survey exploring practices and models of professional development of instructors in virtual schools $(n=259)$ found that 62 percent of the online teachers reported not receiving any professional development before they began teaching 
online. This can be problematic for those teaches new to online instruction as found by Goc Karp and Woods (2003) that the OLPE teachers in their study indicated that they felt disconnected from the students, not in control pedagogically, and fell behind in grading. The researchers attributed this to a lack of online teaching preparation and prior experience (Goc Karp \& Woods, 2003). Specifically, instructor noted that they, "Belatedly realized she could have helped her students by interacting more online” (Goc Karp \& Woods, 2003, p.14). Similar results were found in Brewer (2001) study that found instructors of the online Wellness for Life sections often underestimated the time and effort involved instructing online, resulting in a feeling of social disconnection from students disengagement or lack of engagement on course discussion boards. Brewer (2001) did note that the OLPE instructors of the courses examined were graduate teaching assistants, which may have greatly contributed to their underestimation or lack of time to properly engage students online. Goc Karp and Woods (2003) recommend that instructors of similar OLPE courses plan work time differently to provide adequate feedback, time for grading, and to change their role as an instructor to one as a facilitator of learning in contrast to traditional direct instruction. OLPE instructors have the potential to accommodate these new realties by guiding and personalizing learning, assessing student understanding of learning objectives, creating and facilitation group discussions, developing group projects, making constant adjustments to course resources, and responding to student questions. Facilitating these accommodations is the appropriate use of available technology in OLPE courses that best aligns with content objective and outcomes.

There are a few studies that have specifically focused on instructors of OLPE (Daum \& Buschner, 2012; Williams, 2014), but the ones are available, provide the first pieces of the descriptive foundation for research in the area. As the body of knowledge continues to grow, it 
will be critical for physical education teacher education programs to consider the online teaching methods within their programs. In the Daum and Buschner (2012) study only 13 of the respondents indicated that they developed their own OLPE courses. The OLPE instructors surveyed in the study represent only a small sample of the current practicing OLPE teachers, but their responses displayed a wide range of support, opposition, and general hesitations about OLPE. Research will need to define effective teaching practices, applicable curriculum theory and design, evaluation methods, the optimal mediums for program administration, and ideal learning outcomes in OLPE (Daum \& Buschner, 2012). It seems that there is a very real possibility that the students now graduating from physical education programs will be required to teach online at some point in their careers.

PETE faculty perception of OLPE. Daum's (2012) research was a qualitative study investigating physical education teacher educators' attitudes about OLPE. The purpose of the research was to determine physical education teacher educator’s perceptions and attitudes towards K-12 OLPE. In-depth open-ended interviews were conducted with tenured track PETE professors $(n=25)$ to address the following research items; (1) PETE's faculty's knowledge of online education, (2) PETE’s faculty’s perceptions of K-12 OLPE, and (3) PETE’s faculty’s perceptions of teaching online pedagogy to pre-service teachers. Data were collected through semi-structured, open-ended telephone interviews. Questions in the interview included five demographic questions and 15 open-ended questions. A consensus was found among the participants that K-12 OLPE was equipped to meet SHAPE Standard 2 relating to the cognitive domain, but an overwhelming perception was that it was unable to satisfy SHAPE Standard 1 that pertains to the psychomotor domain (Daum, 2012). An unavoidable concern expressed by PETE faculty in regards to OLPE was student accountability in completing physical activity 
requirements (Daum, 2012). Participants in the study all held the view that elementary level OLPE was not feasible as it would be developmentally inappropriate to teach fundamental motor skills. The author highlighted this sentiment with a quote from one of the participants, "You can go back and do video analysis and look over the skill, but there is something to being in the moment and giving someone feedback when they are actually producing a movement” (p. 48). Most of the participants felt OLPE would be successful in the cognitive domain, but an unavoidable concern expressed by the OLPE instructors is student accountability in completing physical activity requirements.

Other common concerns expressed by PETE faculty in the study where the diminished social aspects and instant feedback in OLPE. Despite the prevalence of online education in higher education, the majority of participants had minimal knowledge of OLPE and believed that only individuals that where home-schooled or lived in rural areas where enrolled in OLPE. In spite of this 20 of the 25 participants expressed that OLPE was likely to become a larger part of physical education in the future. The remaining five participants found OLPE to be a negative trend and detrimental to physical education. Regardless of these differing opinions, a majority of PETE faculty in the study believed that future physical educators needed to receive training in online pedagogy. The research has also found, through interviews with PETE instructors, that many of them were new to general online education and required more training to prepare future physical education teachers to teach online. Although, the small number of participants $(n=25)$ in this study may be viewed as a limitation, the in depth interviews with those PETE method instructors provided a rich description of the professionals who prepare future physical educators perceptions of OLPE. Some of the interviews also suffered from participants lack of knowledge about K-12 OLPE and the questions that where asked. This, in turn, led to some of the questions 
in the interviews to be misinterpreted or not answered. Daum's study presents one of the first OLPE studies published and it provides a descriptive foundation for future research in OLPE and PETE.

PETE technology preparation. Looking into OLPE from a PETE programmatic standpoint it is important to address technology integration and the accreditation process. According to NCATE (2008) advanced standards for physical education teacher candidates must understand and be fluent in with technology in, “delivering developing, prescribing and assessing instruction, problem-solving; school and classroom administration; education research, electronic information access and exchange; and personal and professional productivity (p.17).” Gibbone and Mercier (2014) suggested that PETE programs offer technology specific courses to introduce preservice teachers to educational technology used in the discipline. This single course method is a commonly used strategy for integrating technology into preservice teacher programs.

Technology courses are to be experimental in nature and have a field based experience so that teacher candidates will have the opportunity to explore the different functions and applications of technology in a physical education setting (Gibbone \& Mercier, 2014). Field based experience with technology is a crucial part in sufficing the accreditation component, but also aids in spreading best technology practices/lessons to public schools. This opportunity gives preservice teachers the venue to introduce the concepts and lessons of technology interrogation and share them with their mentor teachers (Gibbone \& Mercier, 2014).

Wyant, Jones, and Bulger (2015) descriptive study investigated the influence of a single PETE programs technology course to determine the strengths, weaknesses, and potential benefits of such a course in an undergraduate program. The course examined was a domain specific course taught to preservice physical education students in their final year. The instructor of the 
course facilitated learners in developing an understanding of properly integrating educational technology into physical education by utilizing a constructivist based learning approach. In this model, the function of technology is based on the context of the learning activity, student needs, and content. Students received hands on learning with specific technology within authentic learning tasks that emphasized solving real world problems.

The focus of the study was on the influence the technology course had in advancing preservice physical education teachers level of concern and adoption. The mixed methods study utilized the Stages of Concern Questionnaire (SoCQ) and a pre/post Stages of Adoption of technology survey to how much the course influenced the students concerns and beliefs about technology in physical education. To identify information rich cases a stratified purposeful sample procedure was employed with the original convenience sample of 34 junior and senior level preservice physical educator teachers enrolled in the technology course (Wyant, Jones, and Bulger, 2015). The SoCQ was used before students completed the course to discriminate between the six highest scores on awareness $(n=6)$ and refocusing $(m=6)$. The resulting sample of preservice teachers represented individuals in the study who had opposing feelings toward technology in physical education. After the course concluded the student completed the SoCQ and Stages of Adoption of Technology survey again in order to create quantitative case profiles for each student. These students also participated in a semi structured interview conducted to gauge student's prior experiences with technology and their experience participating in the technology course.

Four themes emerged from the results of the study: (1) increased technological and technological pedagogical knowledge; (2) persistent first and second order barriers to technology use; (3) necessity of experiential and hands on learning; and (4) variation in warrant for 
technology use (Wyant, Jones, and Bulger, 2015). It was found that students experienced enhanced working knowledge of technology and self-efficacy in using technology in a physical education setting. Students across both groups found the hands on learning experiences with technology to be important, which the authors believed contributed to the positively perceived outcomes of the course (Wyant, Jones, and Bulger, 2015). The authors attributed this positively perceived outcome was the result of the constructivist learning in the course that created a supportive environment that enhanced the chances of early success.

Conversely, the single course was found to be less effective at addressing barriers to teacher change with technology, these internal/external barriers would need to be addressed before change could occur. Juniu (2011) has suggested an organic technology model for PETE that looks into not only new technologies, but the creative use and repurposing of existing tools. The premise in the model described is that technology alone does not automatically equate to quality teaching (Juniu, 2011). The author suggest that teacher education programs prepare teachers to first understand the fundamentals of their discipline/content and rather than only being presented in a single course, that technology needs to be infused throughout a PETE curriculum demonstrating integration in multiple contexts of the discipline. Juniu (2011) puts forward that the challenge for PETE programs will be to create an environment that encourages innovative uses of technology through hands-on experiences throughout the entire PETE curriculum. Supportive of this notion, the authors suggested that, "If all faculty members meaningfully use and reinforce technology in their teaching, it provides preservice teachers with effective modeling and differentiated experiences with technology across the curriculum” (Wyant, Jones, and Bulger, 2015, p. 147). Before this can occur, the authors note that PETE 
programs must support faculty in integrating technology by offering resources and training to prepare them to do so.

In agreeance with Mosier (2014), Wyant, Jones, and Bulger (2015) expressed that for current and future teachers, it is not enough to discuss technology integration in generalized terms or to attend a traditional workshop to acquire basic technological skills; rather, what is most needed is a more holistic approach. Potentially compounding upon issues of integrating technology throughout the PETE curriculum, is that technology itself has created the means in which physical education can be delivered online. With the emergence of OLPE, PETE could follow a similar holistic approach in exposing preservice teachers to technology that enhances teaching and learning in an online setting. This approach could be incorporated with a holistic technology integration approach with the inclusion of demonstrating the practical applications of technology used in physical education in both the gymnasium and online domain.

In regards to current trends in physical activity grades K-12 and their effect on hiring considerations and training in physical education pedagogy, Price (2015) stated, "There are mixed reviews regarding the value of [OLPE] courses, but as physical educators, we can be assured that as the use of technology continues to evolve there will be more school districts adopting there practices” (p. 5). One piece of this puzzle may lie in selecting appropriate frameworks to support specific program outcomes when teaching physical education online.

\section{Theory to Practice in Online Physical Education}

As the research in OLPE continues to grow, it will become critical for teacher education programs to consider appropriate uses of technology and pedagogical practices in not only faceto-face settings, but also virtual and online environments. Digital technology and the rapid expansion of the internet have allowed physical education content to be delivered online. 
Perceived limitations and barriers to OLPE are diminishing as new technologies and tools boast improvements in processing, screen resolution, storage capacity, battery life, and connectivity. However, the delivery of OLPE presents the challenge for teachers to transition traditional movement-oriented content and student experiences to a virtual environment.

Within formal teacher training programs, negotiations are on-going regarding the limited resources, capacity, and curricular space. Results from a national survey targeting teacher education programs efforts preparing pre-service teachers for online education suggest that $1.3 \%$ $(\mathrm{N}=522)$ have field experiences for pre service teachers in online education, while an additional 13\% indicated current plans to integrate virtual field experiences (Kennedy \& Archambault, 2012). Within PETE, Williams (2014) suggest preservice teachers remain inadequately prepared to translate content to an online environment and future training related to OLPE is needed. Furthermore, Williams (2014) suggested that OLPE instructor, "Should have a strong ability to type, enjoy sitting in front of a PC, and interested in grading written work, and communicating in different formats” (p.203). Skillsets and teacher functions that possibly conflict with pre-service teachers whose perspectives of a career in physical education (Quillen, 2010).

Considering the unique instructional and contextual variables of physical education, teachers of OLPE must have an understanding of the potential barriers, benefits, and realistic student outcomes in an online environment. The 2007 SHAPE Initial Guidelines for Online Physical Education, provide recommendations for content, assessment, technology, instructional design, and necessary support and infrastructure. These guidelines have been used to inform the development of OLPE courses and provide a framework for evaluating courses currently being delivered. This task seems quite monumental as teachers would need to design learning experiences that facilitate student achievement of standards and grade level outcomes identical to 
those within traditional/face-to-face physical education environments (Mohnsen, 2012; SHAPE, 2007). Frameworks that support the infusion of web-based technologies in physical education could aid in finding the balance between the two.

\section{Online Health Behavior Change Framework.}

Theories that underpin the wellness for life curriculum — the most prevalent curriculum in OLPE literature (Daum \& Buschner, 2014)_are largely related to behavior change (i.e. selfdetermination theory, theory of reasoned action, social cognitive theory, etc.). This is due in part to the goal of such courses is that students with guidance and equipped with health and wellness knowledge will begin to adopt a healthy lifestyle. Many health behavior interventions are now administered through the internet, while many are grounded in behavior change theory, none account for the influence of administering these interventions online (Ritterband, Thorndike, Cox, Kovatchev, \& Gondev-Frederick, 2009). Accounting for the effects of the internet when delivering behavior change interventions, facilitates a better understanding the factors involved and translation of empirical findings into strategies for improvement (Ritterband, et al., 2009).

The Online Behavior Change Model for internet interventions was created to, "Help guide future internet intervention development and predict and explain behavior changes and symptom improvement produced by internet interventions” (Ritterband, et al., 2009, p. 18). The behavior change model for internet interventions is comprised of nine major components: (1) user characteristics; (2) environmental factors; (3) website use/adherence; (4) support; (5) website characteristics; (6) mechanisms of change; (7) behavior change; (8) symptom improvement; (9) treatment Maintenance (see Figure 1). Ritterband et al., describe user characteristics as fixed (i.e. gender, age, ethnicity, etc.), but can be influenced by environmental factors such as family, friends, employer, school, or societal level influences such as social 
media, policy, and other cultural factors. These environmental factors can then affect website use and adherence, which is the application in which the behavior change intervention is delivered.

Furthermore, Ritterband et al., breaks down the website component within the model into eight main areas that; appearance, behavioral prescriptions, burdens, content, delivery, message, participation, and assessment. Each of these eight areas dictate the development and use of the website and can be modified with consideration to user characteristics and environmental factors prevalent in the population in which the behavior change is being administered. For example, the delivery aspect of the website component concerns the way in which the content is delivered, methods such as; use of audio, video, mobile devices, and learning management systems. Each represents a different method of relaying content to users that has an effect on a person's use of the website based on individual engagement, perceived usefulness, and enjoyment through the behavior change program. Online education research has suggested that students prefer audio, video, and interactivity as elements of online courses (Wei \& Liqiang, 2011; Allen \& Seaman, 2012). A student may be more engaged by these elements of delivery which in turn can have a greater effect on individual knowledge and motivation to persist through an online course.

The behavior change model presented by the authors is informed by numerous disciplines and theories of motivation, social marketing/adverting, web-based design/development techniques, models of knowledge transfer, behavior change, and the authors' clinical experience. Ritterband et al., (2009) purport that this creates a holistic model of behavior change and symptom improvement that pertains specifically to Internet interventions. For OLPE, this model facilitates the measurement of user needs to tailor the course to individual students. This is the crux of a wellness for life curricular model, individualized assessment through personal health 
and wellness exercise prescriptions, written by the students after being exposed to the wellness for life content.

\section{Instructional Design Theory}

Hilgart, Ritterband, Thorndike, and Kinzie (2012) proposed updates to the behavior change model for internet interventions that grounded the model in instructional design theory (IDT). The authors proposed that by using the behavior change model for Internet interventions along with research to guide design practice and inform development, developers of internet interventions could increase their ability to achieve desired outcomes. The infusion of IDT into the Online Behavior Change Model provides the additional supporting framework for assessing the needs of learners, to determining gaps in student attitudes, and exploring behaviors and knowledge relative to desired outcomes (Hilgart, et al., 2012). The addition layering of instructional design within the model was segmented into three categories: analysis; evaluation; and strategy (see Figure 2).

IDT Analysis. The Analysis portion encompasses user characteristics and environmental factors within the Online Behavior Change Model. Within the Analysis portion, user characteristics focus on the assessment of students, course learning objectives, demographics and development of learning goals. The environment refers to the context in which the learning will take place, which is specifically examined within three domains; physical, social, and institutional. With physical referring to the environment that the learner will complete the tasks; within social reflects learners social connections and influential networks (e.g. family, friends, employer, etc.); and institutional considerations relate to the goals and views held by the organization supporting the course. The authors assert that each of these three domains taken in consideration for environmental factors affects student's ability and willingness to access and use 
a course or program (Hilgart et al., 2012). This assessment process is used to determine what gaps may be present within those areas described above, each gap discovered during this phase is considered an area of need. When using the IDT model, online course stakeholders can identify potential supports and barriers to design a course appropriately based off a needs assessment that is both context and content specific.

The second analysis_-referred to as the task analysis— considers the content, type of educational tasks, and learning experience required to meet learning objectives. The task analysis is examined within each of the three learning domains; cognitive, psychomotor, and affective. Studies comparing online wellness for life course to similar face-to-face courses have shown equal cognitive gains, mixed results have occurred in both the psychomotor and affective domains (Cardinal, 2007; Brewer, 2001; Futrell, 2009; Kocher-Brown, 2003; McNamara, et al., 2008). Hilgart et al., (2012) assert that thoughtful consideration of the learning experience, within each of the learning domains, will increase the likelihood that learners can successfully develop the desired course outcomes in relation to knowledge, skills, behaviors, and attitudes. In summary, the analysis phase of the IDT process involves two sets of examinations. The first analysis identifies the learners, the learning objectives, and the environment in which the learning occurs. The second analysis considers the content, type of tasks, and learning experiences required to meet learning objectives.

IDT strategy. The next component of the IDT process within the Online Behavior Change Model is the strategy, which focuses on organization, delivery, and management of instruction. Organization refers to the structure, sequences, and pacing of the course. The delivery concerns the grouping of students and instructional media used to relay content to students. Lastly, management focus on the scheduling and implementation of instruction. The 
strategy component guides the development of instructional activities informed by both tested theories (e.g. gamification) and the aforementioned analysis component (Hilgart, et al., 2012). Hilgart, et al. states that "The crafting of instructional strategies is considered the most crucial step in the IDT process; It is the step that can contribute the most to making instruction successful” (p. 6). Provided with information from the analysis component of the IDT process, informed stakeholders can focus on the development of learning activities. For example, based off the results in the analysis, could inform the delivery strategy of a course in regards to student groupings based off of learning goals, prior knowledge, skill ability, attitude on subject or motivation level. The IDT strategy activities allow for the design and development of learning activities tailored to current students, learning environment, and content with the most up to date information available (Hilgart et al., 2012).

IDT evaluation. The last component of the IDT process within the Online Behavior Change Model is the evaluation phase. The evaluation phase is an assessment of the assumptions made in the previous two phases with consideration to outcomes at four levels: (1) learner reactions, (2) learning achievement, (3) transfer of learning, and (4) organizational results. The formative evaluation phase — consisting of the first two levels — is to be a constant ongoing approach that allows for revision and implementation of new learning strategies based upon information gathered in the first two phases of the IDT process. The summative evaluation phase may focus on all four outcome levels. By implementing this type of ongoing formative process it allows developers to identify weakness and make corrections before full scale implementation. The flexibility of the process also allows it to account for inevitable advents in technology that influence the initial assessment and development phases of the IDT processes (Hilgart et al., 2012). 
Research in OLPE that purposefully focus on identifying the elements of design, development and the theories underpinning those practices, allows for the all of elements to be refined and improved upon. The behavior change model for internet interventions with the inclusion of the IDT process provides instructors of OLPE with a methodology for designing online courses. OLPE instructors employing the framework informed with the most current research available to guide design and development will facilitate OLPE ability to help students achieve desired outcomes in all learning domains. Proponents of e-learning and OLPE indicate that online learning enables students to experience independence, accelerated learning, frees up physical boundaries, and allows them to take courses not offered locally (Mosier, 2012). Empirically sound and theoretically based research must be used to identify influential factors of student success in online learning (Alem, 2014). This would allow for a deeper understanding of the support, design, and delivery strategies that OLPE stakeholders could use to facilitate student success within online courses.

\section{Student Success in Online Physical Education}

Currently, limited data are available specific to OLPE courses student retention rates and attrition factors. However studies that have investigated student perceptions and characteristics of OLPE shed light on factors that influence student persistence and completion of OLPE courses. High attrition rates in OLPE have been attributed to a lack of student self-direction, guidance/support from parents and instructor; circumstantial issues (i.e. pregnant, home environment, emotional issues), overload credit hours, and technology readiness (Brewer, 2001; Goc Karp \& Woods, 2003; Kane, 2004). Daum and Buschner (2014) point out that, “It is easy to wonder how many of the issues the teacher and students faced in Goc Karp and Woods (2003) and Kane’s (2004) studies were due to the technology of the time” (p. 209). Yet, more recent 
studies have pointed out similar issues in instances in which students didn't persist in OLPE (Daum \& Buschner, 2012; Williams, 2014). Daum and Buschner (2012) found that one quarter of OLPE instructors reported student completion rates to be below 60 percent. Reported factors influencing attrition were the lack of time management, organization skills, motivation, technology background and maturity to work independently. All of these issues were presented as confounding factors causing students to fall behind, fail to turn in assignments, and ultimately drop out.

Demographic and OLPE enrollment trends. Mosier’s investigation of the Florida Virtual Schools (FLVS) OLPE program offered insight to student demographic information including age, gender, ethnicity, GPA, reasons for enrolling, enrollment type (traditional, accelerated, or extended) and completion rates. At the time of the study, OLPE courses at FLVS accounted for 10 percent of the total enrollment $(\mathrm{N}=19,994)$ for the $2008-2009$ school year. Of those enrolled in OLPE, 85 percent $(n=17,036)$ attended public schools public schools, 10 percent home school, two percent charter, and 3 percent attended private school. One aspect examined in the study was the causal correlation between courses completion and student characteristics. Course completion was defined for the purposes of the study in three categories; (1) course completers, (2) non-completers withdrawn or failing, and (3) non-completers who never accessed the online course. Mosier’s rational for examine this aspect of OLPE was that stakeholders — online teachers, teacher educators, and administrators — have taken interest into how the characteristics and experiences of students enrolled in the FLVS compare between completers and non-completers, the results of which could shed light on why students are successful or unsuccessful in OLPE course work. The study found that of all students enrolled, 52 percent were designated completers ( $n=10,333), 40$ percent non-completers/never 
activated/no grade $(n=8,054)$, and 8 percent non-completers who withdrew or failed the course $(n=1,557)$. Upon entering the OLPE course the 49 percent of students indicated a 3.0 or higher GPA. Unfortunately, grade point average, which has been shown as an indicator of student persistence in an online course, was self-reported and not used in drawing comparisons between the three designated groups (Mosier, 2010; Osborn 2001; Roblyer \& Davis 2002). Another indicator of student persistence, socially economic status, indicated by free and reduced lunch, showed a significant difference in completion rates amongst students. Students who reported receiving a free/reduced lunch did not complete the course 62 percent of the time.

Student readiness, particularly in regards to experience with online course work, appeared to be a factor in student's persistence through OLPE courses. Most of FLVS OLPE student population was comprised of 9-12th grade students $(16,373)$, with 76 percent being $11^{\text {th }}$ and $12^{\text {th }}$ grade students. This finding was similar to other studies investigating student characteristics in online course completion, where older students closer to graduation were more likely to persist through online course work (Mosier, 2010; Rankin, 2013; Roblyer, Davis, Mills, Marshall \& Pape, 2008). Likewise, experience level, defined by prior engagement in online courses in the FLVS, correlated with student course completion. Specifically, students’ who had completed a previous online course (32\%) were more likely to continue that trend then those who either had no experience (33\%) or had experience, but did not complete an online course (23\%; Mosier, 2010). These findings support other research in OLPE that have indicated students tend to underestimate the amount of time and effort required to be successful in online physical activity courses (Brewer, 2001; Daum, 2012; Williams, 2014).

Lack of communication and social presence within OLPE has become a common theme within the field of research and has attributed to student and instructor dissatisfaction with online 
physical activity courses (Daum \& Buschner, 2015; Kane, 2004; Goc Karp \& Woods, 2003; Williams, 2014). Mosier (2010) found, completers and non-completers reported less or lower quality engagement in OLPE as compared to face-to-face courses. Forty-five percent of noncompleters who withdrew reported the OLPE courses had the same level of engagement as a traditional course, 37 percent reported less engagement, 13 percent more engagement, and 5 percent did not respond to the question. Additionally 24 percent of completers indicated that communications with peers as poor (Mosier, 2010). Mosier attributed this to, “At FLVS, part of the reason for limited student-student interaction is that students enroll all year long and, for the most part, students are not working at the same place in the course at the same time, thereby limiting opportunities for group work” (p. 84). Conversely, student-to-instructor communication appeared to sufficiently meet students’ needs and expectations. Eighty-three percent of students indicated they communicated at least once a month with the instructor directly, either by email or telephone. A finding that was different from other online studies, was that telephone was the preferred method of student-to-instructor communication followed by email (Mosier, 2010). This is surprising given the course was administered fully online, but could be attributed to the FLVS policy that requires all instructors make contact with students over the phone within the first week of class. An important dimension of communication not addressed was the establishment of rapport among the instructor and students (Mosier, 2010). This omission may be valuable to consider and explore in future studies because a lack of social interaction has been cited in as a determinant to student persistence in previous OLPE research (Brewer, 2001; Futrell, 2009; Williams, 2014).

Mosier's (2010) study represents the most comprehensive examination of student characteristics within OLPE that confirms the results previous research and sheds light on areas 
for investigation. The results of the study support previous OLPE research findings in regards to student characteristics and experiences, such positive student perceptions about the flexibility and personalization provided by OLPE (Futrell, 2009; Kane, 2004; Goc Karp \& Woods, 2003). Correlations between student characteristics and completion or non-completion present the need to further study reasons for student persistence and attrition in OLPE. Ransdell, Rice, Snelson, and Decola (2008) indicated that dropout rate in online health related fitness course was linked to the quality of program. Similarly Brewer (2001) attributed a higher dropout rate in online physical activity courses to a lack of support from peers, poorly designed courses, and inexperienced and/or incompetent instructors. Examining pre-existing barriers and facilitators to student success in OLPE, will not only inform course design and delivery, but could aid in the development of early warning systems in OLPE courses. Ransdell et. al., (2008) suggested student competence screening before being allowed to enroll in OLPE, which reinforces a recommendation in the 2007 SHAPE Initial Guidelines for Online Physical Education. Screening systems that help identify individuals who are at risk for failing or not completing online course work, could have the potential support schools in facilitating online student success. The first step in ensuring that students are developing the skills and knowledge needed to be active for a lifetime is to examine the factors influencing persistence and attrition in OLPE.

\section{Monitoring and Predicting Success}

Alem, Plaisent, Bernard and Chitu (2014) conducted a systematic review of literature on student online readiness assessment tools published or unpublished from 1990 to 2010 to identify existing instruments and explore there validly. To identify relevant research and tools in the literature three groups of key words—synonyms of e-learning, development of instruments, and readiness — were searched for within academic databases and matching research retrieved. 
Inclusion of research was contingent upon five outline criteria: (1) Studies published in journals, conference proceedings, and reports of expert groups, (2) studies aimed at the development of the measuring instrument in the context of online learning readiness, (3) editorials, books, theses, and studies done on a professional basis were not considered, (4) studies published in another language other than English or French were excluded, and (5) studies published from 1990 to 2010. (Alem et al., p. 376)

The authors identified 5,107 studies that met initial standards outline above. After a review of titles and abstracts, using the same inclusion criteria, the field was narrowed to 58. Many of the tools uncovered in the review were considered homemade tools-developed internally by university departments and professors without regard to relevant published research in scientific journals_ —or did not demonstrate good psychometric qualities, generally lacking statistical rigor (Alem et al.). Next, the 58 articles were subjected to full text readings by the authors and assessed found 10 instruments that met the criteria, yet no standard prediction tool existed. The quality of the 10 identified articles was again assessed on five criteria; (1) type of research, (2) content validity, (3) pre-test and/or pilot test, (4) construct validity, and (5) reliability. The authors considered standards one through three to be highly desirable, but four and five to be mandatory cogency’s of predictive instrument measurement (Alem et al.). Of the ten studies identified, two of the studies—-Roblyer, Davis, Mills, Marshall, \& Papa (2008) and Osborn (2001) — met all five quality criteria set by the authors for student online persistence and success instruments.

Educational Success Prediction Instrument. The Educational Success Prediction Instrument (ESPRI) survey was developed by Roblyer and Marshall (2002) as an instrument to differentiate between successful and unsuccessful students enrolled in high school online course. 
The anticipated results of which could provide foundational information of effective counseling and support for future students considering online coursework. Research in distance education focusing on both learner characteristics and learning environment characteristics were used to inform the development of the ESPRI and create a single predictive model for online student success. The ESPRI assists stakeholder understanding and development of the structure, strategies, and support system involved in an online course that promote online learning and retention (Roblyer \& Marshall, 2002). Originally, the ESPRI was a 70-item instrument the utilized a 7-point Likert scale measuring five cognitive belief constructs (independent variables). The construct included: technology skill/access, organization and self-regulation, achievement, responsibility, and risk taking. Within each construct, respondents indicate their level of agreement (strongly agree 1 - strongly disagree 7) on statements such as "When I have to do something on a computer, I usually try to figure it out myself," or "I tend to wait until the last minute to get things done.” The ESPRI was distributed to students (n=135) across 13 online high schools and able to predict passing students with 100 percent confidence and failing with 95 percent. It was found that successful students rated themselves higher in organizational skills, self-efficacy, initiative, technology skill/access, and spent less time working outside of school. Although, Roblyer and Marshall (2002) found the ESPRI to be successful, it was recommended that the instrument be tested with additional groups and a larger population.

The instrument was later refined by Roblyer, Davis Mills, Marshall, and Pape (2008) based upon past factor analysis and logistical regression findings within each of the constructs, omitting items that made little contribution to the prediction indexes. Additionally, 10 student characteristic questions, related to student background and online learning environment, were added based upon literature published since the initial findings. With the addition of 10 items 
related to student characteristics, version two of the ESPRI included 60 items of equal number in each of the cognitive constructs: organization, achievement beliefs, responsibility, risk-taking, and technology skills/access. In combination with student scores on cognitive variables, the student characteristic questions were and hypothesized to contribute to student success. Roblyer et al., administered the ESPRI-V2 in the same New England region virtual high school ( $N=$ 2,880) as the original Roblyer and Marshall (2002) study. After the initial survey of students, ESPRI-V2 was again reduced:

Because online instructors and administrators had observed that online students would be more likely to complete an abbreviated instrument, a factor analysis was done to determine if items could be reduced in number for future administrations while maintaining acceptable reliability and maximizing explained variance among items (Roblyer, et al., 2008, p. 98).

A principal components extraction method with varimax rotation was used with the purpose of reducing items while maintaining as much information possible from the original constructs (Roblyer, et al, 2008). The results, allowed for elimination of the construct of responsibility and reduced the ESPRI-V2 to 23 items comprising four constructs: technology use/self-efficacy (6 items); achievement beliefs/locus of control (six items); instructional risk taking (six items), and organization strategies (five items). The total scale reliability for both the 60-item and 23-item version of the ESPRI-V2 was found to be alpha $=0.92$. This Cronbach's alpha score indicates a high level of internal consistency among the ESPRI-V2 constructs.

The authors found that the best combination of predictors from the outcome of a direct logistical regression included: ESPRI sum; student background variables of age and self-reported GPA; the environmental variables, home computer availability and available school time for online course work. This model was able to predict student success in an online course at 93 percent and student failure at 30.4 percent (Roblyer, et. al., 2008). To analyze the data, Roblyer 
et al. (2008) employed a logistical regression using the five cognitive belief constructs and various combinations of student demographic factors as independent variables with course completion (i.e. pass/fail) as the dependent variable. For the purposes of the ESPRI-V2 the pass/fail criteria was defined as: students completing the course with a grade of $\mathrm{A}, \mathrm{B}$, or $\mathrm{C}$ were identified as passing (successful); student who withdrew (W), dropped (I), or completed the course with a grade of D or F were identified as failing (unsuccessful). The authors concluded that the measurements made within the ESPRI-V2 in combination student demographic (e.g. GPA, success in previous online course, etc.) and environmental characteristics develop a useful predictive model for online student success. As a result, the ESPRI-V2 constructs and other measures (e.g. self-reported GPA, age, ethnicity, etc.) can be entered into the logistical equation resulting from the regression to determine the probability of success or failure in an online class, referred to this as Probability of Pass or POP score (Roblyer et al., 2008). In turn, organizations offering online courses can use POP scores to identify at-risk students. Because student population's characteristics and environments differ, POP scores would need to be generated for different populations to assess levels of student attributes. After which, organizations can formulate appropriate interventions targeting individual constructs and student demographics that have been determined to be indicators of at-risk students. For example, interventions such as pre-course orientation sessions can be required if a students were to score low in the organizational skills or online self-efficacy constructs. Those pre-course orientation courses can then focus on addressing how to organize and work in an online learning environment.

While the ESPRI-V2 addresses student environmental and demographic characteristics, the survey items associated with those factors pertain to the high school level and do not address concerns students may have in higher education. Osborn’s (2001) distance learning survey 
represents the only other study identified by Alem et al. (2014) that met all of the quality criteria for student online persistence and success instruments. Moreover, Osborn’s (2001) survey addresses student environmental and demographic characteristics with items in each construct focused on university level online courses.

Distance Learning Survey. Osborn’s (2001) prediction model is based on a combination of both student characteristics and course environment characteristics within a graduate student population. A framework based on models of attrition and retention was used to identify constructs influencing success and failure in university level online courses (Osborn, 2001). Four models contribute to Osborn’s (2001) framework; Billings Model of Correspondence Course Completion, Tinto’s Model of Student Persistence, Kennedy and Powell’s Descriptive Model, and Kember's Open Learning Model. From these models, Osborn asserts that three areas central to understanding student behavioral intention to persist in online learning including, (1) entry characteristics; (2) social integration; and (3) academic integration. Osborn justified these three foundational pieces of the framework stating, "Theory in the area of student attrition supports a multivariate framework to account for the complexity inherent in analyzing the student's participation in multiple spheres of activity” (p. 41). These three general areas informed the initial development of the Distance Learning Survey (DLS) which consisted of the nine following constructs predicting completion, (1) computer confidence; (2) enrollment encouragement; (3) financial; (4) locus of control; (5) motivation; (6) study environment; (7) support; (8) preparation; and (9) tenacity. Additionally, the DLS included seven-single item predictor variables, (1) age; (2) GPA; (3) educational level; (4) hours worked per week; (5) credit hours taken in the current semester; (6) number of previous distance learning courses taken; and (7) years out of college (Osborn, 2001). 
Initial items corresponding to the nine constructs above were within a self-reported survey distributed to students enrolled in online and videoconferencing courses at the University of North Texas $(N=396)$. The survey consisted of 28 Likert scale items ( 1 strongly disagree to 5 strongly agree) and seven ordinal or ratio predictive variables (Osborn, 2001). At the time the surveys were administered the only online and videoconferencing courses available were exclusively graduate level library science courses. The survey was administered at the beginning of the semester to students (84 percent graduate-level) and results of course completion were provided by the instructors of each course (Osborn, 2001). Course completion and noncompletion was defined in the study by either pass or fail. To determine the predictive validity of the DLS survey, a discriminant analysis procedure based course completion was conducted and tested against a sample randomly selected from the population (Osborn, 2001). The results of the analysis omitted three constructs, financial stability; need for support; and preparation for the course, which reduced the DLS to the remaining six constructs-computer confidence, enrollment encouragement, locus of control, motivation, study environment, tenacityaccounting for 56.81 percent of the variance (Osborn, 2001). Of the six constructs, computer confidence (alpha $=.789)$, study environment (alpha $=.682)$, and motivation (alpha $=.392$ ) were the strongest in differentiating completing students (i.e. pass) from non-completing students (i.e. fail). Contributing to the prediction model were four single-item predictor variables, number credit hours taken in the semester; previous experience with distance learning; educational level; and GPA. The remaining three constructs and four single-item predictor variables were able to correctly classify 82 percent of the students as completers or non-completers (Osborn, 2001).

Osborn found that 87 percent of online graduate students in the study were successful (i.e. course completers) in the online courses studied. The author attributed this high pass rate to 
student age and proximity to degree completion. Other entry characteristics, such as GPA and educational level, made an important contribution to the final prediction equation, but were not sufficient predictors individually. Additionally, Osborn found that at-risk students were generally taking more credit hours, unstable study environments, lower motivation, less computer confidence, previously dropped out of college and had no experience in an online courses. Atrisk students tended to be undergraduates with lower GPAs who received less encouragement to take an online course from family, friends, or employers (Osborn, 2001). Osborn's results and interpretations correspond with previous findings of online student success (Hart, 2012; Ivankova \& Stick, 2005; Roblyer et al., 2008; and Xu \& Jaggers, 2014).

An unexpected finding in the study was that at-risk students were working fewer hours per week at a job outside of class time. Osborn (2001) postulated that this could relate more to time management for at-risk online students, rather than total amount of study time available during the week, thus suggesting time management as a key variable in student persistence and completion of an online course. The time management variable is addressed within the items in the ESPRI-V2's constructs of organization and academic risk taking. Osborn suggested using the DLS instrument in other disciplines and/or with undergraduate populations could contribute to more precise discriminant functions and merits further research. Content area experience and demonstrated ability, measured by discipline specific screening, have been shown to be significant predictors of online student success (Slykhuis \& Park, 2006; Rankin, 2013; Yuan \& Kanthawala, 2015). Specifically in OLPE, It has been found that students with higher perceived health related fitness levels, positively impact their motivation to engage in physical activity (Decarlo, 2016). It has been suggested that physical education teachers should be aware of student's motivations to exercise and address health related fitness concepts according to these 
levels. By measuring students motivations to engage or to not engage in physical activity will aid OLPE in supporting students in course work.

Behavioural Regulation in exercise Questionnaire. Markland and Tobin’s (2004) modification to Mullan, Markland, and Ingledew (1997) Behavioral Regulation in Exercise Questionnaire (BREQ) was an effort to reinstate amotivation items into the instrument. Originally the BREQ survey included amotivation items, but they were dropped after Mullan et al., (1997) found that these items caused a high level of skewness and a restricted range of scores when attempting to validate the initial instrument, thus these items were excluded. The significance of the additional a motivational items to the BREQ is it allows for the researchers to investigate the antecedents and consequences of amotivation in relation to exercise behaviour (Markland and Tobin, 2004). Mullan et al,. (1997) speculated that this was likely a result of the participants used in the initial validation study who were already exercising regularly.

Mullan and Tobin (2004) used modified amotivation items that they hypothesized would exhibit a wider range of responses with the participants who had taken part in an exercise referral scheme at a local community leisure center. At this center participants were incentivized to undergo a medical examination and fitness assessment in order to receive a free exercise prescription and set of twelve exercise session with a personal trainer. If the participant was found to be either overweight, obese, have moderate hypertension or depression then they would receive a referral. Over the 3 years, 580 participants had received referrals and BREQ-V2 questionnaires were mailed to all of those participants. The researchers received a response rate of 35 percent $(n=194)$. Overall, the sample of participants were at the upper end of the overweight category of the body mass index and were on average 55 years of age. 
The BREQ-V2 completed by participants consisted of 19 Likert scale questions ranging from "not true for me" to "very true for me." The 19 questions of the BREQ-V2 make up five categories on the continuum of motivation as described by self-determination theory; (1) amotivation, (2) external, (3) introjected, (4) identified, and (5) intrinsic (Markland \& Tobin, 2004). Participants are categorized within a category on the spectrum from amotivated to intrinsically motivated based upon their responses to the BREQ-V2. Those who indicate a higher levels of autonomous regulation of motivation (i.e. identified and intrinsic) are more likely to engage in regular physical activity. The researchers suggest that it is the quality and not the intensity of motivation that is the most influential factor associated with frequent exercise participation and positive perceptions of physical activity (Markland \& Tobin, 2004).

Markland and Tobin (2004) found that the addition of amotivation items to the initial BREQ possessed good factorial validity $(\mathrm{M}=0.76$, range $=0.74-.88$, and $p<0.001)$ and internal consistency $(\alpha=.90)$. Although, it was found that the additional amotivation scale possessed a level of skewedness due to participants indicating low level of amotivation with a small range of scores, it was not on the same level as Mullen et al., (1997). Markland and Tobin (2004) attributed this to recruiting participants from an exercise referral scheme in which subjects voluntarily participated and would likely have some motivation to exercise. However, the researchers did not that items were not developed to assess a lack of perceived competence due to the assumption that inclusion of such items may confound amotivation with perceived competence (Markland \& Tobin, 2004). It was suggested that items related to perceived competence may be a worthwhile addition with a different sample population. For OLPE, the BREQ-V2 provides a validated instrument to measure student physical activity motivation levels in relation to successful course completion. 


\section{Statement of the Problem}

The landscape of education is changing and with it, stakeholders within OLPE, must identify program strengths and weaknesses to better accommodate the online student (Mohnsen, 2012). Proponents of distance learning and OLPE indicate that online learning enables students to experience independence, accelerated learning, unlimited physical boundaries, and expands access to course not offered locally (Allen \& Seaman, 2012; Mohnsen, 2012). Descriptive studies within OLPE have been described both student and teacher characteristics and perceptions of OLPE. Through these studies it has been suggested the type of student successful in OLPE displays characteristics such as responsibility, autonomy, internal locus of control, time management and communication skills (Daum \& Buschner, 2012; Futrell, 2009). However, these are characteristics of learners who persist in most educational environments (Roblyer \& Marshall, 2002; Roblyer, et. al, 2008). Furthermore, these studies did not address student’s physical activity readiness, background information, or environmental factors that may affect student's ability to be successful in an OLPE course. Scholars have called for empirically sound and theoretically based research to identify the most influential factors for determining student success (Alem, et al., 2014). This would allow for a deeper understanding of the support, design, and delivery strategies needed to better facilitate student success within virtual courses.

In Mosier’s (2010) seminal OLPE study, investigating the characteristics of students participating in OLPE at the Florida Virtual School, he describes the importance of embracing OLPE, stating:

While still in the developmental stages the profession must either accept that K-12 online physical education as a choice among students, or reject this [online] approach to the teaching of physical education. If the online approach is embraced, K-12 OLPE can improve in content, teaching, professional development, preservice instruction, student learning and outcomes. If, however, this form of physical education is rejected, it is likely 
that students will choose online/blended physical education courses, but the profession as we know it will not be included (p. 36).

Scholars have posited that the demand for online learning is not going away, and the question is no longer if OLPE is practical but rather, what are the most effective ways of administering OLPE to accommodate the online student (Daum \& Buschner, 2012). Examining potential student-centric barriers for success in online physical activity will aid in the development of early warning systems for OLPE. Currently, limited data are available on student retention rates and attrition factors in OLPE courses. However, studies that have focused on student perceptions and characteristics shed light on possible factors affecting their persistence in OLPE courses. High attrition rates in OLPE courses have been attributed to a lack of support, poorly designed courses and inexperienced and/or incompetent instructors (Brewer, 2001; Ransdell et al., 2008). Several early OLPE studies as well as the 2007 SHAPE Initial Guidelines for Online Physical Education have suggested that certain prescreening efforts be in place prior to student enrollment in OLPE, however, at present no such empirically sound and theoretically based screening instruments exist. Screening and pre-screening systems can help identify students who are at risk of failing and/or not completing online coursework. In OLPE a valid and reliable screening instrument would allow for a deeper understanding of the support, design, and delivery strategies that OLPE stakeholders could use to facilitate student success. Such tools have the potential to provide schools with data-based advising resources that can improve performance and persistence in online coursework (Hart, 2012). 


\section{References}

Alem, F., Plaisent, M., Bernard, P., \& Chitu, O. (2014). Student online readiness assessment tools: A systematic review approach. The Electronic Journal of e-Learning, 12(4), 375382.

Allen, E., \& Seaman, J. (2012). Changing course ten years of tracking online education in the United States. MA: Sloan Center for Online Education.

Allen, E., \& Seaman, J. (2016). Online report card tracking online education in the United States. MA: Sloan Center for Online Education.

Allen, E., Seaman, J., \& Garrett, R. (2007). Blending in the extent and promise of blended education in the United States (pp. 35).

Barbour, M. (2010). Researching K-12 online learning: what do we know and what should we examine? Distance Learning, 7(2), 7-12.

Barbour, M., Siko, J., Gross, E., \& Waddell, K. (2013). Virtually unprepared: Examing the preparation of k-12 online teachers. In R. Hartshorne, T. Heafner \& T. M. Petty (Eds.), Teacher Education Programs and Online Learning Tools: Innovations in Teacher Preparation. Hershey, PA: Information Science Reference.

Barbour, M. K., \& Kennedy, K. (2014). K-12 online learning: A worldwide perspective. Education Faculty Publication, Paper 188.

Beldarrain, Y. (2008). Engaging the 21st century learner: An exploratory study of the relationship between interaction and achievement in the virtual high school. (3311390 Ph.D.), Capella University, Ann Arbor.

Bennett, S., Maton, K., \& Kervin, L. (2008). The 'digital natives' debate: A critical review of the evidence. British Journal of Educational Technology, 39(5), 755-786. 
Brewer, J. D. (2001). The impact of a web-based versus face-to-face instructional format of a lifetime fitness course on students' wellness knowledge, attitudes and behaviors and levels of health-related physical fitness. (3019351 Ph.D.), Kansas State University, Ann Arbor.

Buchanan, A. M., \& Brock, S. (2016). What If they see me miss? Nuances of teaching in a movement-based environment. Strategies Strategies, 29(3), 16-20.

Cardinal, B. J. (2012). How can we help college and university students stay active and healthy for life? JOPERD: The Journal of Physical Education, Recreation \& Dance, 83(8), 5353.

Cardinal, B. J., \& Spaziani, M. D. (2007). Effects of classroom and virtual "lifetime fitness for health" instruction on college students' exercise behavior. Physical Educator, 64(4), 205213.

Cavanaugh, C., Barbour, M. K., \& Clark, T. (2009). Research and practice in K-12 online learning: A review of literature. International Review of Research in Open and Distance Learning, 10(1).

Chemolli, E., \& Gagné, M. (2014). Evidence against the continuum structure underlying motivation measures derived from self-determination theory. Psychological Assessment, 26(2), 575-585. doi: 10.1037/a003621210.1037/a0036212.supp (Supplemental)

Christensen, C., Horn, M., \& Johnson, M. (2008). Disrupting class: How disruptive innovation will change the way the world learns. New York: McGraw-Hill.

Corbin, C. B., Le Masurier, G., \& McConnell, K. (2014). Fitness for Life (6 ed.). Champaign, IL: Human Kinetics. 
Creswell, J. W. (2012). Educational research: Planning, conducting, and evaluating quantitative and qualitative research (4th ed.). Upper Saddle River, NJ: Merrill.

Daum, D., Mosier, B., Buschner, C., Smith, B., Cain, D., \& Witherspoon, L. (2015). Research and best practices related to online physical education. Paper presented at the SHAPE America Convention, Seattle, WA.

Daum, D. N. (2012). Physical education teacher educator's attitudes toward and understanding of online physical education. (3570649 Ph.D.), University of Illinois at UrbanaChampaign.

Daum, D. N., \& Buschner, C. (2012). The status of high school online physical education in the United States. Journal of Teaching in Physical Education, 31(1), 86-100.

Daum, D. N., \& Buschner, C. (2014). Research on teaching blended and online physical education. In R. Ferdig \& K. Kennedy (Eds.), Handbook of Research on K-12 Online and Blended Learning (pp. 201-221): ETC Press.

Decarlo, D. (2016). Student perception of the effect of high school online physical education class participation on fitness knowledge and motivation for physical activity: A qualitative case study. Northcentral University, Prescott Valley, AZ.

Florida Virtual School. (2014). Retrieved 23 Feb. 2014, from http://www.flvs.net

Futrell, J. (2009). A comparative study of virtual high school instruction versus traditional instruction of high school student outcomes and attitudes in physical education. (3360073 Ph.D.), Capella University.

Gibbone, A., \& Mercier, K. (2014). Accomplishing PETE learning standards and program accreditation through teacher candidates' technology-based service learning projects. JOPERD: The Journal of Physical Education, Recreation \& Dance, 85(5), 18-22. 
Goc Karp, G., \& Woods, M. L. (2003). Wellness NutriFit online learning in physical education for high school students. The Journal of Interactive Online Learning, 2(2).

Gorski, S. (1994). Credits by cable: The mind extension university. Educause Review, 29(6).

Hager, R., George, J. D., LeCheminant, J. D., Bailey, B. W., \& Vincent, W. J. (2012). Evaluation of a university general education health and wellness course delivered by lecture or online. American Journal of Health Promotion, 26(5), 263-269.

Hart, C. (2012). Factors associated with student persistence in an online program of study: A review of the literature. Journal of Interactive Online Learning, 11(1), 19-42.

Hensley, L. D. (2000). Current status of basic instruction programs in physical education at american colleges and universities. Journal of Physical Education, Recreation \& Dance, 71(9), 30-36. doi: 10.1080/07303084.2000.10605719

Hilgart, M. M., Ritterband, L. M., Thorndike, F. P., \& Kinzie, M. B. (2012). Using instructional design process to improve design and development of Internet interventions. Journal of Medical Internet Research, 14(3).

Ivankova, N., \& Stick, S. (2005). Collegiality and community - Building as a means for sustaining student persistence in the computer - Mediated asynchronous learning environment. Online Journal of Distance Learning Administration, 8(3).

Jackson, J. M. (2015). An examination of the perceptions of online physical education: How fit is online PE? (3710217 Ed.D.), Bowling Green State University, Ann Arbor.

Juniu, S. (2011). Pedagogical uses of technology in physical education. JOPERD: The Journal of Physical Education, Recreation \& Dance, 82(9), 41-49. 
Kane, J. (2004). The dog ate my disk: Teacher and student perspectives of an online personal fitness course. Florida Alliance for Health, Physical Educastion, Recreation, Dance \& Sport, 42(2), 8-12.

Kaplan, A. M., \& Haenlein, M. (2016). Higher education and the digital revolution: About MOOCs, SPOCs, social media, and the Cookie Monster. Business Horizons, 59(4), 441450.

Kennedy, K., \& Archambault, L. (2012). Offering preservice teachers field experiences in K-12 online learning- A national survey of teacher education programs. Journal of Teacher Education, 63(3).

Kocher Brown, P. L. (2003). A comparison of online instruction versus traditional classroom instruction in a Fitness for Life course. (3093873 Ed.D.), The University of North Carolina at Greensboro.

Kooiman, B. J., \& Sheehan, D. P. (2014). The efficacy of exergames played proximally and over the internet on cognitive functioning for online physical education. American Journal of Distance Education, 28(4), 280-291. doi: 10.1080/08923647.2014.957946

Kwak, J. Y. (2014). Determinants of users' intention to adopt mobile fitness applications: an extended technology acceptance model approach. (Doctor of Philosophy), University of New Mexico, Albuquerque, New Mexico.

Markland, D., \& Tobin, V. (2004). A modification to the behavioural regulation in exercise questionnaire to include an assessment of amotivation. Journal of Sport \& Exercise Psychology, 26(2), 191-196. 
McNamara, J. M., Swalm, R. L., Stearne, D. J., \& Covassin, T. M. (2008). Online weight training. Journal of Strength \& Conditioning Research (Lippincott Williams \& Wilkins), 22(4), 1164-1168.

Melton, B., Russell, J., Moore, C., \& Sweeney, M. (2009). Appropriate instructional practice guidelines for higher education physical activity programs (2nd ed.). Reston, VA: National Association for Sport and Physical Education.

Mohnsen, B. (2012). Implementing online physical education. Journal of Physical Education, Recreation \& Dance, 83(2), 42-47.

Mosier, B. (2012). Virtual physical education: A call for action. JOPERD: The Journal of Physical Education, Recreation \& Dance, 83(3), 6-10.

Mosier, B. (2014). Meeting PETE students in their world: Tracking physical activity through technology. JOPERD: The Journal of Physical Education, Recreation \& Dance, 85(3), 46-49.

Mosier, B., \& Lynn, S. . (2012). An initial exploration of a virtual personal fitness course. Online Journal of Distance Learning Administration, 15(3).

Mosier, B. A. (2010). A descriptive study of Florida virtual school's physical education students: An initial exploration. (3462335 Ph.D.), The Florida State University, Tallahassee, FL.

Mullan, E., Markland, D., \& Ingledew, D. K. (1997). A graded conceptualisation of selfdetermination in the regulation of exercise behaviour: Development of a measure using confirmatory factor analytic procedures. Personality and Individual Differences, 23(5), 745-752.

NASPE. (2007). Initial guidelines for online physical education Position Statement. Restion, VA: Author. 
NASPE. (2009). Appropriate use of instructional technology in physical education Position Statement. Reston, VA.

NCATE. (2008). Advanced standards for physical education

Oblinger, D., \& Oblinger, J. (2005). Is it age or IT: First steps towards understanding the net generation. In D. Oblinger \& J. Oblinger (Eds.), Educating the Net Generation (pp. 2.12.20). Boulder, CO: EDUCAUSE.

Osborn, V. (2001). Identifying at-risk students in videoconferencing and web-based distance education. American Journal of Distance Education, 15(1), 41-54. doi: $10.1080 / 08923640109527073$

Pittman, V. (2003). Correspondence study in the American university: A second historiographic perspective. In M. Moore \& W. Anderson (Eds.), Handbook of Distance Education (pp. 22-37). Mahwah, NJ: Lawrence Erlbaum Associates.

Price, S. L. (2015). Hiring considerations and training in physical education pedagogy: Current trends in physical activity grades K-12. Journal of Physical Education, Recreation \& Dance, 86(3), 5-6. doi: 10.1080/07303084.2015.998516

Quillen, I. (2010). E-learning delivery debated. Education Week, 29(30).

Rankin, D. (2013). Predictors of success for high school students enrolled in online courses in a single district program. (Doctor of Philosophy), Virginia Commonwealth University, Richmon, Virginia.

Ransdell, L. B., Rice, K., Snelson, C., \& Decola, J. (2008). Online health-related fitness courses. JOPERD: The Journal of Physical Education, Recreation \& Dance, 79(1), 45-52.

Rhea, D. J. (2011). Virtual physical education in the K-12 setting. JOPERD: The Journal of Physical Education, Recreation \& Dance, 82(1), 5-50. 
Rice, K., \& Dawley, L. (2009). The status of professional development for K-12 online teachers: Insights and implications. Journal of Technology \& Teacher Education, 17(4), 523-545.

Rice, K., \& Yang, D. (2013). Idaho’s K-12 online teaching endorsement: Lessons learned in online teacher preparation. Paper presented at the International Association for K-12 Online Learning, Blended and Online Learning Symposium, Orlando, FL.

Rice, K. L. (2006). A comprehensive look at distance education in the K-12 context. Journal of Research on Technology in Education, 38(4), 425-448.

Rink, J. (2013). Teaching physical education for learning. Boston, MA: McGraw-Hill.

Ritterband, L. M., Thorndike, F. P., Cox, D. J., Kovatchev, B. P., \& Gonder-Frederick, L. A. (2009). A behavior change model for internet interventions. Annals of behavioral medicine : a publication of the Society of Behavioral Medicine, 38(1), 18-27. doi: 10.1007/s12160-009-9133-4

Roblyer, M., \& Davis, L. (2008). Predicting success for virtual school students: Putting researchbased models into practice. Online Journal of Distance Learning Administration, 11(4).

Roblyer, M. D. (2005). Who plays well in the virtual sandbox? Characteritics of successful online students and teachers. SIGTel Bulletin, 2.

Roblyer, M. D., Davis, L., Mills, S. C., Marshall, J., \& Pape, L. (2008). Toward practical procedures for predicting and promoting success in virtual school students. American Journal of Distance Education, 22(2), 90-109. doi: 10.1080/08923640802039040

Roblyer, M. D., \& Marshall, J. C. (2002). Predicting success of virtual high school students: Preliminary results from an educational success prediction instrument. Journal of Research on Technology in Education (International Society for Technology in Education), 35(2), 241. 
Russell, J., Wadsworth, D., Hastie, P., \& Rudisill, M. (2014). Incorporating E-learning to enhance instruction and student experiences in collegiate physical activity courses. Kinesiology Review, 3(4), 247-252. doi: doi:10.1123/kr.2014-0066

Ryan, R. M., \& Connell, J. P. (1989). Perceived locus of causality and internalization: examining reasons for acting in two domains. Journal of Personality \& Social Psychology, 57, 749761. doi: 10.1037/0022-3514.57.5.749

Saba, F. (2003). Distance education theory, methodology, and epistemology: A pragmatic paradigm. In M. Moore \& W. Anderson (Eds.), Handbook of Distance Education (pp. 321). Mahwah, NJ:: Lawrence Erlbaum.

Saba, F. (2005). Critical issues in distance education: A report from the United States. Distance Education, 26(2), 255-272.

SHAPE-America. (2016). Shape of the nation: Status of physical education in the USA. Reston, VA.

Slykhuis, D., \& Park, J. (2006). Correlates of achievement with online and classroom-based MBL physics activities. Journal of Computers in Mathematics \& Science Teaching, 25(2), 147-163.

Smith, R., Clark, T., \& Blomeyer, R. L. (2005). A synthesis of new research on K-12 online learning. Learning Point Associates. Naperville, IL.

Strand, B. N., Egeberg, J., \& Mozumdar, A. (2010). The prevalence and characteristics of wellness programs and centers at two-year and four-year colleges and universities. Recreational Sports Journal, 34(1), 45-57.

Tabachnick, B. G., \& Fidell, L. S. (2014). Using Multivariate Statistics (6th ed.). Boston: Pearson/Allyn and Bacon. 
Trent, M. (2016). Investigating virtual personal fitness course alignment with the national guideline for online physical education. (Doctor of Philosophy Dissertation), Georgia State University, Atlanta, GA.

USDE. (2008). Evaluation Online Learning: Challenges and Strategies for Success.

Watkins, B. L., \& Wright, S. J. (1991). The foundations of American distance education. Dubuque, Iowa: Kendall/Hunt Publishing Company.

Wei, Z., \& Liqiang, S. (2011). Mobile-learing (m-learning) apply to physical education in colleges. Paper presented at the IEEE Conference on Circuits, Communications and System, Wuhan, China.

Wicks, M. (2010). A national primer on K-12 online learning version 2 (pp. 50). Vienna, VA: International Association for K-12 Learning.

Williams, L. (2014). A case study of virtual physical education teachers' experiences in and perspectives of online teaching. (Ph.D.), University of South Florida, Tampa, FL.

Woods, M. L., Goc Karp, G., Hui, M., \& Perlman, D. (2008). Physical educators' technology competencies and usage. Physical Educator, 65(2), 82-99.

Wu, W., Dasgupta, S., Ramirez, E. E., Peterson, C., \& Norman, J. G. (2012). Classification accuracies of physical activities using smartphone motion sensors. J Med Internet Res, 14(5), e130. doi: 10.2196/jmir.2208

Wyant, J. D., Jones, E. M., \& Bulger, S. M. (2015). A mixed methods analysis of a single-course strategy to integrate technology into PETE. Journal of Teaching in Physical Education, 34(1), 131-151. 
Xu, D., \& Jaggars, S. S. (2014). Performance gaps between online and face-to-face courses: Differences across types of students and academic subject areas. Journal of Higher Education, 85(5), 633-659.

Yuan, S., Ma, W., Kanthawala, S., \& Peng, W. (2015). Keep using my health apps: Discover users' perception of health and fitness apps with the UTAUT2 model. Telemedicine and E-Health, 21(9), 735-741. 


\section{APPENDIX D}

\section{Educational Success Prediction Instrument Version 2 (Roblyer et al., 2008)}

\section{Technology skills/self-efficacy (6 items)}

1) When I have to do something on a computer, I usually try to figure it out myself.

2) I know how to locate a document or a program on my computer.

3) I feel comfortable using a computer.

4) I know how to send an attachment in an email.

5) I use email, instant messaging, or text messaging daily.

6) I have good word processing skills.

\section{Achievement beliefs (6 items)}

1) Many times I lose interest in attaining the goals I set.

2) I rarely set goals for myself.

3) I find that I try harder if I set high goals for myself.

4) I study hard for all of my classes because I enjoy acquiring new knowledge.

5) I tend to persist at tasks until they are accomplished.

6) I believe I am a high achiever.

\section{Instructional risk-taking (6 items)}

1) I do not care what other people think of me if I make mistakes.

2) I am not afraid of making mistakes if I am learning to do new things.

3) I don't mind showing my work in front of others when I am learning new things.

4) If I am given a task to perform that I know little about, I don’t mind giving it a try.

5) When I am learning something new, it is okay if I make errors.

6) I am afraid of failure when I am learning new things.

\section{Organization (5 items)}

1) I find it easier to complete assignments by breaking it into subparts rather than studying the whole subject matter at one time.

2) I keep notes on each subject together arranged in a logical order.

3) I keep my desk or the place where I work very organized.

4) I will often set short-term goals to help me reach a long term goal.

5) I tend to wait until the last minute to get things done. 


\section{APPENDIX E}

\section{Distance Learning Survey (Osborn, 2001)}

\section{Demographic}

1. Gender

a) female

b) male

2. Age?

a) $18-23$

b) $24-29$

c) $30-35$

d) $36-41$

e) $42+$

3. How would you classify your race or ethnic background?

a) American Indian or Alaskan Native

b) Asian

c) Black, non-Hispanic

d) Hispanic

e) International Student (Visa Holder)

f) Pacific Islander

g) White, non-Hispanic

h) Other

4. Select the class standing that best describes you?
a) Freshman
b) Sophomore
c) Junior
d) Senior

5. Current grade point average (GPA)?
a) $0-1.0$
b) $1.1-2.0$
c) $2.1-3.0$
d) $3.1-3.5$
e) $3.6-4.0$

\section{Environmental}

6. How many courses are you currently enrolled in to include this course?
a) 1
b) 2
c) 3
d) 4
e) 5 or more 
7. Approximately how many online courses have you previously taken?
a) 0
b) 1
c) 2
d) 3
e) 4
f) 5 or more

8. Which best describes the type of student you are?
a) Commuter, take classroom and online courses due to availability and flexibility
b) Distance learner, take only online courses
c) Distance learner, but have taken classroom courses in the past
d) Live on campus, full-time student

9. How many hours do you work each week outside the home, on an average?
a) $1-10$
b) $11-20$
c) $21-30$
d) $31-40$
e) $40+$

10. Do you have children or other family members who depend upon you for support?
a) no
b) yes

11. Which best describes how your tuition for this course was paid?
a) employee benefits
b) employer reimbursement
c) tuition assistance
d) parent(s)
e) scholarship/grant
f) self-pay
g) student loan
h) other (please specify)

12. Do you have financial stability over the next year?
a) yes--highly confident
b) yes--confident
c) uncertain
d) not very confident
e) very unsure 


\section{APPENDIX F}

\section{Behavioural Regulation in Exercise Questionnaire - Version 2 (Markland \& Tobin, 2004)}

Why do you engage in exercise? We are interested in the reasons underlying peoples' decisions to engage, or not engage in physical exercise. Please note that there are no right or wrong answers and no trick questions. We simply want to know how you personally feel about exercise. Your responses will be held in confidence and only used for our research purposes. For each question please indicate how true each statement is for you.

\begin{tabular}{|c|c|c|}
\hline Scale: & $0=$ Not true for me & $1=$ Slightly true for me \\
\hline & $\begin{array}{l}2=\text { Sometimes true for me } \\
4=\text { Very true for me }\end{array}$ & $3=$ Mostly true for me \\
\hline
\end{tabular}

1. I exercise because other people say I should

2. I feel guilty when I don't exercise.

3. I value the benefits of exercise.

4. I exercise because it's fun.

5. I don't see why I should have to exercise.

6. I take part in exercise because my friends/family/partner say I should.

7. I feel ashamed when I miss an exercise session.

8. It's important to me to exercise regularly.

9. I can't see why I should bother exercising.

10. I enjoy my exercise sessions.

11. I exercise because others will not be pleased with me if I don't.

12. I don't see the point in exercising.

13. I feel like a failure when I haven't exercised in a while.

14. I think it is important to make the effort to exercise regularly.

15. I find exercise a pleasurable activity.

16. I feel under pressure from my friends/ family to exercise.

17. I get restless if I don't exercise regularly.

18. I get pleasure and satisfaction from participating in exercise.

19. I think exercising is a waste of time.

Category $\quad$ Question Numbers

Amotivation.....................5, 9, 12, 19

External Regulation...............1, 6, 11, 16

Introjected Regulation.............2, 7, 13

Identified Regulation................3, 8, 14, 17

Intrinsic Regulation...............4, 10, 15

Scoring: Calculate the mean scores for each set of items. 
From: Markland \& Tobin (2004) A modification to the behavioural regulation in exercise questionnaire to include an assessment of amotivation. Journal of Sport \& Exercise Psychology. 26(2) p. 191-196. 


\section{APPENDIX G}

\section{Student Informational Email}

\section{E-MAIL INVITATION FOR ON-LINE SURVEY}

PHED 1003: Active Auburn Students,

I am a faculty member in the Department of Kinesiology at Auburn University. I would like to invite you to participate in my research study to identify online student characteristics and environmental factors associated with success and/or failure within online health-related fitness courses. You may participate (or may not participate) if you are currently enrolled in any course section of PHED 1003.

Participants will be asked to complete 3 surveys during the course which will take approximately 10-15 minutes a piece to complete. Also, in order to determine what factors may or may not be associated with student persistence and attrition in online health-related fitness courses, course completion status (i.e. pass/ fail) will need to be collected. All survey data and course completion status will be de-identified and given a unique identifier to ensure participant anonymity.

If you would like to know more information about this study, an information letter can be obtained on our Canvas course site. If you decide to participate after reading the letter, you can access the survey from a survey link within the course.

If you have any questions, please contact me at brocksj@auburn.edu

Thank you for your consideration,

Dr. Sheri Brock 


\section{APPENDIX H}

\section{Informed Consent Document}

The School of Kinesiology at Auburn University supports the practice of protection for human subjects participating in research and related activities. The following information is provided so that you can decide whether you wish to participate in the present study. You should be aware that even if you agree to participate, you are free to withdraw at any time, and that if you do withdraw from the study, you will not be subjected to reprimand or any other form of reproach. Likewise, if you choose not to participate, you will not be subjected to reprimand or any other form of reproach.

You are invited to be in a research study investigating student success in online health-related fitness courses. You were selected as a possible participant because you are currently enrolled in PHED 1003: Active Auburn. We ask that you read this form and ask any questions you may have before agreeing to be in the study and signing this form. This study is being conducted by Tyler Goad

Purpose: The purpose of the study is to identify online student characteristics and environmental factors associated with success and/or failure within online health-related fitness courses. You will be asked to fill out surveys at the beginning and middle of the semester. The surveys should take approximately 15-30 minutes to complete. At the conclusion of the course, survey data will be merged with individual academic performance (i.e. course grade/ standing). The goal of my research is to understand what factors influence student readiness to complete online health-related fitness course work. Insights gained from the proposed study will allow for a greater understanding of OLPE student demographics, cognitive characteristics, achievement beliefs, physical activity behaviors, and how they relate to student success.

Risk/Discomfort: There are no foreseeable risks or discomforts if you agree to participate in this study.

Benefit: Although there may be no direct benefit to you, the possible benefit of you participation is the anticipated improvement of online health-related fitness course services or programs in higher education.

Confidentiality: The records of this study will be kept private and confidential to the extent permitted by law. Any sort of report we might publish, we will not include any information that will make it possible to identify a subject. Data from completed student surveys will be de-identified by a person uninvolved in the research to ensure participant anonymity. Participants will be assigned a research record code so that individual student performance (i.e. course grade/ standing) can be linked at the end of the term. Research records will be stored securely and only researchers will have access to the records. After data sets have been merged, the code list will be destroyed.

Contacts and Questions: The researcher conducting this study is Tyler Goad. You may ask any question you have now. If you have any questions concerning this research study after the session has concluded please contact me at BLANK or email BLANK.

"I have read the above statement and have been fully advised of the procedures to be used in this project. I have been given sufficient opportunity to ask any questions I had concerning the procedures and possible risks involved. I understand the potential risks involved and I assume them voluntarily. I likewise understand that I can withdraw from the study at any time without being subjected to reproach." 


\section{APPENDIX I}

\section{AU University Online HRF Course Syllabus}

\section{Course Number:}

Course Title: Active AU

Term: Fall 2017

2. Credit Hours: 2 credit hours

Prerequisites: None

3. Texts or Major Resources: The two resources for this course are the e-book and a Movband 3 wearable fitness tracker as noted below.

\section{E-book}

This course will utilize an e-book version of the textbook that will be made available to you in the Canvas site associated with your course. Since you use an e-book in your class, there are a few important things to know up-front:

- DO NOT BUY OR ORDER A TEXTBOOK FOR THIS CLASS. It will be provided to you in Canvas.

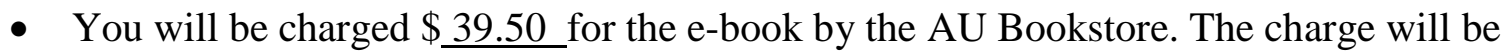
made to your AU e-bill on the 16th class and will appear as "Bookstore Charges" on the e-bill issued following that date.

- No charge will be made to your account if you drop the class before the 15th class

- You will be able to view the course text in Canvas, and will also be able to view it using the Canvas mobile application.

- For billing questions/concerns, contact, Assistant Director of the AU Bookstore,

$>$ Movband 3 Fitness Tracker

To purchase your Movband 3 please go to and select "Kinesiology Store" listed on the left list of tabs.

1. Click on and select the Movband 3.

2. Click "Add to Cart."

3. Next enter your Active AU Section Number and click "Continue."

4. Select "Checkout" and enter your "Email address"

5. Last, enter your credit card information to complete the purchase.

Your Movband 3 has been pre-ordered, so when you complete your payment process you can collect it from the School of Kinesiology

1. Bring your receipt (electronic or printed) and photo identification.

2. Collection of your Movband 3 is available between the hours of 8:00am-4:45pm at the Kinesiology Building for 2 days before classes begin and during the first week of classes 
3. You will be given your Movband 3 when you provide your receipt, photo identification, course section number, and provide your signature for receipt.

* If your Movband malfunctions, YOU are responsible for contacting your instructor and help.movable.com for support and troubleshooting immediately. An unreported malfunctioning Movband is not an excuse for missing activity.

\section{Course Description:}

Throughout this course, students will learn basic concepts associated with the development and maintenance of physical activity, as well as be exposed to the different fitness opportunities offered in the local area while engaging in health-promoting and wellness activities.

Active AU is a course designed to allow students to participate in physical activity of their choice at a time and location that best fits their schedule, and is electronically recorded and synced to your instructor using a fitness tracking device (Movband 3). More information about Movbands is given below (see Course Requirements / Evaluation - section 7).

\section{Course Objectives:}

Upon completion of the course objectives, the student will be able to:
A. Define exercise terms.
B. Identify public health benefits of engaging in regular physical activity.
C. Exhibit understanding of the FITT principles.
D. Exhibit knowledge of behavioral strategies to change behavior and health.
E. Exhibit knowledge of techniques to enhance motivation (i.e., goal setting).
F. Exhibit knowledge of preparing and recovering from exercise.
G. Identify physical activity and wellness opportunities in and around AU's campus.
H. Report future interests and goals for physical activity engagement.

\section{Course Content:}

Week 1: $\quad$ Purchase www.AU.edu/kine and Pick-up your Movband (see 3. Texts or Major Resources in this syllabus);

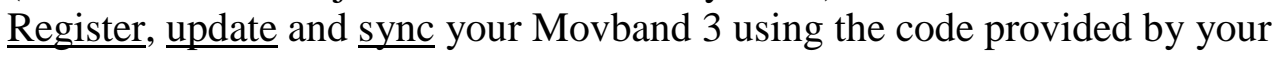
instructor (see MOVBAND REGISTRATION and UPDATING YOUR MOVBAND in this syllabus) -

Week 2: $\quad$ Syllabus Quiz -

Practice Week - This week is intended for you to practice using your Movband, however if you reach $\underline{5,000}$ total moves for the week, this will count toward your 12 weeks expected for the semester. To receive credit, you must have joined your Instructor's section/group on Movable using the code provided by your instructor and sync your Movband by

Week 3: Canvas Module \#1 - Exercise Vocabulary Achieve Total Weekly Moves of $\underline{56,000}$ 


\section{*Please note your grade is based on Weekly "Moves" not "steps"}

Week 4: Achieve Total Weekly Moves of $\underline{56,000}$

NOTE: Your total expected moves will increase every 3 weeks as indicated below.

Week 5: Canvas Module \#2 - Health Benefits of Engaging in Regular Physical Activity Achieve Total Weekly Moves of $\underline{63,000}$

Week 6: Achieve Total Weekly Moves of $\underline{63,000}$

Week 7: Canvas Module \#3 - FITT Principles Achieve Total Weekly Moves of $\underline{63,000}$

NOTE: Last day to withdraw from course with no grade penalty. "W" assigned - 3/3/16

Week 8: Midterm Exam - Complete Course Survey

Achieve Total Weekly Moves of $\underline{70,000}$

Week 9: Canvas Module \#4 - Behavioral Change Strategies Achieve Total Weekly Moves of $\underline{70,000}$

Week 10: Canvas Module \#5 - Preparing and Recovering from Exercise Achieve Total Weekly Moves of $\underline{70,000}$

Week 11: Achieve Total Weekly Moves of $\underline{77,000}$

Week 12: Achieve Total Weekly Moves of $\underline{77,000}$

Week 13: Achieve Total Weekly Moves of $\underline{77,000}$

Week 14: Achieve Total Weekly Moves of $\underline{84,000}$

Week 15: Final Exam/Course Survey - Complete Course Survey (potential make-up week for excused absences - If utilized, 84,000 weekly moves *No partial credit will be given.

\section{Course Requirements / Evaluation:}

$\underline{\text { Item }}$

Syllabus Quiz

5 Canvas Modules

Midterm Exam (Course Survey)

*Participation (Total Weekly Moves $=12$ weeks x 5 pts) 60

(1 week=Sun 12:01am-Sat 11:59pm)

Final Exam (Course Survey)

Total

\section{Points Percentage}

$5 \quad 5 \%$

$25 \quad 25 \%$

$5 \quad 5 \%$

$60 \%$ 
Orientation/Syllabus Quiz (5\%) - Week 1 posted on Canvas. Review the Course Syllabus on Canvas and then complete the Syllabus Quiz.

Canvas Module Assessments (5 points each = 25\%) - will be conducted online using Canvas. Each quiz is timed based on the number of questions (2 minutes per question.) Students cannot work together. Quiz questions are randomly generated from the e-book.

Midterm Exam (5\%) - Complete Course Survey on Canvas

The midterm exam will consist of a short course survey on Canvas regarding your experiences in Active AU.

Participation -Total Weekly Moves (5 points per week $=60 \%$ ) - Students are required to achieve a weekly total of "moves" as recorded by the Movband 3.

(1 week = Sunday 12:01am-Saturday 11:59pm)

Weekly move data are automatically provided to instructors when Movband trackers are registered according to your Active AU course section and synced with a computer or smartphone. It is strongly suggested that you sync your Movband frequently (daily) to ensure your physical activity is being recorded properly. Check to be sure the amount of moves synced correlates with the amount displayed on your device. If it does not correlate, contact help.movable.com for assistance, screenshot your device for documentation, and let your instructor know as soon as possible. Also please note that the expected "Total Weekly Moves" increase as the semester progresses as indicated in the table below and Course Content.

\begin{tabular}{|l|l|l|l|}
\hline Total Weekly Moves & -5 points earned & 0 points earned & +5 points earned \\
\hline 56,000 & $<28,000$ & $28,000-55,999$ & $56,000+$ \\
\hline 63,000 & $<35,000$ & $35,000-62,999$ & $63,000+$ \\
\hline 70,000 & $<42,000$ & $42,000-69,999$ & $70,000+$ \\
\hline 77,000 & $<49,000$ & $49,000-76,999$ & $77,000+$ \\
\hline 84,000 & $<56,000$ & $56,000-83,999$ & $84,000+$ \\
\hline
\end{tabular}

* If your Movband malfunctions, YOU are responsible for contacting your instructor and help.movable.com for support and troubleshooting immediately. An unreported malfunctioning Movband is not an excuse for missing activity.

Final Exam/Course Survey (5\%) - Complete Course Survey on Canvas

The final exam will consist of a short course survey on Canvas regarding your experiences in Active AU.

Grading Scale:

$$
A=100-90 \%
$$




$$
\begin{aligned}
& B=89-80 \% \\
& C=79-70 \% \\
& D=69-60 \% \\
& F=\text { Below } 60 \%
\end{aligned}
$$

\section{CLASS ATTENDANCE}

Attendance will be recorded through Movband weekly reports that are automatically visible to your instructor when you register your device, join your section's group, and sync your device using a computer or smartphone. It is suggested to sync often to ensure your moves are being documented properly. If you do not sync your Movband 3 by the weekly due date (Saturday 11:59pm), the report will show your instructor that you had " 0 " moves for the week. Completed moves that have not been synced by the due date will not be counted.

\section{MOVBAND REGISTRATION}

Please follow these steps for Movband Registration:

1. Purchase and pick-up your Movband 3 according to the detailed instructions listed in section 3 of this syllabus (Texts or Major Resources). Bring your receipt and photo identification for pick-up.

2. Connect your Movband 3 to a computer using the included USB charging cord.

3. Go to movable.com/hello-movband3 and follow the steps to Connect, Install, Download Movband Sync, and Register using your invitation code

4. If you have a smartphone you can sync your Movband 3 wirelessly after you install the "Movable" app from the App Store on your phone. Otherwise, you will need to connect your Movband to your computer to sync.

\section{UPDATING YOUR MOVBAND}

Please follow these steps for updating your Movband to the latest firmware using a PC or Mac (failure to update to the latest firmware may cause syncing problems):

On a PC:

1. Connect your Movband to your computer using the supplied USB charging cord.

2. Locate the movable sync icon in the lower right tray by the clock of your computer. (You may need to expand the viewable icons by clicking the up arrow.)

3. Right click the Movable sync icon.

4. Click Check for Updates (If you do not see a pop-up box, try minimizing the other screens that are open, as the box may be hiding behind them).

5. If you see "Update to Version 3.12 is Required”, click “Upgrade Now”. (If the Firmware Version is already 3.12, no further action is required).

6. MOST IMPORTANT! Do not unplug the device until the upgrade has completed. This could render the device unusable.

On a Mac

1. Connect your Movband to your computer using the supplied USB charging cord.

2. Locate the movable sync icon in the upper right tray by the clock of your computer.

3. Click the sync icon.

4. Click About Movband sync. 
5. Click Update sync.

6. MOST IMPORTANT! Do not unplug the device until the upgrade has completed. This could render the device unusable.

\section{TIPS FOR USING YOUR Movband 3:}

1. Sync daily and verify the number of moves! This ensures that your Movband is recording your moves properly so you will receive credit appropriately.

2. Charge your Movband 3 weekly. A flashing battery icon will appear in the top right corner of the device when the battery needs to be recharged. Charging takes approximately 2 hours.

3. If your Movband malfunctions, YOU are responsible for contacting your instructor AND info@movable.com for support and troubleshooting immediately. An unreported malfunctioning Movband is not an excuse for missing activity.

4. Your Movband 3 is NOT waterproof. It is suggested to keep your Movband dry other than sweat/light rain. Swimming, showering or other water activities are not suggested.

5. It is suggested to wear your Movband 3 on your ankle or shoelace securely when biking or participating in other activities with limited arm movements. If you use the clip accessory, secure the device under a waistband or shoelaces to prevent loss.

6. Selecting "Custom Range" on your dashboard will allow you to look at moves for "This Week”, as opposed to the default monthly total.

\section{Course Policy Statements:}

* No daily attendance policy will be in effect for this course, however please note all other policies in sections 8,9 , and 10 of this syllabus.

\section{A. Attendance:}

\section{Physical Activity and Wellness Program Attendance Policy}

The material and experiences in this class are important and if you are not in class, you cannot take an active role as a student. Class attendance and appropriate participation is paramount to your success as a student. Participation is defined as, but not limited to, "fully engaging in the course content and activities at a level that is deemed appropriate by the instructor." Failure to appropriately participate in the course content and activities will result in a deduction of points from a student's overall course grade. Students arriving tardy to class will lose 1 point from their final grade per offense. Once a student has accrued five unexcused absences he/she will not be permitted to take the final examination and will receive a grade of FA (as stipulated by the Physical Activity and Wellness Program guidelines). Moreover, students who accrue eight (8) absences (excused, unexcused and/or combination of each type) will receive a grade of FA.

\section{B. Excused Absences:}

Students are granted excused absences from class for the following reasons: illness of the student or serious illness of a member of the student's immediate family, the death of a member of the student's immediate family, trips for student organizations sponsored by an academic unit, trips for university classes, trips for participation in intercollegiate athletic events, subpoena for a court appearance, and religious holidays. Students who wish to have an excused absence from class for any other reason must contact the instructor in advance of the absence to request permission. The instructor will weigh the merits of the request and render a decision. 
When feasible, the student must notify the instructor prior to the occurrence of any excused absences, but in no case shall such notification occur more than one week after the absence. Excused absence documentation should be submitted to the Instructor within one week of the absence. Appropriate documentation for all excused absences is required. Please refer to the AU University Student Policy eHandbook www.AU.edu/studentpolicies for more information on excused absences.

C. Make-Up Policy:

Arrangement to make up missed examinations due to properly authorized excused absences must be initiated by the student within one week from the end of the period of the excused absences. The format of the make-up exam will be as specified by the instructor. If the student fails to follow these instructions the excused absence in question will be calculated as an unexcused absence.

Course Contingency: If normal class and/or lab activities are disrupted due to illness, emergency, or crisis situation, the syllabus and other course plans and assignments may be modified to allow completion of the course. If this occurs, an addendum will be made to your syllabus and/or course assignments will replace the original material.

Inclement Weather: In case of inclement weather, check your AU email account for alternative class location and/or assignments.

\section{Academic Honesty Policy:}

All portions of the AU University student academic honesty code (Title XII) found in the AU University Student Policy eHandbook www.AU.edu/studentpolicies will apply to this class. All academic honesty violations or alleged violations of the SGA Code of Laws will be reported to the Office of the Provost, which will then refer the case to the Academic Honesty Committee.

\section{Disability Accommodations:}

Students who need accommodations are asked to electronically submit their approved accommodations through AU Access and to arrange a meeting during office hours the first week of classes, or as soon as possible if accommodations are needed immediately. If you have a conflict with my office hours, an alternate time can be arranged. To set up this meeting, please contact me by e-mail. If you have not established accommodations through the Office of Accessibility, but need accommodations, make an appointment with the Office of Accessibility,

Please note that accommodations are not retroactive. Accommodations begin after: (1) a meeting with the Office of Accessibility to determine appropriate accommodations; and (2) a meeting with the Instructor arranged by the student. 


\section{TABLES}

Table 7

E-Learning Course Classifications

\begin{tabular}{lll}
\hline $\begin{array}{l}\text { Percent of } \\
\text { Content } \\
\text { Delivered } \\
\text { Online }\end{array}$ & Type of Course & \multicolumn{1}{c}{ Typical Description } \\
\hline $0 \%$ & Traditional & $\begin{array}{l}\text { Course where no online technology used content is } \\
\text { delivered in writing or orally. }\end{array}$ \\
1 to $29 \%$ & Web Facilitated & $\begin{array}{l}\text { Course that uses web-based technology to facilitate } \\
\text { what is essentially a face-to-face course. May use a } \\
\text { course management system (CMS) or web pages to } \\
\text { post the syllabus and assignments. }\end{array}$ \\
& Blended/Hybrid & $\begin{array}{l}\text { Course that blends online and face-to-face delivery. } \\
\text { Substantial proportion of the content is delivered } \\
\text { online, typically uses online discussions, and } \\
\text { typically has a reduced number of face-to-face } \\
\text { meetings. }\end{array}$ \\
& & $\begin{array}{l}\text { A course where most or all of the content is } \\
\text { delivered online. Typically have no face-to-face } \\
\text { meetings. }\end{array}$
\end{tabular}

Note: From "Changing Course Ten Years of Tracking Online Education in the United States” (Allen \& Seaman, 2012, p. 7). 
Table 8

Advantages and Disadvantages of Online Physical Education

Advantages

- Students can complete coursework at convenience.

- Students progress at their own pace.

- Students can complete coursework from anywhere

- Students can easily communicate with the teacher

- Students can easily communicate with other students when they want to.

- Students living in remote areas may be better served.

- Students receive immediate feedback.

- Students can review material that is unclear to them.

- Teachers can make content changes quickly and easily.

- Teachers can personalize teaching for each student.

- Students with special needs could be better served.

- Students are motivated by computer technology

- Students can take it as an elective course once they have completed district requirements.

\section{Disadvantages}

- Limited research to support online learning in physical education.

- Concerns regarding accountability of student learning and performance.

- Focus is preliminary health-related fitness, not comprehensive physical education.

- Challenges monitoring student accountability of physical activity behaviors

- Threatens programs and teaching positions in brick and mortar schools.

- Screen time replaces moderate to vigorous physical activity

- Limited affective learning objectives such as responsible personal and social behavior, cooperation, teamwork, ethical decision making and respect.

Note: Adapted from “Implementing Online Physical Education” (Mohnsen, 2012, p.43) 
Table 9

National Guidelines for Technology Use in Physical Education

Appropriate Use of Instructional Technology in Physical Education Guidelines

1. The use of instructional technology in physical education is designed to provide a tool for increasing instructional effectiveness

2. The use of instructional technology in physical education is designed to supplement, not substitute for, effective instruction.

3. The use of instructional technology in physical education should provide opportunities for all students, versus opportunities for few

4. The use of instructional technology in physical education can prove to be an effective tool for maintaining student data related to standards-based curriculum objectives. 
Table 10

Description of Factors and Examples of the Survey Instruments

\begin{tabular}{|c|c|c|c|}
\hline Factor & $\begin{array}{l}\text { Number } \\
\text { of Items }\end{array}$ & Factor Description & Sample Item \\
\hline $\begin{array}{l}{ }^{1} \text { Technology } \\
\text { Skills/ Self- } \\
\text { efficacy }\end{array}$ & 6 & $\begin{array}{l}\text { Computer skill and access } \\
\text { technology. }\end{array}$ & $\begin{array}{l}\text { "When I have to do something } \\
\text { on a computer, I usually try to } \\
\text { figure it out myself." }\end{array}$ \\
\hline $\begin{array}{l}{ }^{1} \text { Achievement } \\
\text { beliefs }\end{array}$ & 6 & $\begin{array}{l}\text { Belief in oneself and in one's } \\
\text { ability to achieve. }\end{array}$ & "I rarely set goals for myself.” \\
\hline $\begin{array}{l}{ }^{1} \text { Instructional } \\
\text { risk-taking }\end{array}$ & 6 & $\begin{array}{l}\text { Taking responsibility for one's } \\
\text { actions and taking individual } \\
\text { initiative. }\end{array}$ & $\begin{array}{l}\text { "When I am learning something } \\
\text { new, it is okay if I make } \\
\text { errors." }\end{array}$ \\
\hline${ }^{1}$ Organization & 5 & $\begin{array}{l}\text { Ability to approach tasks in } \\
\text { an organized and goal- } \\
\text { oriented way. }\end{array}$ & $\begin{array}{l}\text { "I tend to wait until the last } \\
\text { minute to get things done." }\end{array}$ \\
\hline $\begin{array}{l}{ }^{2} \text { Motivation to } \\
\text { Exercise }\end{array}$ & 19 & $\begin{array}{l}\text { Motivation to engage or not to } \\
\text { engage in physical activity. }\end{array}$ & $\begin{array}{l}\text { "I feel guilty when I don’t } \\
\text { exercise.” }\end{array}$ \\
\hline $\begin{array}{l}{ }^{3} \text { Study } \\
\text { Environment }\end{array}$ & 7 & $\begin{array}{l}\text { Perception of the } \\
\text { environment, including } \\
\text { physical space and time. }\end{array}$ & $\begin{array}{l}\text { "How many hours do you work } \\
\text { each week outside the home, on } \\
\text { an average?" }\end{array}$ \\
\hline${ }^{3}$ Demograhpics & 5 & $\begin{array}{l}\text { Age, Gender, Ethnicity, Class } \\
\text { standing, and self-reported } \\
\text { GPA }\end{array}$ & $\begin{array}{l}\text { "Which best describes your } \\
\text { class standing?" }\end{array}$ \\
\hline
\end{tabular}

Note:

${ }^{1}$ Factors and items from ESPRI-V2 (Roblyer, et al. (2008)

${ }^{2}$ Factors and items from BREQ-V2 (Markland \& Tobin, 2004)

${ }^{3}$ Factors and items from DLS (Osborn, 2001) 
Table 11

Overview of Proposed Analysis

\begin{tabular}{|c|c|c|c|}
\hline $\begin{array}{l}\text { Research } \\
\text { Question }\end{array}$ & $\begin{array}{c}\text { Independent Variable(s) } \\
\text { (Instrument) }\end{array}$ & $\begin{array}{c}\text { Dependent } \\
\text { Variable }\end{array}$ & Proposed Analysis \\
\hline RQ 1 & $\begin{array}{l}\text { Cognitive Characteristics: } \\
\text { Technology skills/ Self- } \\
\text { efficacy, Achievement beliefs, } \\
\text { Instructional risk taking, } \\
\text { Organization (ESPRI-V2) } \\
\text { - Motivation to Exercise (BREQ- } \\
\text { V2) }\end{array}$ & $\begin{array}{l}\text { Course completion } \\
\text { status* }\end{array}$ & ANOVA \\
\hline RQ 2 & $\begin{array}{l}\text { Demographics: Age, Gender, } \\
\text { Ethnicity, Class standing, and } \\
\text { self-reported GPA (DLS) }\end{array}$ & $\begin{array}{l}\text { Course completion } \\
\text { status* }\end{array}$ & $\begin{array}{l}\text { Descriptive statistics, } \\
\text { frequency distribution, } \\
\text { and Pearson's Chi } \\
\text { Square test }\end{array}$ \\
\hline RQ 3 & $\begin{array}{l}\text { Environment: Course load, } \\
\text { Previous online course } \\
\text { experience, Type of student, } \\
\text { Hours of work outside of } \\
\text { school, and Financial stability } \\
\text { (DLS) }\end{array}$ & $\begin{array}{l}\text { Course completion } \\
\text { status* }\end{array}$ & $\begin{array}{l}\text { Descriptive statistics, } \\
\text { frequency distribution, } \\
\text { and Pearson's Chi } \\
\text { Square test }\end{array}$ \\
\hline RQ 4 & $\begin{array}{l}\text { - Cognitive Characteristics } \\
\text { (ESPRI-V2) } \\
\text { - Motivation to Exercise (BREQ- } \\
\text { V2) } \\
\text { - Demographics (DLS) } \\
\text { - Environment (DLS) }\end{array}$ & $\begin{array}{l}\text { Course completion } \\
\text { status* }\end{array}$ & $\begin{array}{l}\text { Binary logistical } \\
\text { regression }\end{array}$ \\
\hline
\end{tabular}

*Course completion status: Students completing the course with a grade of A, B, or C will be designated as successful (i.e. passing); students who withdrawal (W), drop (I), or complete the course with a grade of $\mathrm{D}$ or $\mathrm{F}$ will be identified as unsuccessful (i.e. failing). 


\section{FIGURES}

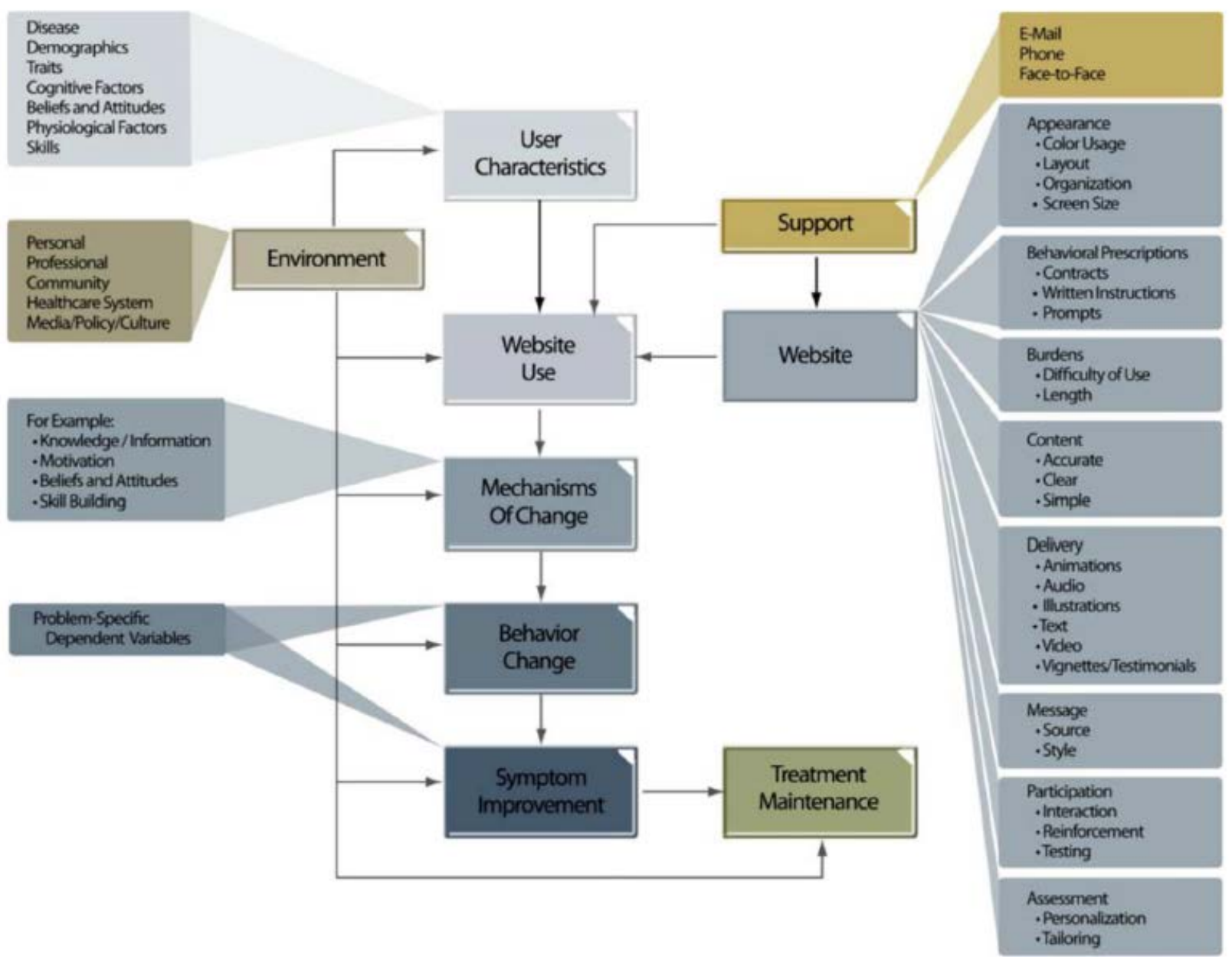

Figure 1. Online Behavior Change Model (Ritterband, et al., 2009, p. 14) 


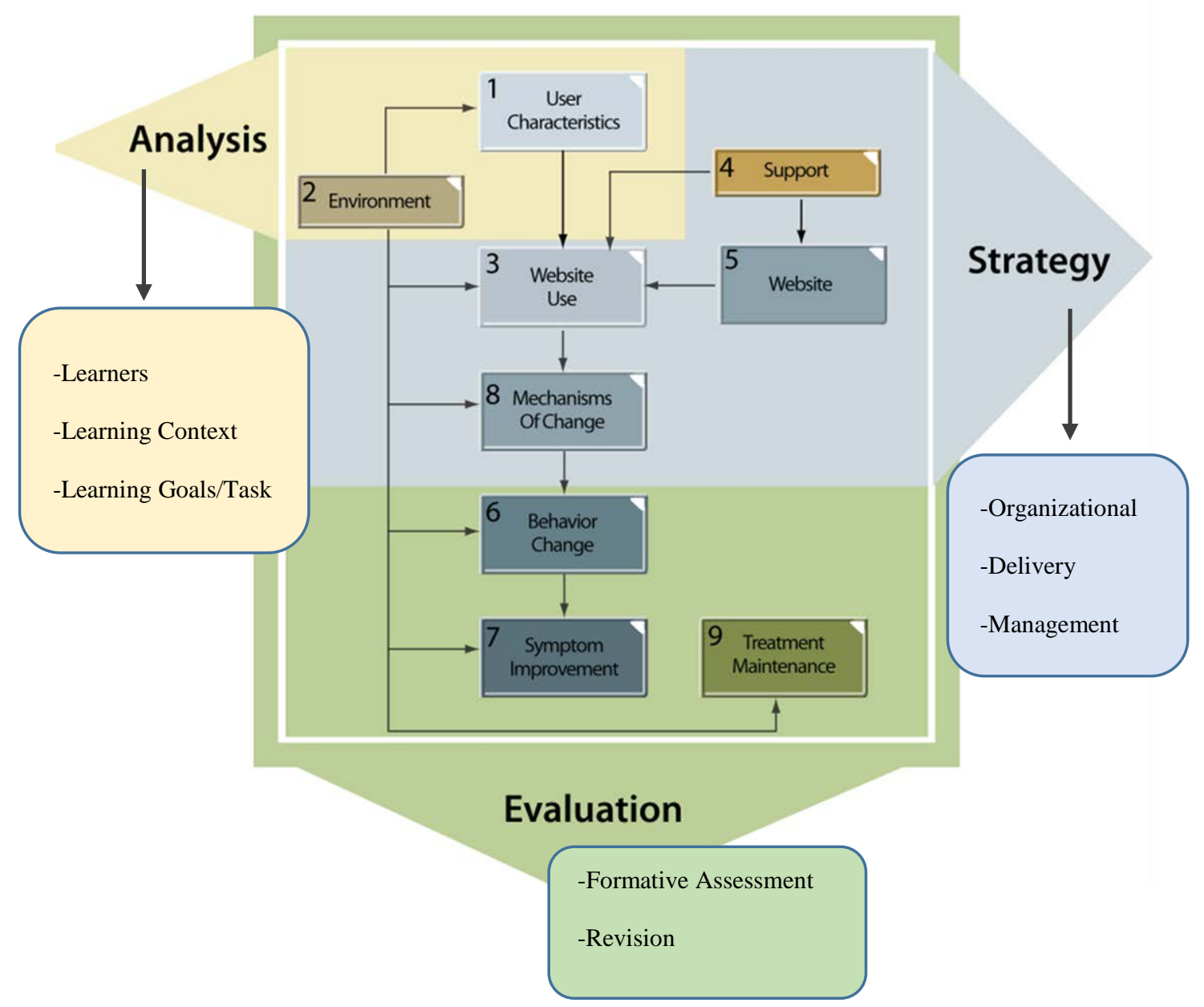

Figure 2. Instructional design process model for online behavior change model (Hilgart et al., 2012, p. 17). 